\title{
RESERVOIR CHARACTERIZATION OF UPPER DEVONIAN GORDON SANDSTONE, JACKSONBURG STRINGTOWN OIL FIELD, NORTHWESTERN WEST VIRGINIA
}

Final Report

October 1, 1998 - September 30, 2001
By
S. Ameri
K. Aminian
K. L. Avary
H. I. Bilgesu
M.E. Hohn
R. R. McDowell
D. L. Matchen

July 2001

Performed Under Contract No. DE-AC26-98BC15104

West Virginia University

Appalachian Oil and Natural Gas Research Consortium Morgantown, West Virginia 


\section{DISCLAIMER}

This report was prepared as an account of work sponsored by an agency of the United States Government. Neither the United States Government nor any agency thereof, nor any of their employees, makes any warranty, express or implied, or assumes any legal liability or responsibility for the accuracy, completeness, or usefulness of any information, apparatus, product, or process, disclosed, or represents that its use would not infringe privately owned rights. Reference herein to any specific commercial product, process, or service by trade name, trademark, manufacturer, or otherwise does not necessarily constitute or imply its endorsement, recommendation, or favoring by the United States Government or any agency thereof. The view and opinions of authors expressed herein do not necessarily state or reflect those of the United States Government or any agency thereof. 


\begin{abstract}
The Jacksonburg-Stringtown oil field contained an estimated 88,500,000 barrels of oil in place, of which approximately 20,000,000 barrels were produced during primary recovery operations. A gas injection project, initiated in 1934, and a pilot waterflood, begun in 1981, yielded additional production from limited portions of the field. The pilot was successful enough to warrant development of a full-scale waterflood in 1990, involving approximately 8,900 acres in three units, with a target of 1,500 barrels of oil per acre recovery. Historical patterns of drilling and development within the field suggests that the Gordon reservoir is heterogeneous, and that detailed reservoir characterization is necessary for understanding well performance and addressing problems observed by the operators.
\end{abstract}

The purpose of this work is to establish relationships among permeability, geophysical and other data by integrating geologic, geophysical and engineering data into an interdisciplinary quantification of reservoir heterogeneity as it relates to production.

Conventional stratigraphic correlation and core description shows that the Gordon sandstone is composed of three parasequences, formed along the Late Devonian shoreline of the Appalachian Basin. The parasequences comprise five lithofacies, of which one includes reservoir sandstones. Pay sandstones were found to have permeabilities in core ranging from 10 to $200 \mathrm{mD}$, whereas non-pay sandstones have permeabilities ranging from below the level of instrumental detection to $5 \mathrm{mD}$; Conglomeratic zones could take on the permeability characteristics of enclosing materials, or could exhibit extremely low values in pay sandstone and high values in non-pay or low permeability pay sandstone.

Four electrofacies based on a linear combination of density and scaled gamma ray best matched correlations made independently based on visual comparison of geophysical logs. Electrofacies 4 with relatively high permeability (mean value $>45 \mathrm{mD}$ ) was determined to be equivalent to the pay sandstone within the Gordon reservoir. Three-dimensional models of the electrofacies in the pilot waterflood showed that electrofacies 4 is present throughout this area, and the other electrofacies are more disconnected.

A three-layer, back-propagation artificial neural network with three slabs in the middle layer can be used to predict permeability and porosity from gamma ray and bulk density logs, the first and the second derivatives of the log data with respect to depth, well location, and log baselines.

Two flow units were defined based on the stratigraphic model and geophysical logs. A threedimensional reservoir model including the flow units, values of permeability calculated through the artificial neural network and injection pressure-rate information were then used as inputs for a reservoir simulator to predict oil production performance for the center producers in the pilot area. This description of the reservoir provided significantly better simulation results than earlier results obtained using simple reservoir models. 
Bulk density and gamma ray logs were used to identify flow units throughout the field. As predicted by the stratigraphic analysis, one of the flow units crosses stratigraphic units in the reservoir. A neural network was used to predict permeability values for each flow unit in producer and injection wells. The reservoir simulator was utilized to predict the performance of two flood patterns located to the north of the pilot area. Considering the simple model utilized for simulation, the results are in very good agreement with the field history. 


\section{TABLE OF CONTENTS}

Disclaimer $\quad$ ii

Abstract

Table of Contents

List of Figures

List of Tables $\quad$ ix

\begin{tabular}{ll|l} 
Executive Summary & $x$
\end{tabular}

1. Introduction 1

1.1. Field History 1

1.2. Development History 6

1.3. Autocorrelation of Geophysical Logs 13

2. Reservoir Description 15

2.1. Regional Geology 15

2.1.1. Structure 15

2.1.2. Stratigraphy 15

2.2. Geology of the Field 20

2.2.1. Structure 20

2.2.2. Stratigraphy 21

2.2.3. Core Description 22

2.2.4. Stratigraphic Framework 24

2.3. Stratigraphy and Production 31

2.4 Petrology 33

2.5 Petrophysics $\quad 35$

2.6. Electrofacies 44

2.6.1. 3-D Electrofacies Cubes $\quad 47$

2.7. Lithofacies $\quad 52$

3. Outcrop PermeabilityStudy 53

4. Modeling And Simulation 56

4.1 Data Collection and Analysis $\quad 56$

4.2 Permeability Prediction $\quad 57$

4.2.1 Permeability-Porosity Correlations 57

4.2.2 Permeability Prediction with Neural Network Model 57

4.2.3 Porosity Prediction with Neural Network Model 62

4.2.4 Mini-Permeameter Measurements 63

4.3 Production History Analysis 64

4.3.1 Production History of the Field: Synopsis 64

4.3.2 BOAST98 Simulator Overview 65 
4.3.3 Simulation of Primary Production $\quad 65$

4.3.4 Simulation of the Pilot Waterflood 65

4.3.5 "Flow Unit" Model 66

4.3.6. Application of Flow Unit Model to the Reservoir 77

5. Summary and Conclusions $\quad 82$

6. References Cited 84 


\section{LIST OF FIGURES}

1.1. Location of Jacksonburg-Stringtown Field 1

1.2. Map of Jacksonburg-Stringtown field 2

1.3. Total primary oil production 3

1.4. Location of gas injection wells 4

1.5. Wells associated with the pilot waterflood project 4

1.6. Cumulative oil production from 34-acre dual five-spot pilot waterflood 5

1.7. Cumulative oil production for full-scale waterflood 5

1.8. Spectral analysis of completion date for all producing oil wells 7

1.9. Field development for the Jacksonburg-Stringtown field 8

1.10. Locations of producing wells drilled in $1897 \quad 9$

1.11. Locations of producing wells drilled in $\mathbf{1 8 9 8} 10$

1.12. Locations of producing wells drilled in $\mathbf{1 8 9 9} 11$

1.13. Locations of producing wells drilled in $\mathbf{1 9 0 0} 12$

1.14. Spider plot showing correlations between wells 14

2.1. Structural features of northern West Virginia 16

2.2. Generalized stratigraphic column for the study area 16

2.3. Thickness of Gordon interval 17

2.4. Thickness of the Gordon Stray sandstone 18

2.5. Regional distributions of sandstones within the Acadian clastic wedge 19

2.6. Sandstones in the Jacksonburg-Stringtown region 19

2.7. Structure contour map for top of Gordon 20

2.8. Location of cores and cross sections 21

2.9. Definitions of lithofacies 23

2.10. Correlation of core to log 24

2.11. Correlation of all available cores 26

2.12. Correlation of wireline logs for cored wells 26

2.13. East-west stratigraphic cross sections 27

2.14. North-south stratigraphic cross sections 27

2.15a. Thickness of featureless sandstones (Fss) in parasequence A 28

2.15b. Thickness of featureless sandstones (Fss) in parasequence B 29

2.15c. Thickness of featureless sandstones (Fss) in parasequence C 30

2.16. Reservoir sandstone, estimated cumulative production and structure 32

$\begin{array}{ll}\text { 2.17. Bivariate correlation matrix } & 34\end{array}$

2.18. Cementing history inferred for Gordon sandstones from thin sections 35

2.19. Permeability logs for cored wells 36

2.20. Graph of permeability vs. depth for Peter Horner \#9 (095-741) 37

2.21. Permeability map for Thompson Heirs \#8 (095-1124 38

2.22. Regular 10 x 10 grid from F. R. Ball \#18 (095-1125) 40

2.23a. Permeability map for Peter Horner \#9 (095-741) 41

2.23b. Permeability map for F. R. Ball \#18 (095-1125) 41

2.23c. Permeability map for F. R. Ball \#18 (095-1125) 42

2.23d. Permeability map for Peter Horner \#9 (095-741) 42

2.23e. Permeability map for Irene Reilly \#13 (103-1315 43 
2.23f. Permeability map for F. R. Ball \#19 (095-1126) 43

2.23g. Permeability map for F. R. Ball \#18 (095-1125 44

2.24. Chart showing the attributes of the four electrofacies 46

2.25. Vertical slice maps showing electrofacies 48

2.26. Two vertical electrofacies cross sections 49

2.27. Three vertical electrofacies cross sections 50

2.28. Two east-west slices through 3-D cube of simulated electrofacies 51

3.1. Location of outcrop exposures of the Devonian Hampshire Formation 55

3.2. Histograms and associated statistics describing permeability data 55

4.1. Comparison of Core and Well Log Porosity Values 58

4.2. Core Permeability-Porosity Correlation 58

4.3. Core Permeability-Well Log Porosity Correlation 59

4.4. Artificial Neural Network Structure 60

4.5. Architecture of A Neural Network 61

4.6. Core Porosity Prediction Results 63

4.7 Permeability-Porosity Correlations for Pay Sandstone 67

4.8 Permeability-Porosity Correlations for Conglomerate 67

4.9 Definition of the Flow Units in Pilot Area 68

4.10 Permeability-Porosity Correlations for Unit I in the Pilot Area 69

4.12a Thickness of Flow Unit I 70

4.12b Permeability-Thickness of Flow Unit I 71

4.12c Mean Permeability of Flow Unit I 72

4.12d Thickness of Flow Unit II 73

4.12e Permeability-Thickness of Flow Unit II 74

4.12f Mean Permeability of Flow Unit II 75

4.13 Permeability-Porosity Correlations for Unit II in the Pilot Area 76

4.14 Predicted and Actual Oil and Water Production for MM-1 76

4.15 Porosity-Permeability Relationship for flow unit I 78

4.16 Porosity-Permeability Relationship for flow unit II 78

$\begin{array}{ll}\text { 4.17 Flow Units In Well B-19 } & 79\end{array}$

4.18 Flow Units In Well B-18 80

4.19 Production Performance and Simulator Predictions for B-18 Pattern 80

4.20 Production Performance and Simulator Predictions for B-21 Pattern 81

4.21 Performance and Predictions for Combined B-18 andB-21 Patterns 81 


\section{LIST OF TABLES}

2.1 Lithofacies Characteristics 21

2.2 Petrographic and Petrophysical Characteristics of Lithofacies 52

$\begin{array}{ll}\text { 4.1 } \mathbf{R}^{2} \text { Values for Permeability Prediction } & 62\end{array}$

4.2 $\mathrm{R}^{2}$ Values for Porosity Prediction 62

$\begin{array}{ll}\text { 4.3 Description of Flow Units } & 77\end{array}$

4.4 R $\mathbf{R}^{2}$ Values for Permeability Prediction 78 


\section{Executive Summary}

The Jacksonburg-Stringtown oil field contained an estimated 88,500,000 barrels of oil in place, of which approximately 20,000,000 barrels were produced during primary recovery operations. A gas injection project, initiated in 1934, and a pilot waterflood, begun in 1981, yielded additional production from limited portions of the field. The pilot was successful enough to warrant development of a full-scale waterflood in 1990, involving approximately 8,900 acres in three units, with a target of 1,500 barrels of oil per acre recovery. However, PennzEnergy (now East Resources) encountered technical barriers to production that must be overcome if they are to reach this enhanced production goal.

The West Virginia University Research Corporation is developing a three-dimensional model of permeability for the Upper Devonian Gordon sandstone reservoir in the field. Two approaches are being used: analysis of geophysical and core data, and direct measurement of permeability in core and in outcrops that are analogous to the subsurface reservoir. The goal is to establish relationships among permeability, geophysical and other data by integrating geologic, geophysical and engineering data into an interdisciplinary quantification of reservoir heterogeneity as it relates to production.

The Gordon sandstone is composed of three parasequences, formed along the Late Devonian shoreline of the Appalachian Basin. The parasequences comprise five lithofacies, of which one includes reservoir sandstones. Pay sandstones were found to have permeabilities in core ranging from 10 to $200 \mathrm{mD}$, whereas non-pay sandstones have permeabilities ranging from below the level of instrumental detection to $5 \mathrm{mD}$; Conglomeratic zones could take on the permeability characteristics of enclosing materials, or could exhibit extremely low values in pay sandstone and high values in non-pay or low permeability pay sandstone.

Four electrofacies based on a linear combination of density and scaled gamma ray best matched correlations made independently based on visual comparison of geophysical logs. Electrofacies 4 with relatively high permeability (mean value $>45 \mathrm{mD}$ ) was determined to be equivalent to the pay sandstone within the Gordon reservoir.

Core data from six wells in the reservoir were utilized in an artificial neural network to predict permeability from Gamma ray and bulk density logs, the first and the second derivatives of the log data with respect to depth, well location, and log baselines. A three-layer, back-propagation network with three slabs in the middle layer (each slab having a different activation function) could predict permeability values that correlated with observed values at an acceptable level. Similar results were obtained in the prediction of porosity from log and well parameters.

Production performance in a pilot waterflood could not be accurately predicted using a simple reservoir model based on well records, well logs, and core analysis data, leading to use of a more detailed description of the reservoir characteristics and heterogeneities and the definition of two flow units. The first includes the lower part of the conglomerate-sandstone sequence and the upper part of the sandstone section, and the second is the lower part of the sandstone. The second flow unit has the higher porosity and permeability. A three-dimensional reservoir 
description including the flow units and injection pressure-rate information were then used as inputs for the reservoir simulator to predict oil production performance for the center producers in the pilot area. This description of the reservoir provided significantly better simulation results.

Bulk density and gamma ray logs were used to identify flow units throughout the field. Flow Unit II is the major producing unit in the reservoir, whereas Flow Unit I is a minor contributor to the total production. Flow Unit II crosses stratigraphic units in the reservoir. A neural network was used to predict permeability values for the flow units. The reservoir simulator was utilized to predict the performance of two flood patterns located to the north of the pilot area. Considering the simple model utilized for simulation, the results are in very good agreement with the field history. 


\section{INTRODUCTION}

\subsection{Field History}

The Stringtown field was discovered in 1895. It is located on the western flank of the Burchfield syncline, in southeastern Wetzel, eastern Tyler, and northwestern Doddridge counties, West Virginia (Fig. 1.1). Over 500 wells were drilled in the field between 1897 and 1901 (Fig. 1.2); most were plugged by 1910. Average well spacing was 13 acres per well. The average initial potential of these wells was $72 \mathrm{BOPD}$, with a range of 0 to $300 \mathrm{BOPD}$ (King, 1980). The wells were initially stimulated (Ahot@with nitroglycerine. Many wells have been shot several times to increase production. The average production life of the wells was approximately 20 years. Based on an effective area of 4,388 acres, primary recovery has been estimated at between 1454 (King, 1980) and 1590 (Morrison, 1991) BOPA. Primary production was a result of solution gas drive and gravity drainage through the mid 1920's and resulted in production of an estimated 13 MMBO (Morrison, 1991) from the waterflood area (Fig. 1.3). Primary production ranged from $824 \mathrm{BOPA}$ to 2,700 BOPA, using lease production records. For the entire Jacksonburg-Stringtown field, with an area of 15,386 acres, primary production was estimated at $20 \mathrm{MMBO}$ and original oil in place was estimated at 88.5 MMBO (Whieldon and Eckard, 1963).

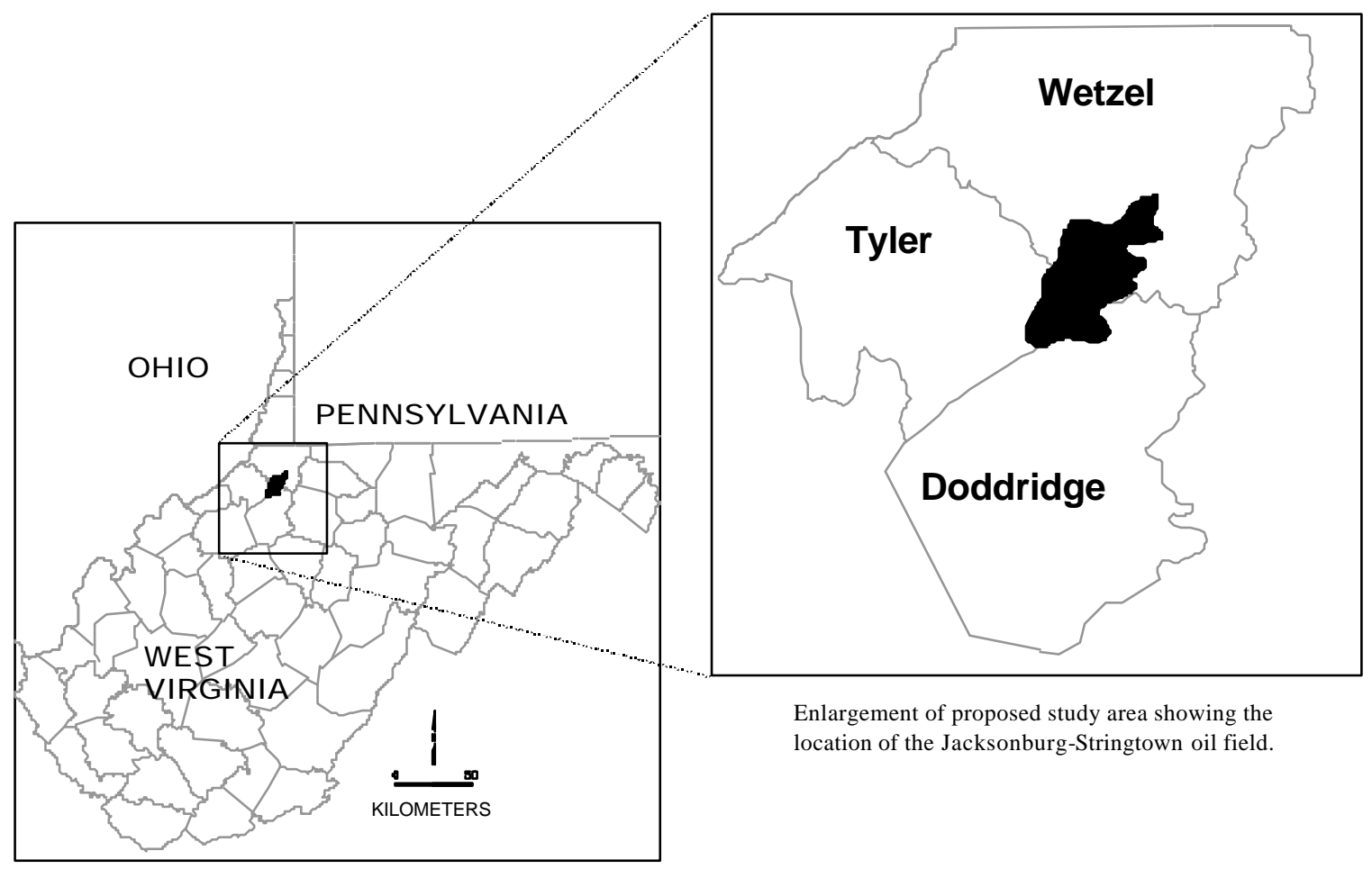

Figure 1.1. Location of Jacksonburg-Stringtown Field in northwestern West Virginia. 


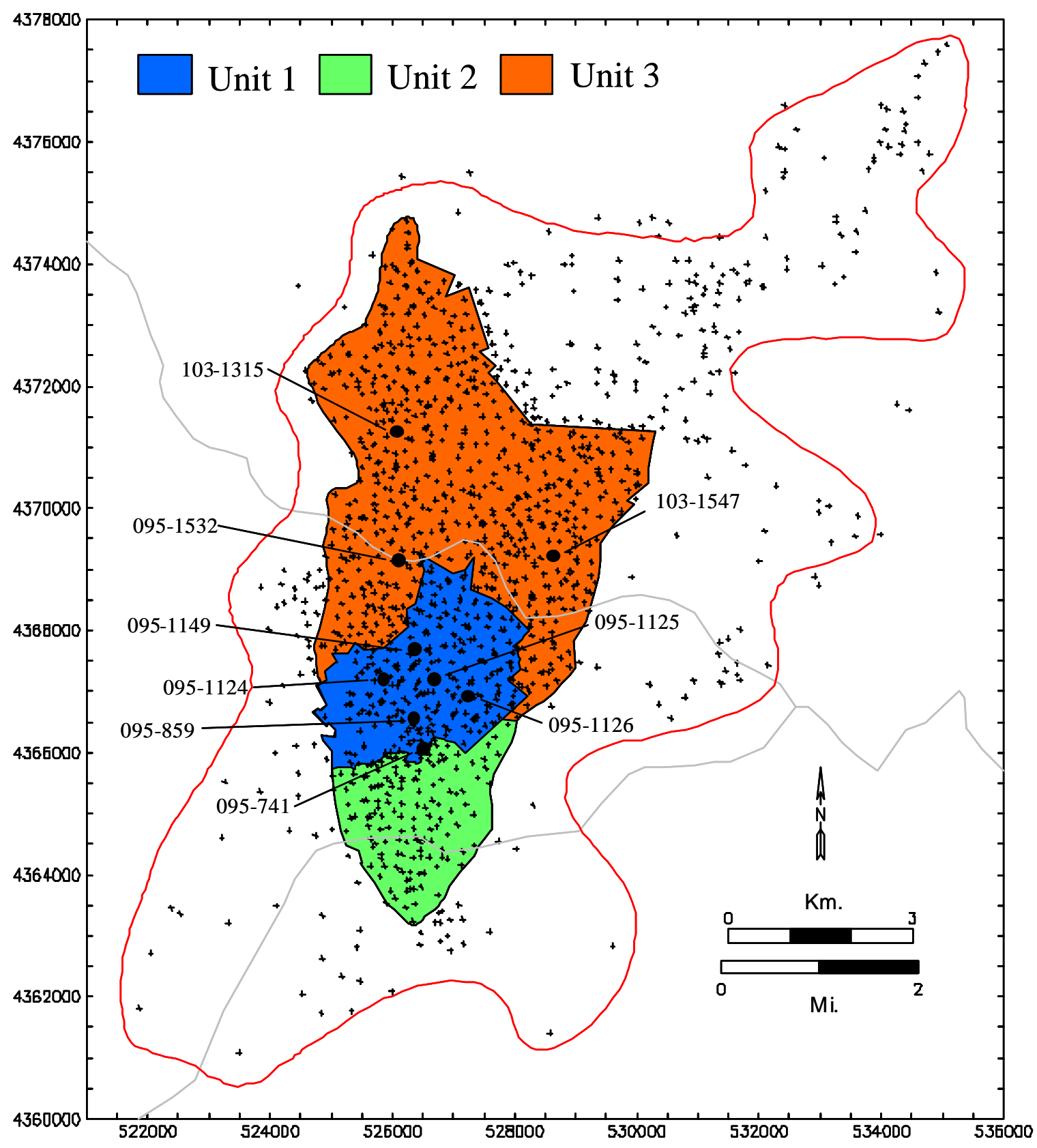

Figure 1.2. Map of Jacksonburg-Stringtown field, with well locations, outline of field (red line), production units as defined by PennEnergy (color shading), and locations of cored wells (filled circles with permit numbers).

Gas injection began in 1934 (Boone and others, 1986) or mid 1920's (Putscher and King, 1983). Limited development and testing continued through the 1950's, with five injection wells spread out through the field (Fig. 1.4). Recovery attributed to gas injection averaged 154 BOPA over a limited portion of the field (Boone and others, 1986). 
The pilot waterflood of the Gordon was installed in 1981, as an approximately 34 acre dual fivespot (Fig. 1.5). An average of 1300 BOPA was recovered in 4 years, Figure 1.6, pilot waterflood cumulative production). Water injection rates were limited due to supply. Lower than predicted (1500 BOPA) recovery is believed to be due to dump flooding of the eastern five-spot (Boone and others, 1986).

The full-scale waterflood began in 1990 (Fig. 1.7). Since 1990, more than 100 new wells have been drilled for water injection and 40 new wells drilled for production. Of these newly drilled wells, 24 of them have been drilled with low angle deviations, to accommodate surface topographic and logistical constraints. PennzEnergy, the operator at the time, divided the field into 3 areas or units for waterflood development (Fig. 1.2). Unit I, consisting of 1,815 acres, was formed in 1981, and contains the pilot waterflood. Unit II, 5,723 acres, was formed in 1986 and is located north of and adjacent to Unit I. Unit III, 1,360 acres, was formed in 1995 and is located south of Unit I.

From January, 1991 through February, 1999 1,864,782 barrels of oil have been produced as a result of the full-scale waterflood.

Water for injection in the full-scale flood is transported from shallow water wells drilled near the Ohio River to the field via a 15-mile long pipeline constructed for that purpose.

Stringtown Primary Annual Oil Production

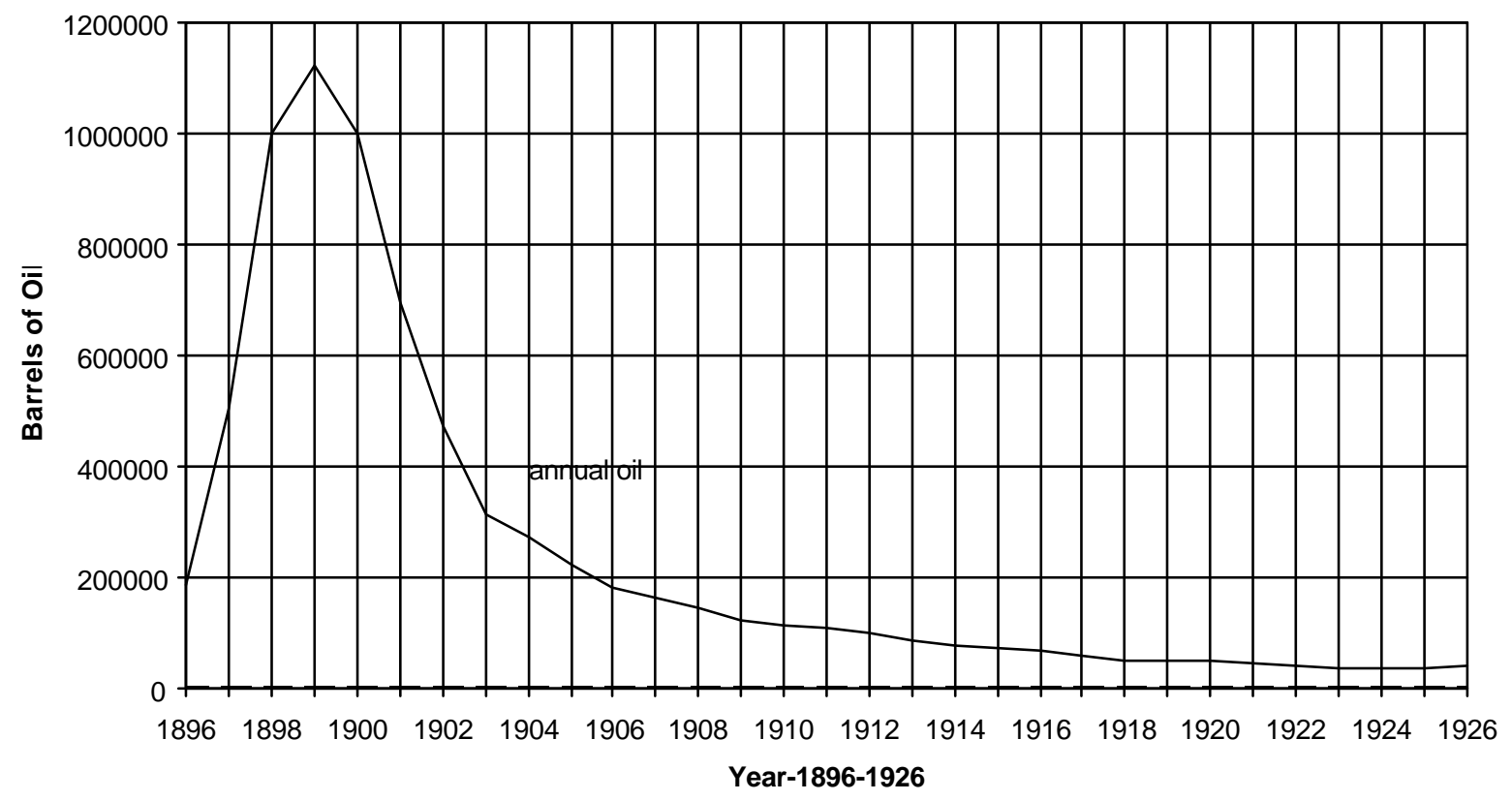

Figure 1.3. Total primary oil production determined from lease production records for about 7,600 acres unitized presently. 


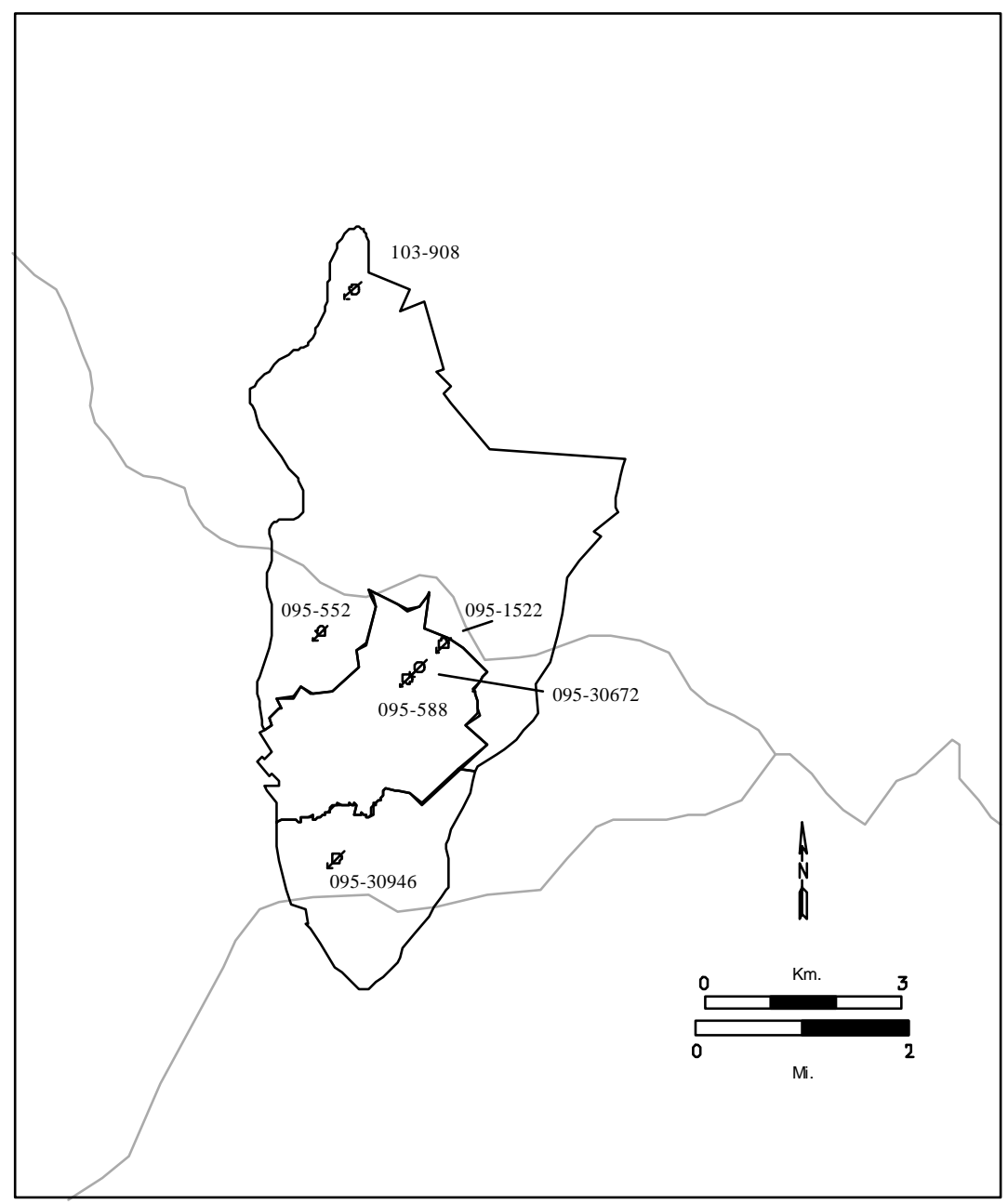

Figure 1.4. Location of gas injection wells from early 1900's. Black outlines show production units defined by PennzEnergy.

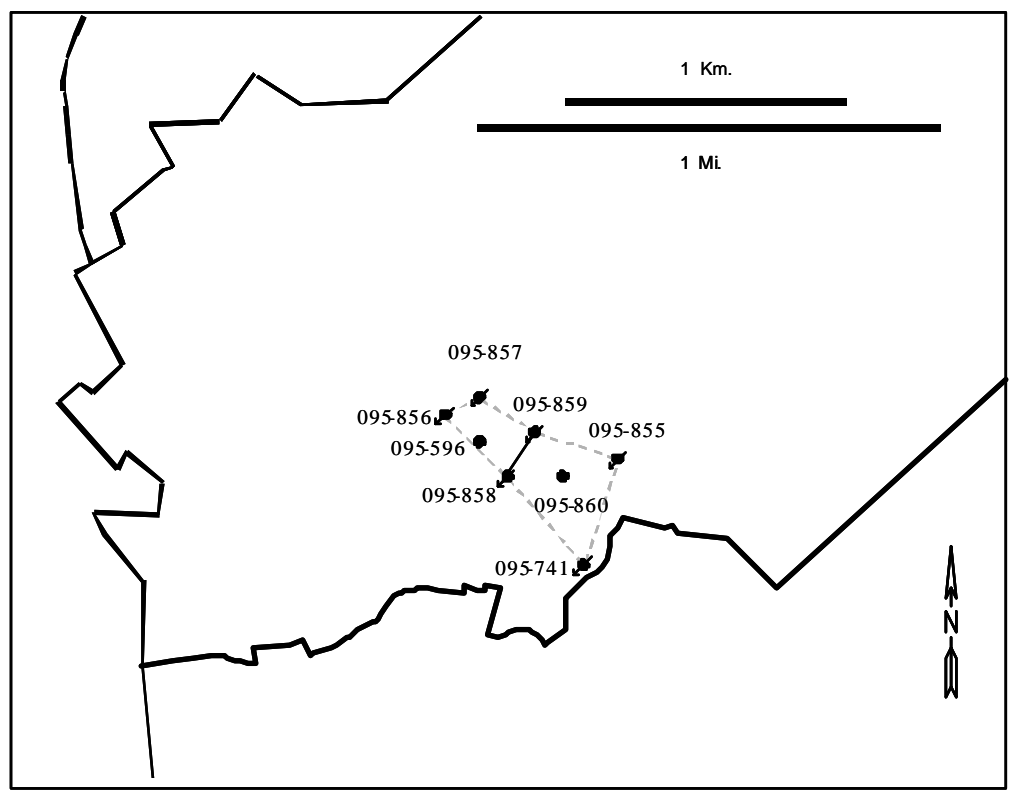

Figure 1.5. Wells associated with the pilot waterflood project. Producing wells for the project were 095-596 and 095-860. All wells lie within production unit 1 (Fig. 1.4). 
Stringtown Pilot Waterflood Cumulative Production

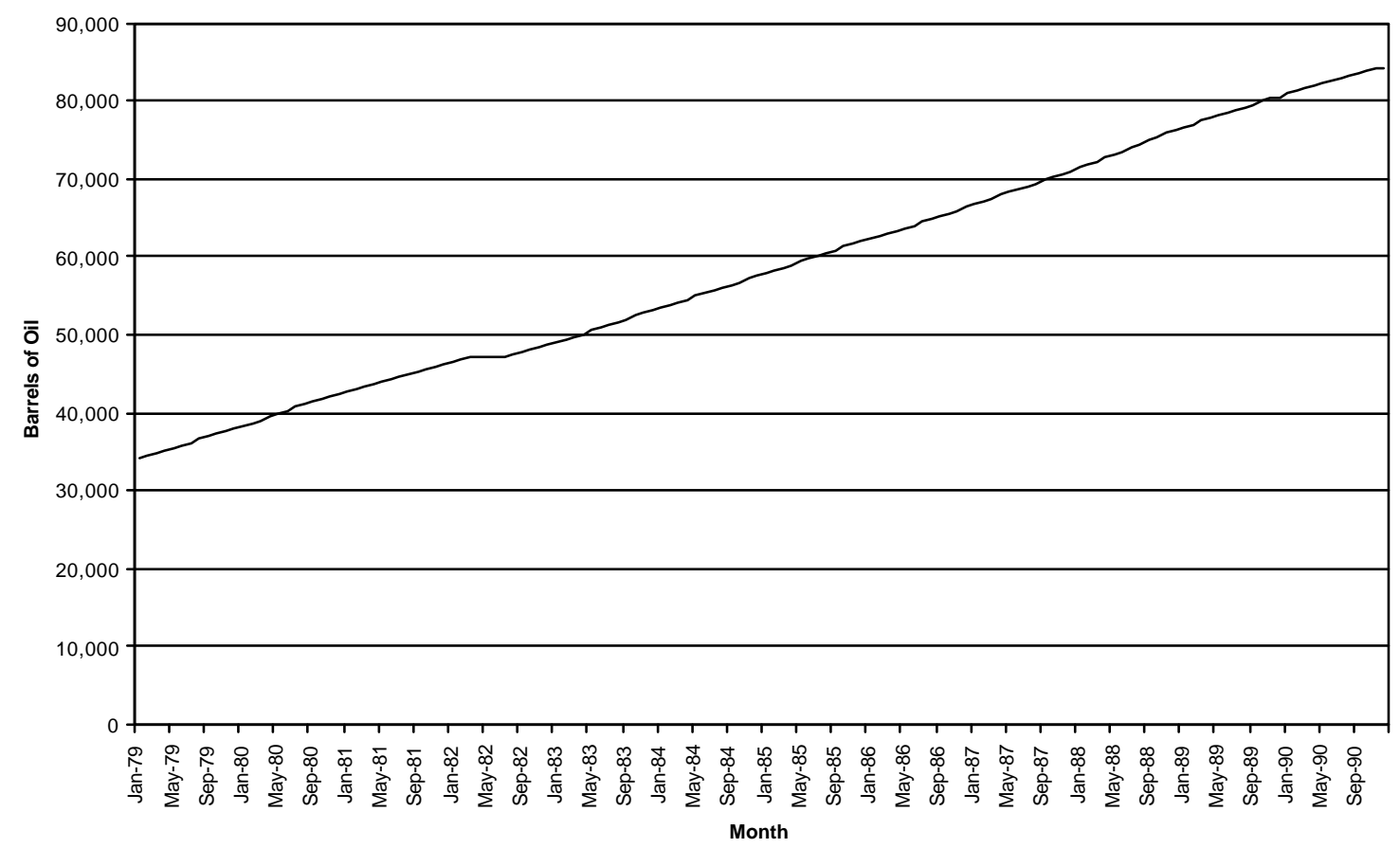

Figure 1.6. Cumulative oil production from 34-acre dual five-spot pilot waterflood (shown in Fig. 1.5).

Stringtown Waterflood Production History

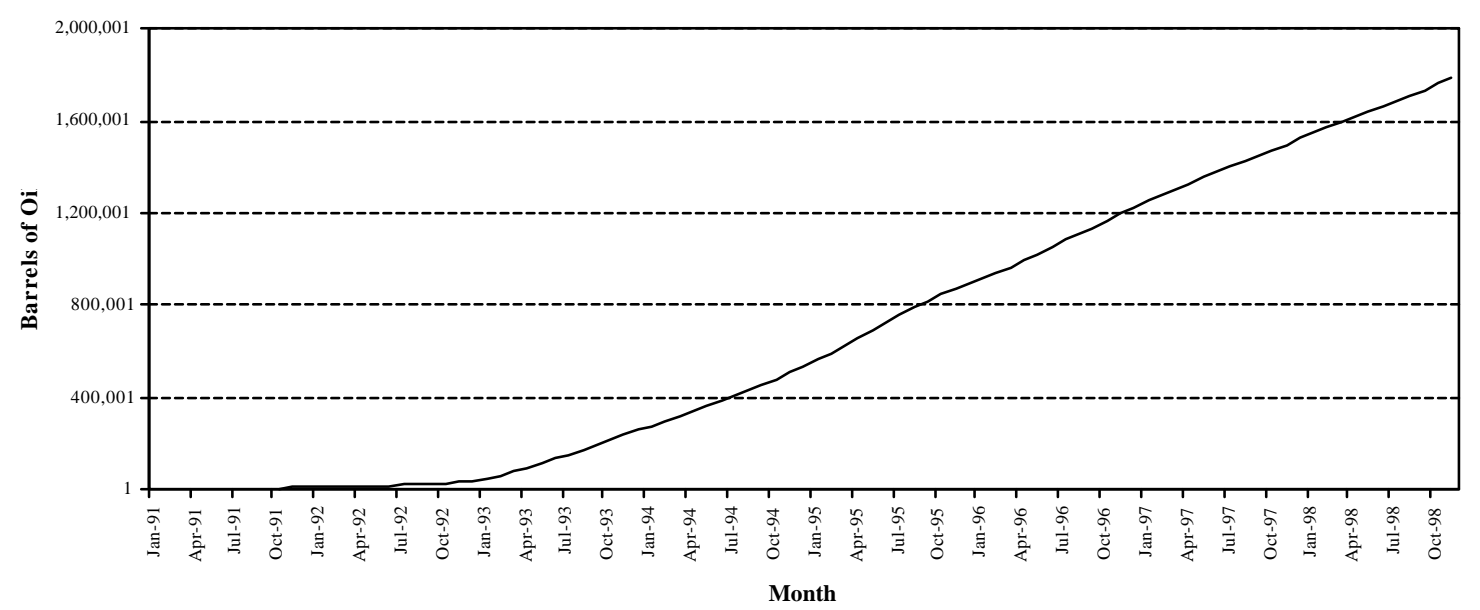

Figure 1.7. Cumulative oil production for currently-developed 5,300 acres of full-scale waterflood. 


\subsection{Development History}

A data set containing the completion dates for all producing oil wells in the JacksonburgStringtown field was subjected to spectral analysis and periods of significant development or expansion of the field were identified. Figure 1.8 shows the results of this analysis with clusters of well completions marked. Figure 1.9 shows the geographic distribution of producing wells in a series of maps for each of the episodes of well completions shown in Figure 1.8. Over 500 wells were drilled in the field between 1897 and 1901 (Figure 1.9A). Most of these wells were plugged by 1910 .

Throughout the development of the Jacksonburg-Stringtown field isolated areas of new production have been discovered within the field. These intrafield discoveries appear in Figure 1.9 as tightly grouped well completions in portions of the field that have had no previous producing wells; these wells are clearly not offset from existing production. After the initial discovery period for the field (1887-1903), each of the next five periods of development (Figs. $1.9 \mathrm{~B}, \mathrm{C}, \mathrm{D}, \mathrm{E}$, and $\mathrm{F}$ ) show intrafield discoveries of new production. Based on previous reservoir characterization studies (Hohn and others, 1993a, 1993b), the combination of several periods of well completions through time and the presence multiple, intrafield discoveries of new production during each of these periods, corresponds to the extent of compartmentalization or heterogeneity within the producing reservoir. The pattern observed for the JacksonburgStringtown field suggests that the Gordon reservoir within the field should be more heterogeneous than the Mississippian Big Injun sandstone reservoir studied previously (Hohn and others 1993a, 1993b; McDowell and others, 1996).

Early drilling in the field up to and including 1897 (Fig. 1.10) took place along a north-south axis, and resulted in discovery of several locations of relatively high production. Drilling during 1898 established the main outlines of the field and better defined the spots of high production (Fig. 1.11). Subsequent drilling in 1899 found additional oil between the isolated areas of high production, but most areas of high production had already been located (Fig. 1.12). By the end of 1900 (Fig. 1.13), wells were being drilled in the less-favorable areas along the western and northeastern field margins.

Within the first decade of drilling and production, two main trends were evident in the field: a north-south trend of relatively high production along the western margin of the field, and a northnortheast trend in the eastern half. Neither trend is continuous; spots of relatively high production appear like beads along a strand. This appearance of discontinuity might reflect original reservoir conditions, or could be the result of declining reservoir pressure throughout this period.

Stratigraphic studies summarized in this report show that the reservoir in this field is made up of several, roughly linear sandstone units that are superimposed locally. Geographic distribution of these units corresponds well to observed patterns in estimated cumulative production. 


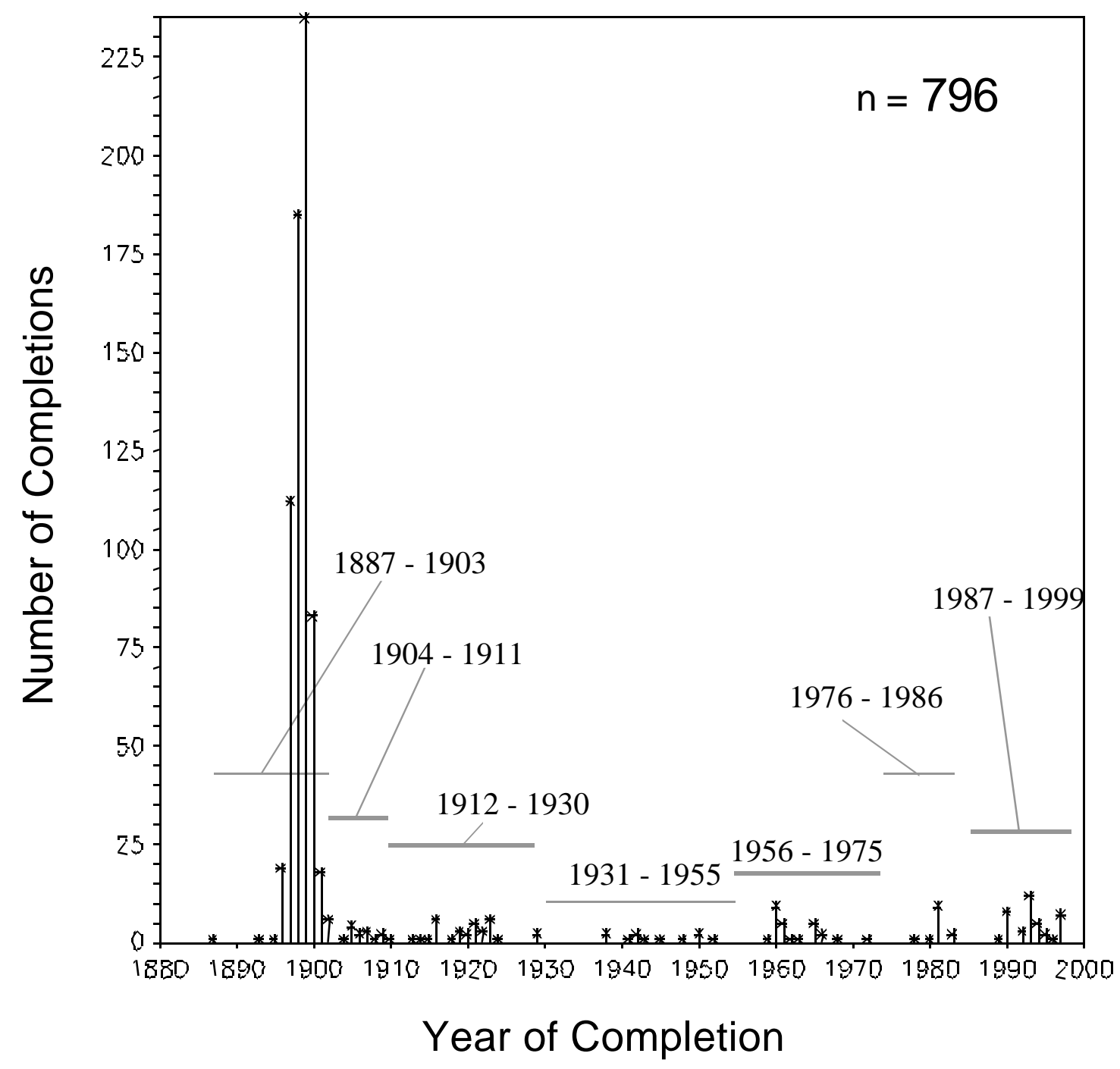

Figure 1.8. Spectral analysis of completion date for all producing oil wells in the Jacksonburg-Stringtown field. Seven significant periods of development or expansion have been identified within these data. 


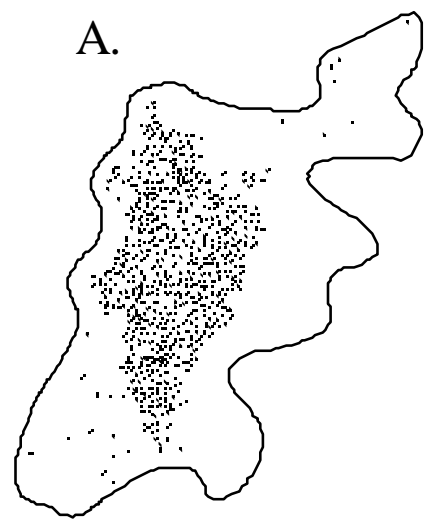

$1887-1903$

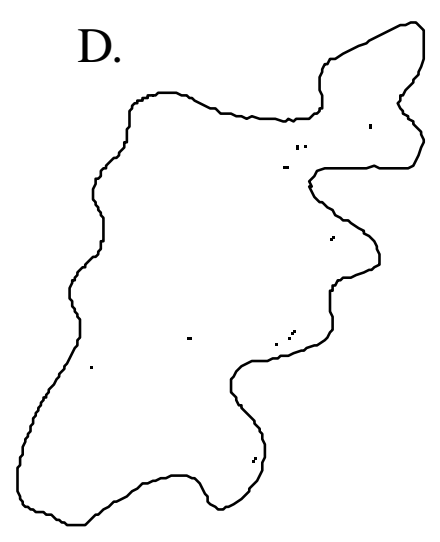

$1931-1955$

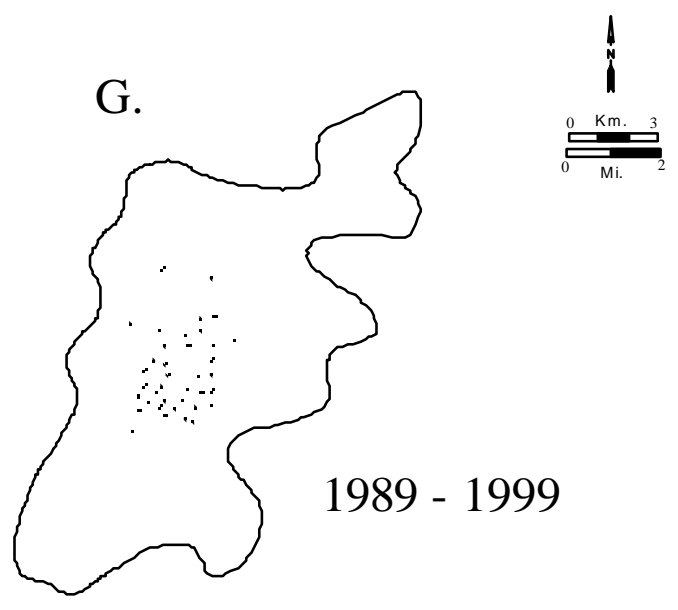

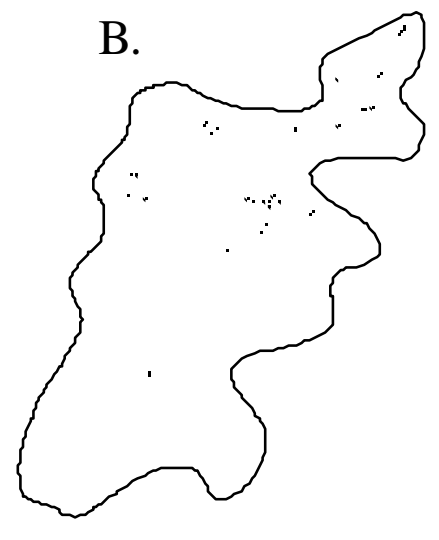

$1904-1911$

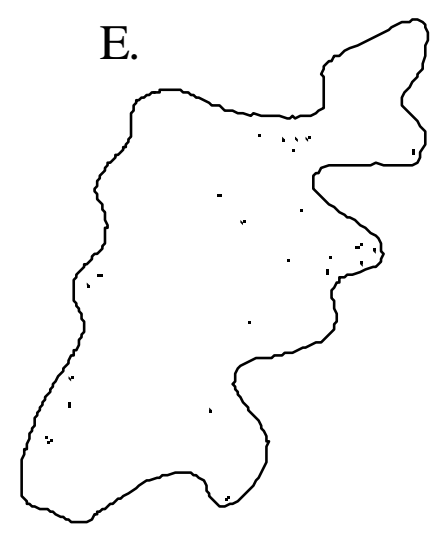

$1956-1975$

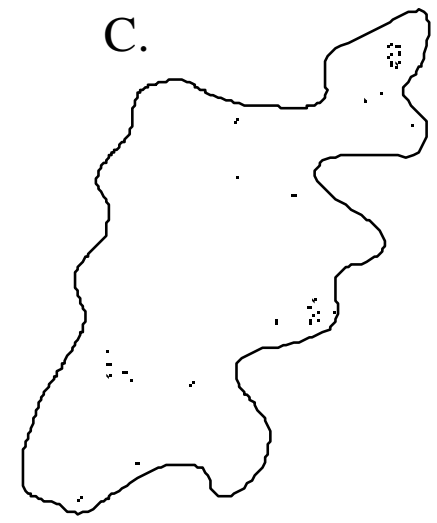

$1912-1930$

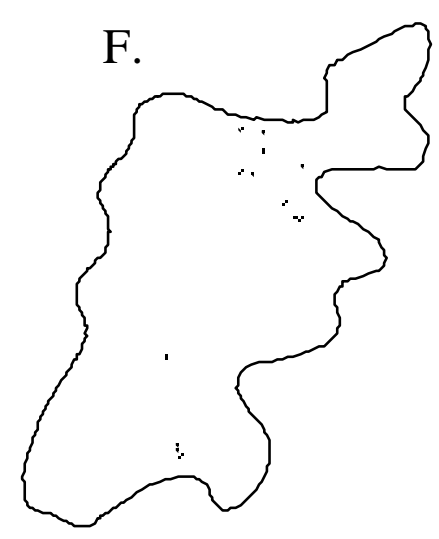

$1976-1986$

Figure 1.9. Field development for the Jacksonburg-Stringtown field. Clusters of well completions identified by spectral analysis (see Figure 1.8) are displayed showing the geographic locations of wells completed during each time period. The approximate boundary of the field has been superimposed for reference. 


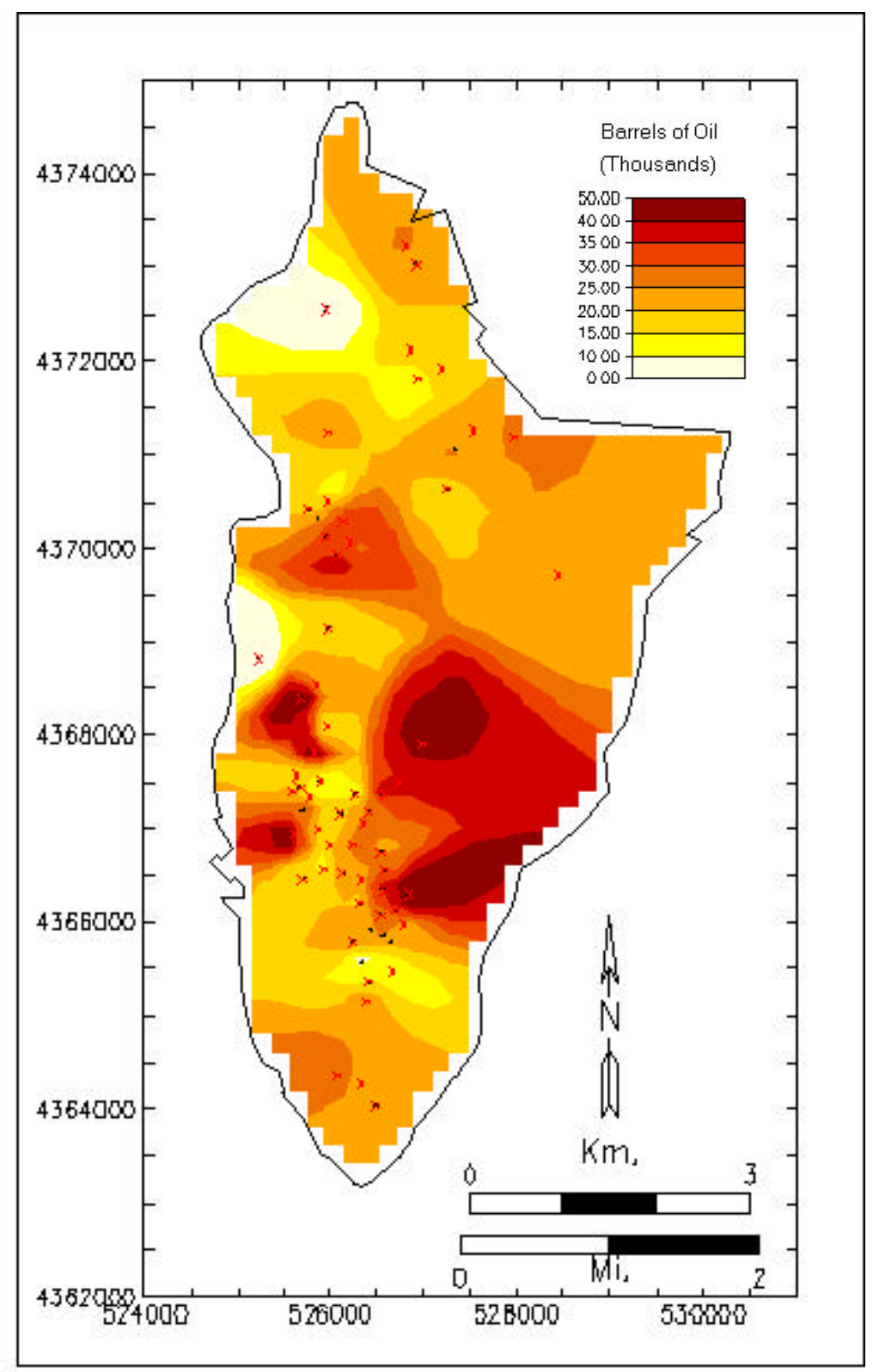

Figure 1.10. Locations of producing wells drilled in 1897 (x), previous to 1897 (.), and estimated ultimate production from wells drilled in 1897 and previous years. The outline of the operator's portion of the Jacksonburg-Stringtown field is shown for reference. 


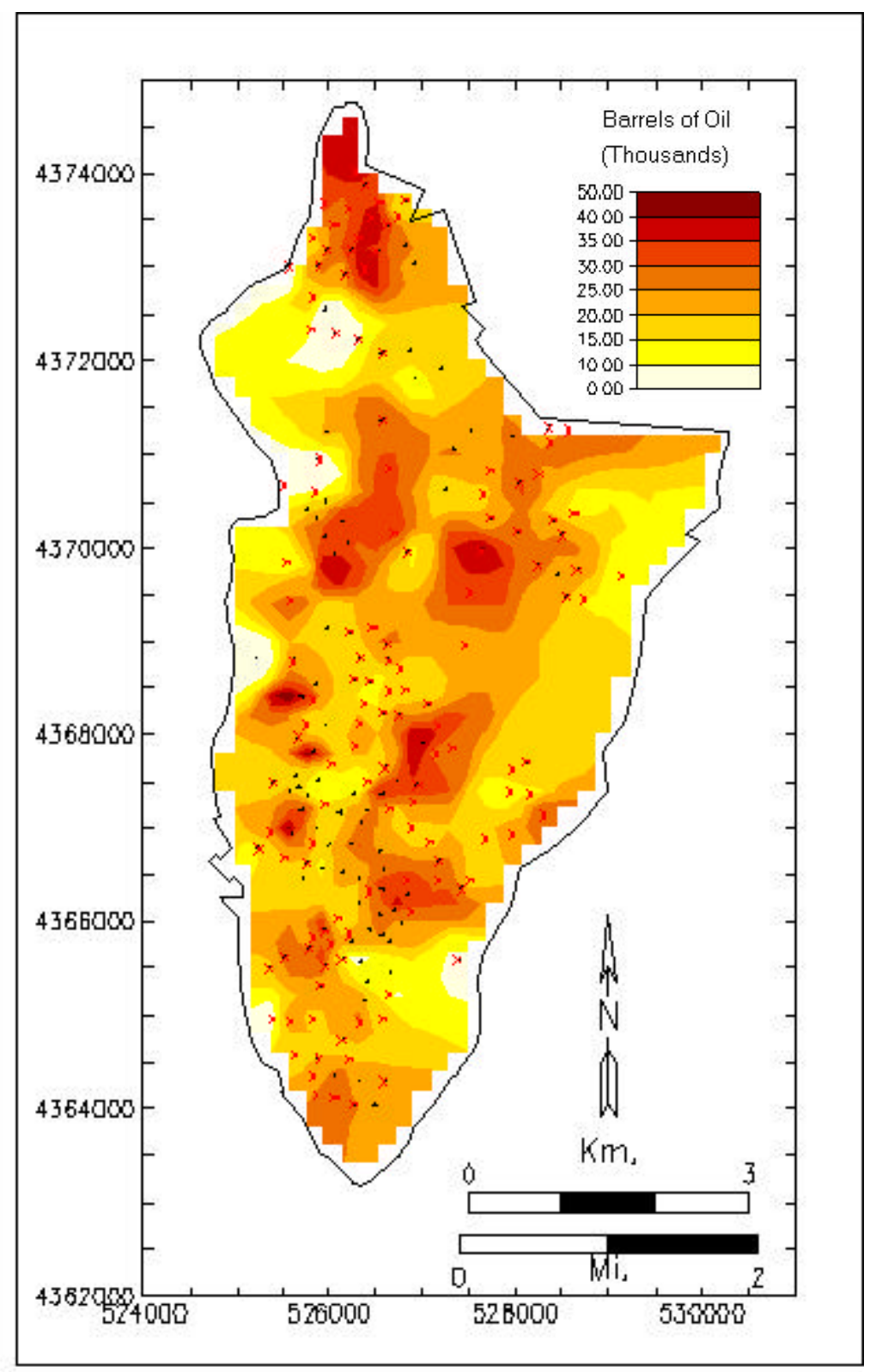

Figure 1.11. Locations of producing wells drilled in 1898 (x), previous to 1898 (.), and estimated ultimate production from wells drilled in 1898 and previous years. The outline of the operator's portion of the Jacksonburg-Stringtown field is shown for reference. 


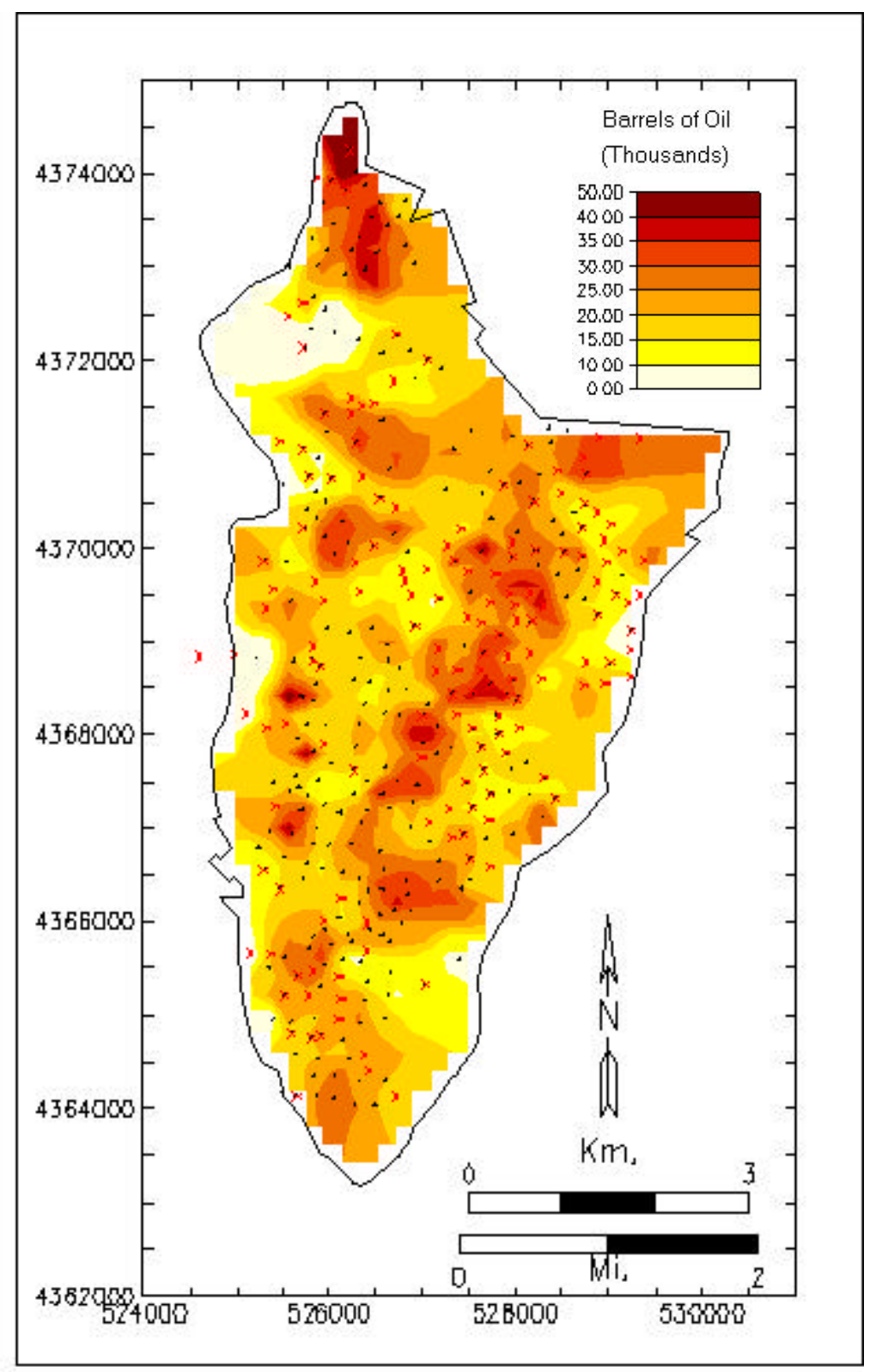

Figure 1.12. Locations of producing wells drilled in $1899(x)$, previous to $1899($.$) , and$ estimated ultimate production from wells drilled in 1899 and previous years. The outline of the operator's portion of the Jacksonburg-Stringtown field is shown for reference. 


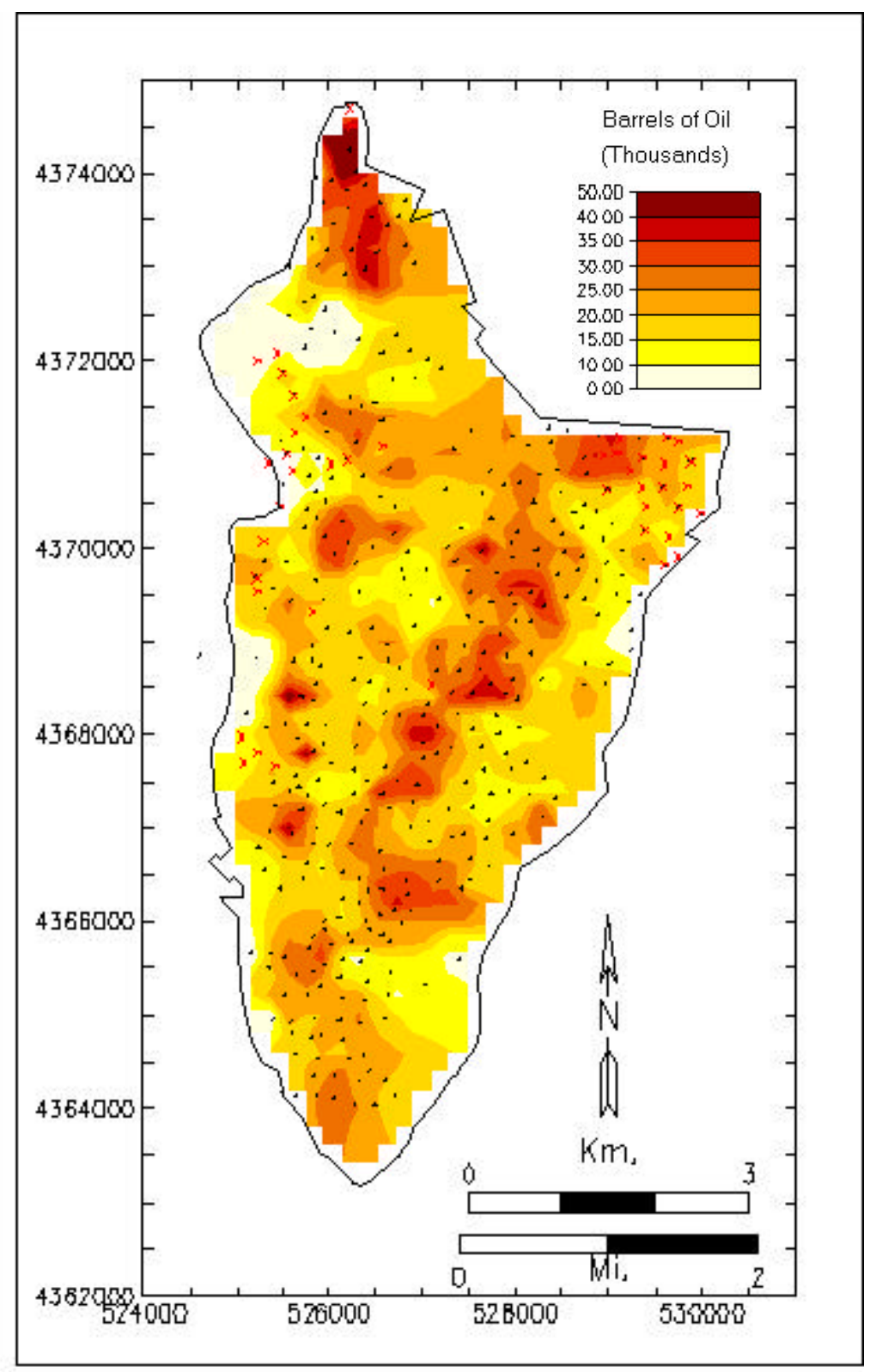

Figure 1.13. Locations of producing wells drilled in 1900 (x), previous to 1900 (.), and estimated ultimate production from wells drilled in 1900 and previous years. The outline of the operator's portion of the Jacksonburg-Stringtown field is shown for reference. 


\subsection{Autocorrelation of Geophysical Logs}

Three wells were chosen from the six cored wells in the Jacksonburg-Stringtown field with gamma ray and density logs and were used to test the computerized autocorrelation software written for a previous reservoir characterization project (Hohn and others, 1994). Gamma ray and density logs from wells 095-1124 (Thompson Heirs 8), 095-1125 (F. R. Ball 18), and 1031547 (E. B. Lemasters O-13) were first correlated manually. Next, digitized logs from each well were subjected to autocorrelation using a computer program based on correlation algorithms from Davis (1973). No disagreements were encountered between the two methods of correlation.

A suite of 115 digitized $\operatorname{logs}$ with both gamma ray and density signature were subjected to autocorrelation. Results from this computer procedure were saved in a data file. Output data consisted of the distance (meters) between wells; the azimuth (degrees) between wells; the correlation coefficient $(\mathrm{R})$ for the best correlation between each pair of wells; and the shift in well depth (meters) to be applied to the second well of the pair to achieve the best correlation. Figure 1.14 presents the results of this procedure in the form of a "spider" plot (Poelchau, 1987) showing the geographical distribution of correlation coefficients between wells as vectors scaled to the value of R. Examination of the Figure indicates that the best correlations between neighboring wells are found consistently along the eastern edge of the field. The reasons for this trend will be discussed in other parts of this report.

Lack of significant structural complexity within the Jacksonburg-Stringtown field reduced the need for adjustment of log elevations to achieve good correlation. Furthermore, the presence of a recognizable stratigraphic horizon on all geophysical logs (top of the Gordon interval) obviated the need to rely on computerized autocorrelation in the preparation of three-dimensional datasets based on correlated geophysical logs. For a description of the use of computerized autocorrelation in the exact opposite of this situation in another reservoir characterization study, see Hohn and others (1994). Computerized autocorrelation was relegated to a "back-up" procedure to assist the Project's stratigrapher with the correlation of logs that proved difficult or ambiguous using visual methods. 


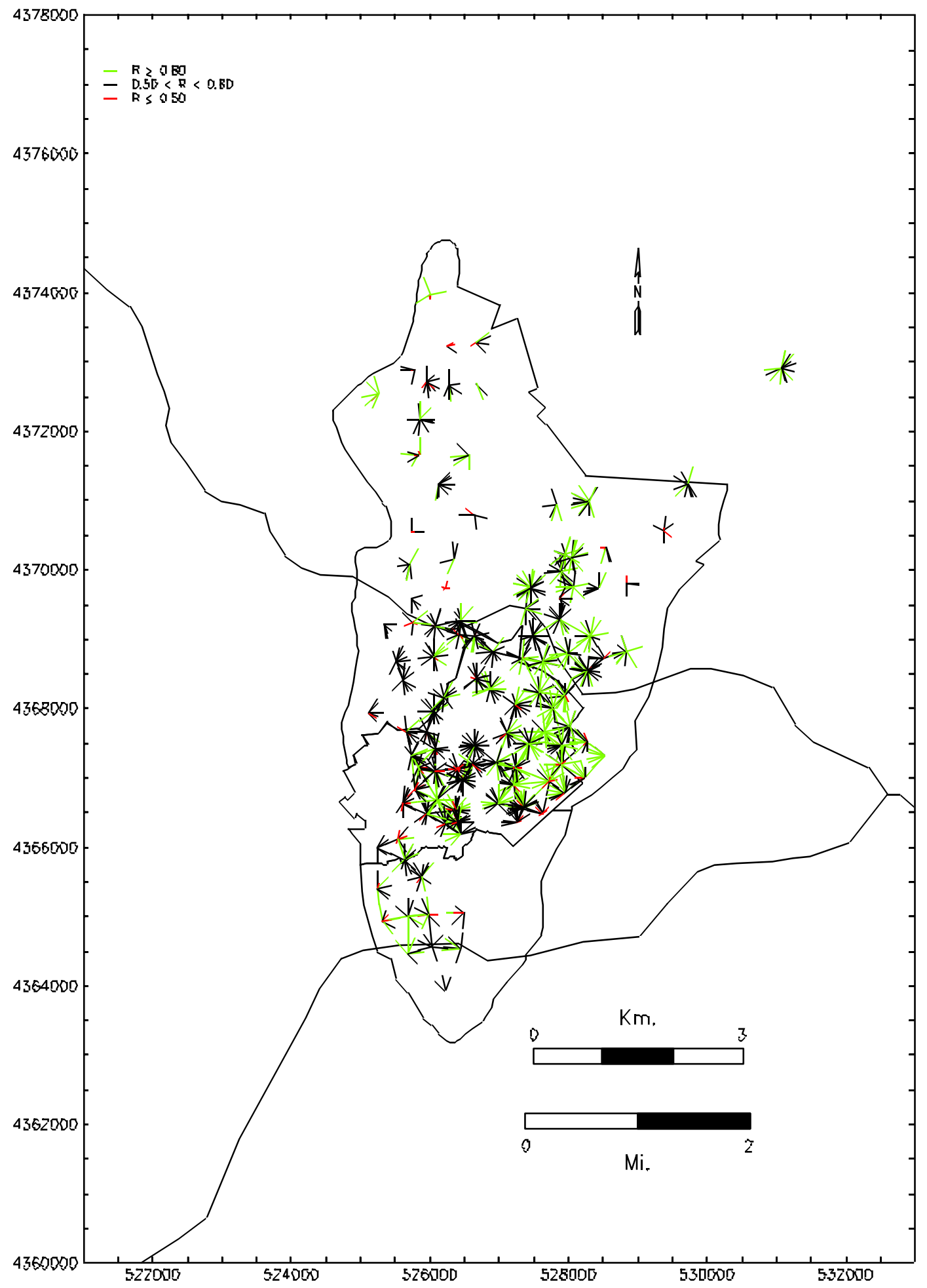

Figure 1.14. Spider plot showing the geographic distribution of "good" (green vectors; $R>0.8$ ); "intermediate" (black vectors; $0.5<R<0.8$ ); and "bad" ( $r e d$ vectors; $R<0.5$ ) correlations between wells in the Jacksonburg-Stringtown field. Notice the concentration of good correlations along the eastern margin of the field. Outline of the operator's portion of the field is shown for reference. 


\section{RESERVOIR DESCRIPTION}

\subsection{REGIONAL GEOLOGY}

\subsubsection{Structure}

The field is situated along the axis of the Burchfield syncline, between the Arches Fork and Littleton anticlines (Fig. 2.1). Like many of the oilfields in West Virginia (Granny Creek, Rock Creek, Griffithsville), oil is trapped downdip of gas accumulated along the structural highs.

\subsubsection{Stratigraphy}

Gordon sandstones are part of the thick, Upper Devonian sedimentary section. Nomenclature in this area is unclear. In West Virginia, the outcrop equivalents are called the Hampshire Formation (Fig. 2.2). The sediment composition varies considerably. In the eastern outcrop belt, the rock is non-marine red shales and fluvial sandstones of the Hampshire Formation; in the western outcrop belt, of distal marine shales of the Chagrin, Ohio and Chattanooga shales. The intervening sedimentary rocks grade between these two extremes, containing at different locations, fluvial, shoreline, or shelf sandstones and shales; the Gordon lies along the shoreline trend of this spectrum. In general, the marine content decreases to the east.

Sandstones of this interval are more commonly known by an informal terminology developed by drillers exploring for oil and gas during the late 1800s. Informal stratigraphic names include "Gantz", "Bayard", "Gordon", and "Fifty-foot". Productive sandstones in the JacksonburgStringtown oilfield lie within the Gordon interval. Gordon sandstones are stacked in a northsouth trend that extends northward into Pennsylvania (Fig. 2.3). The oilfield lies in the southern part of this trend.

The Gordon interval is often subdivided into the Gordon and Gordon Stray sandstones. The Gordon Stray is found higher in the section than the Gordon and displays a pattern that mimics the distribution of the entire Gordon interval (Fig. 2.4). Stratigraphic cross sections show the relationship between these sandstones (Figs. 2.5 and 2.6). These sandstones are interpreted as shoreline/shoreface sandstones as they occupy a broad, arcuate trend at the point of maximum regression of the Acadian clastic wedge. Although Boswell and Jewell (1988) used the term Gordon Stray for the sandstones in the field, the current operator (East Resources) uses the term Gordon. For the purposes of this report and to avoid confusion, the operator's terminology has been adopted. 


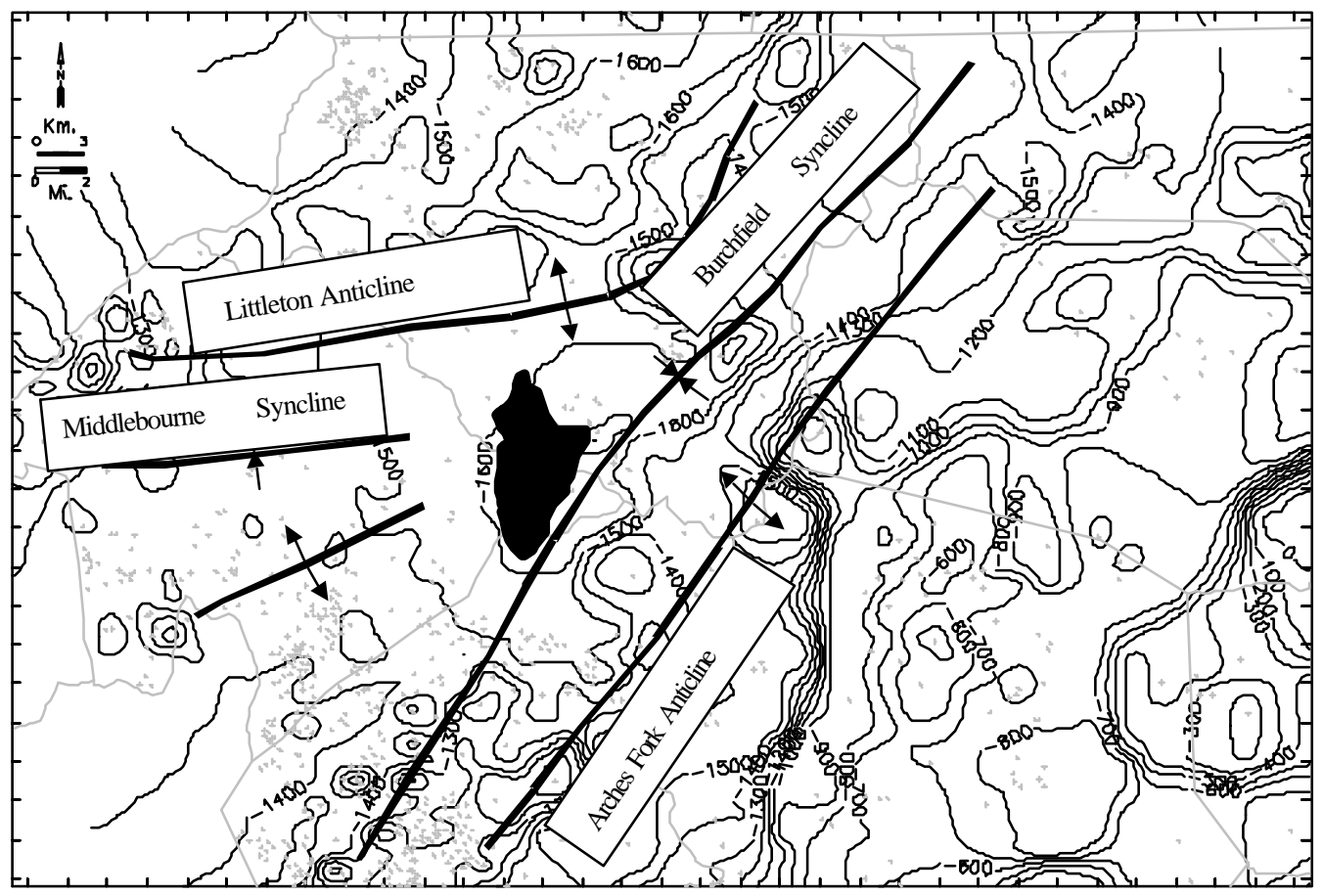

Figure 2.1. Structural features of northern West Virginia. Contours are drawn on the top of the Berea Sandstone. Contour interval is $\mathbf{1 0 0}$ feet.

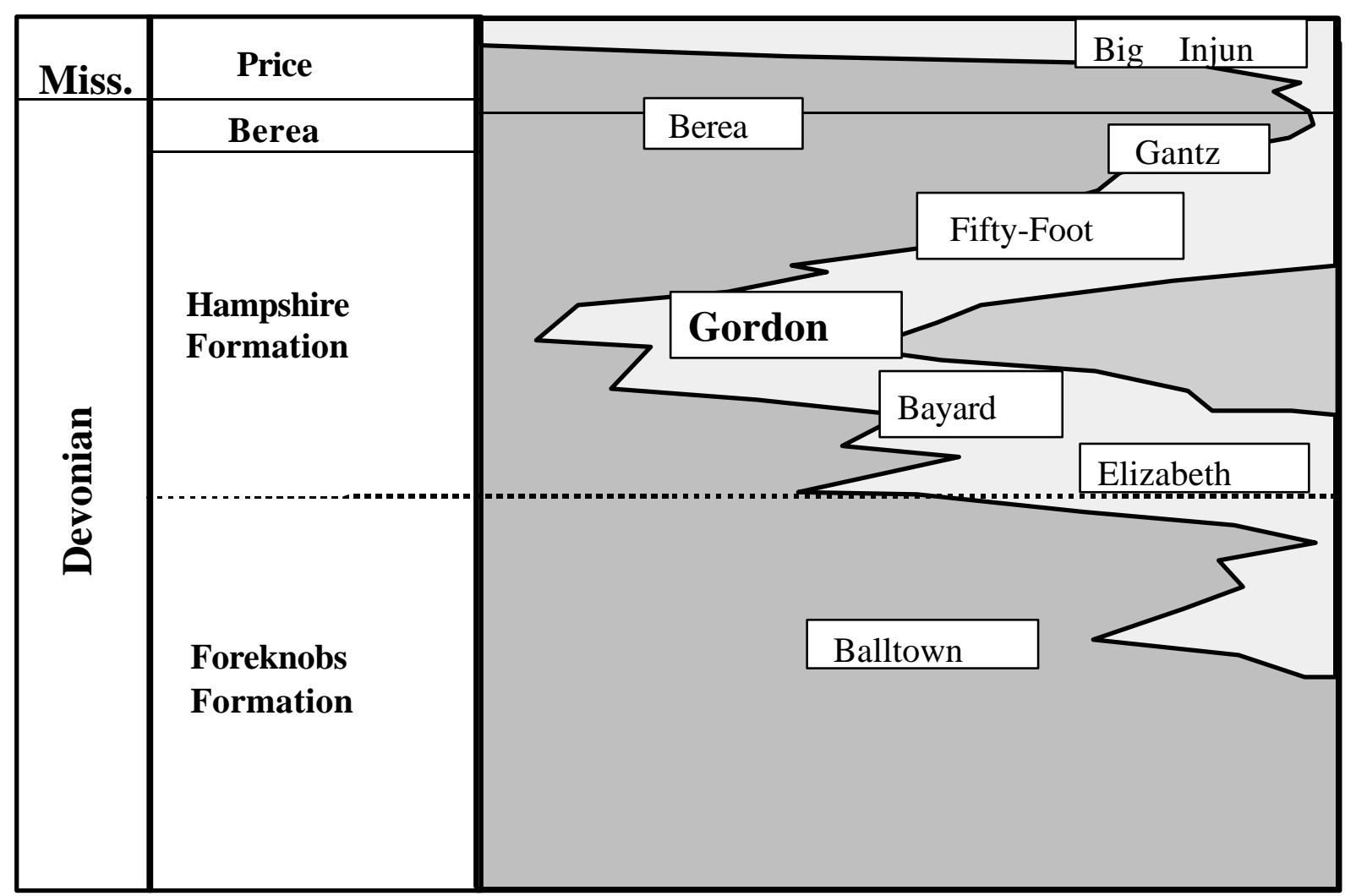

Figure 2.2. Generalized stratigraphic column for the study area including both outcrop and subsurface terminology. 


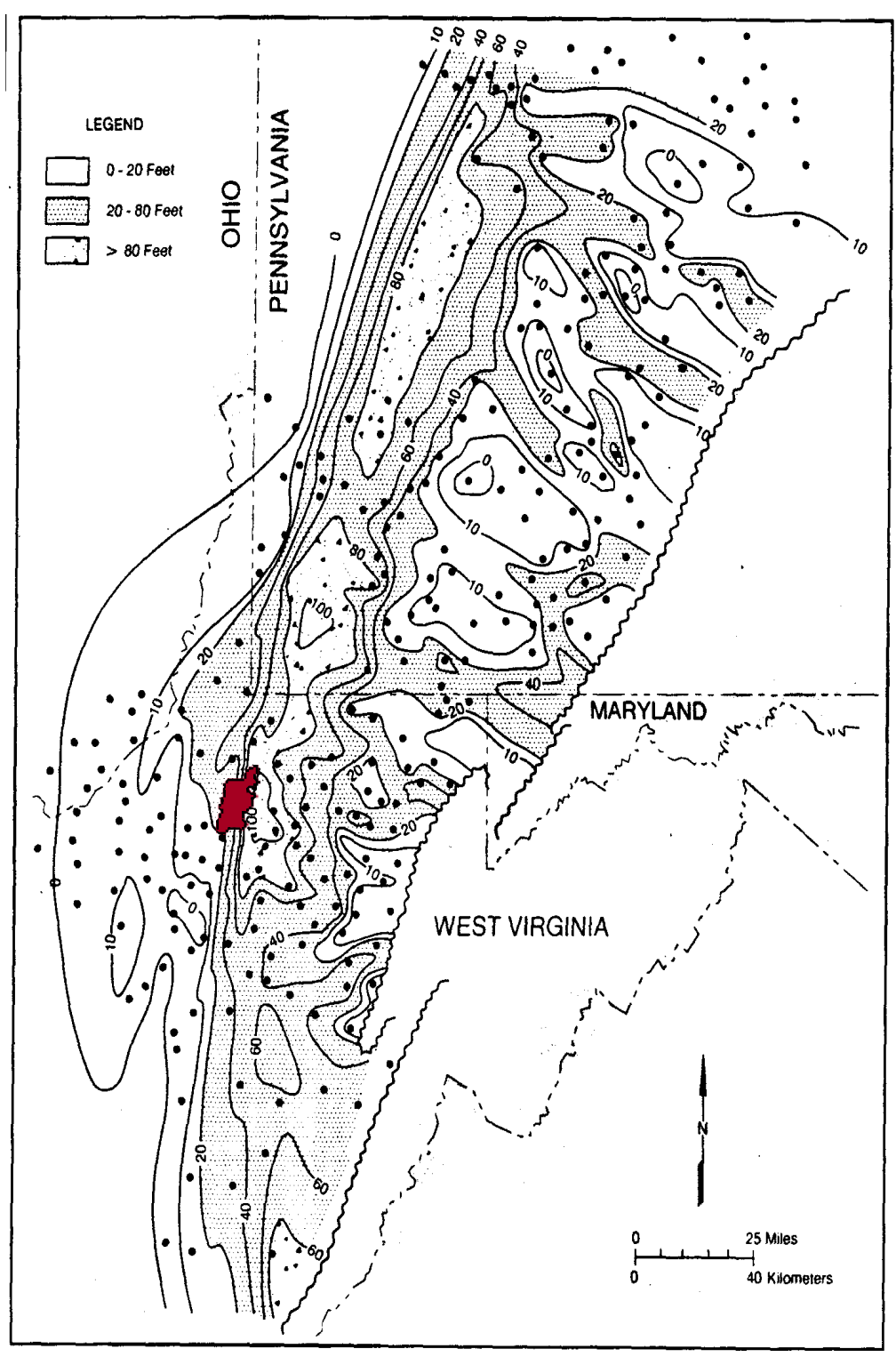

Figure 2.3. Thickness of Gordon interval (from Boswell and other, 1996). 


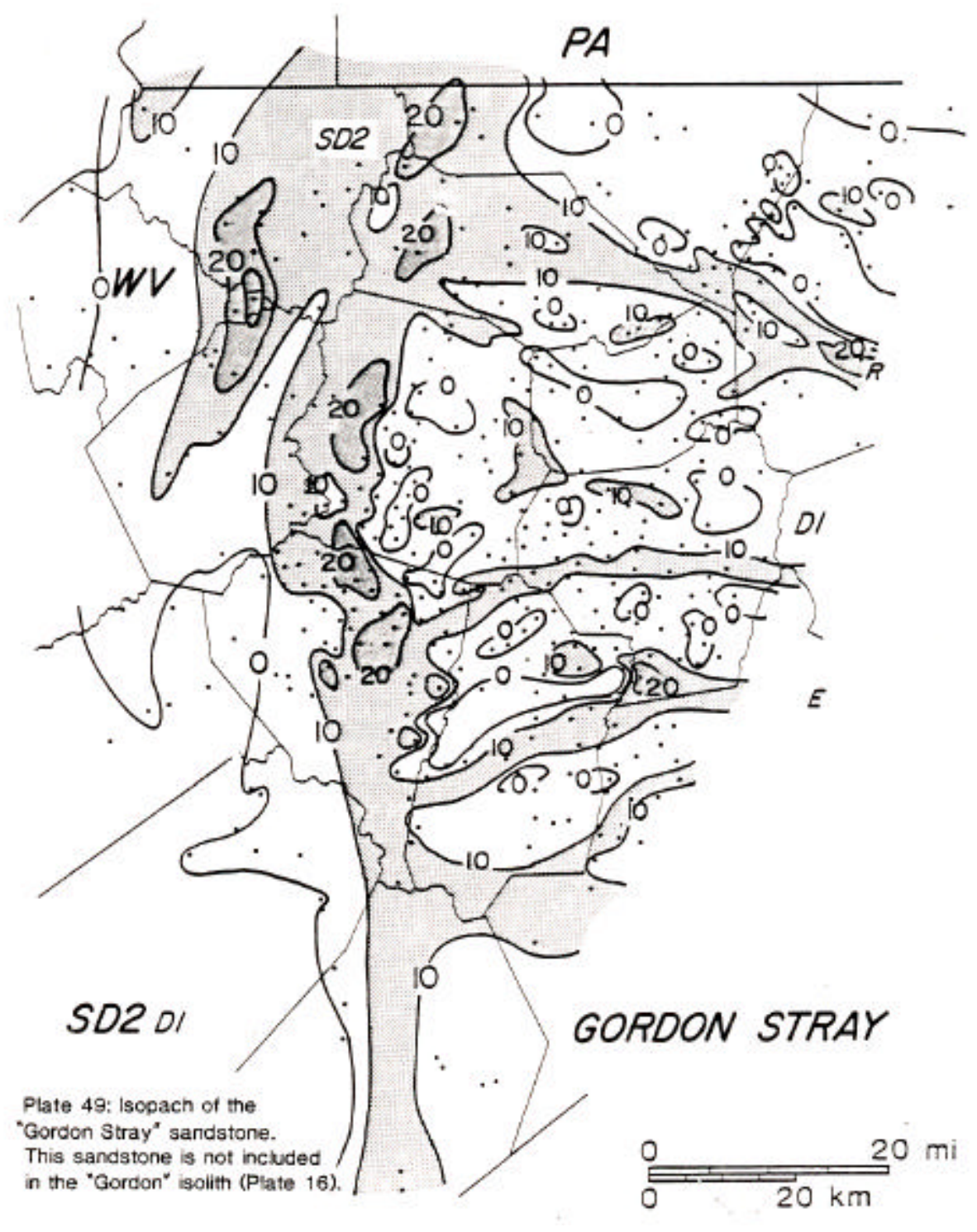

Figure 2.4. Thickness of the Gordon Stray sandstone (from Boswell and Jewell, 1987). 


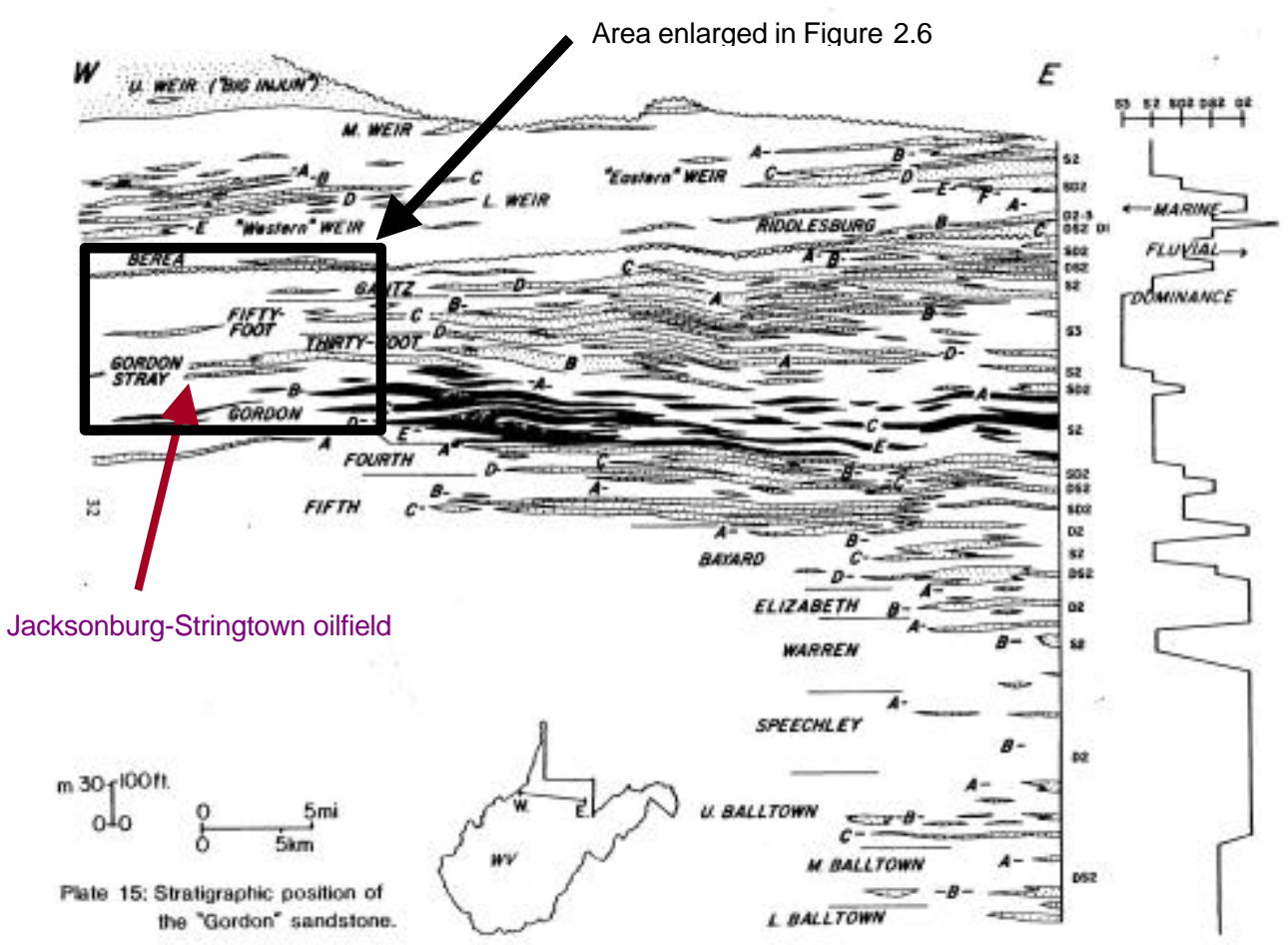

Figure 2.5. Regional distributions of sandstones within the Acadian clastic wedge (from Boswell and Jewell, 1988).

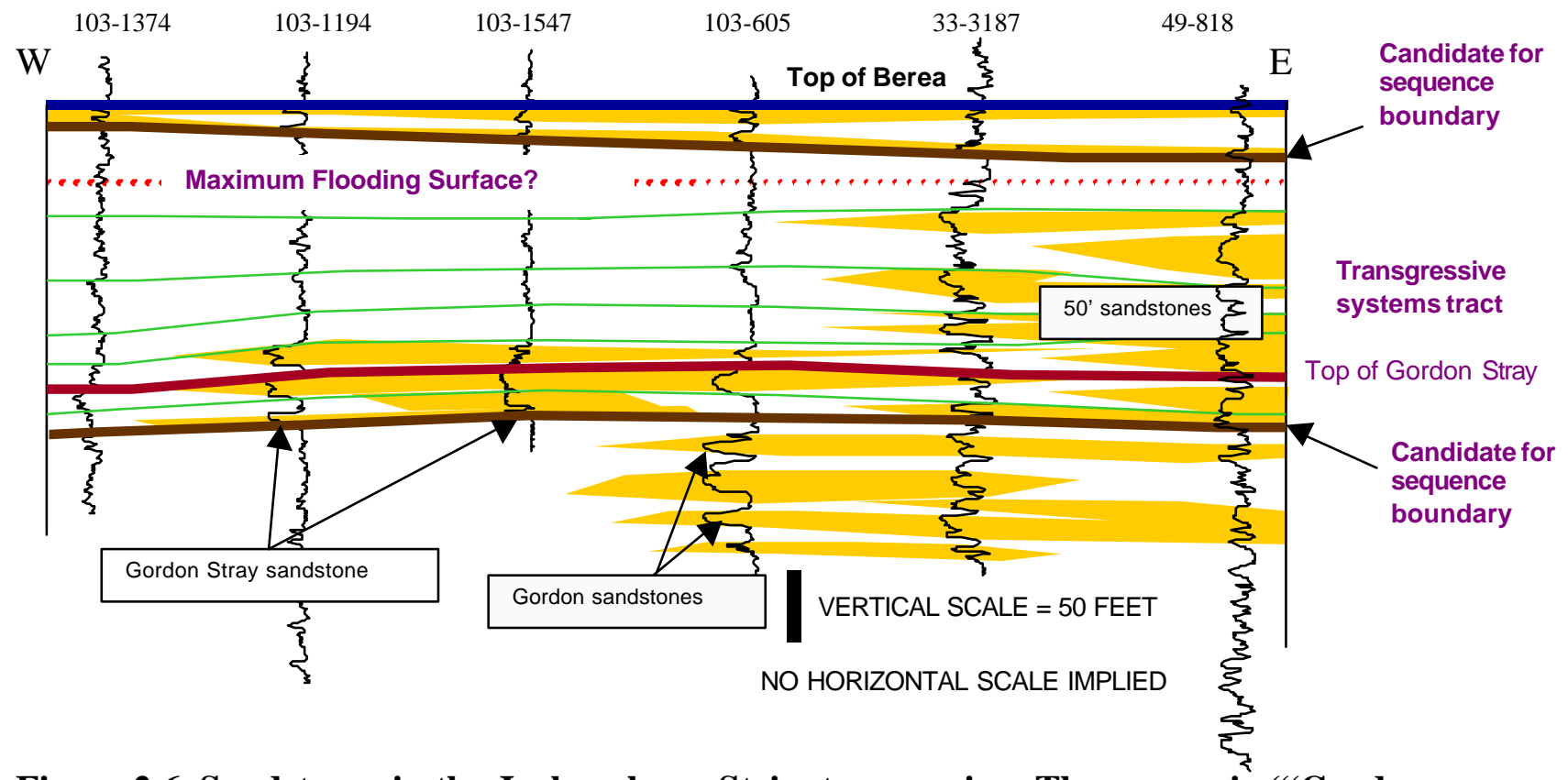

Figure 2.6. Sandstones in the Jacksonburg-Stringtown region. The reservoir ("Gordon Stray" of Boswell and Jewell, 1988) lies above and westward of the primary Gordon trend. Westward offset of the Gordon Stray suggests that it was deposited during a forced regression. Within the Gordon trend, sandstones consist of individual, stacked sandstone bodies, individually 30-50 feet thick. 


\subsection{Geology of the Field}

\subsubsection{Structure}

Structure maps on the top of the Gordon in the field (Fig. 2.7) show a synclinal pattern trending NNE-SSW. An east-west trending fault separates the structurally higher southern portion from the rest of the field. Displacement of 30 feet along this fault should effectively isolate the southern part of the Gordon reservoir in the field. With the exception of the effects of this small fault, compartmentalization in the field is probably the result of sedimentological and diagenetic features.

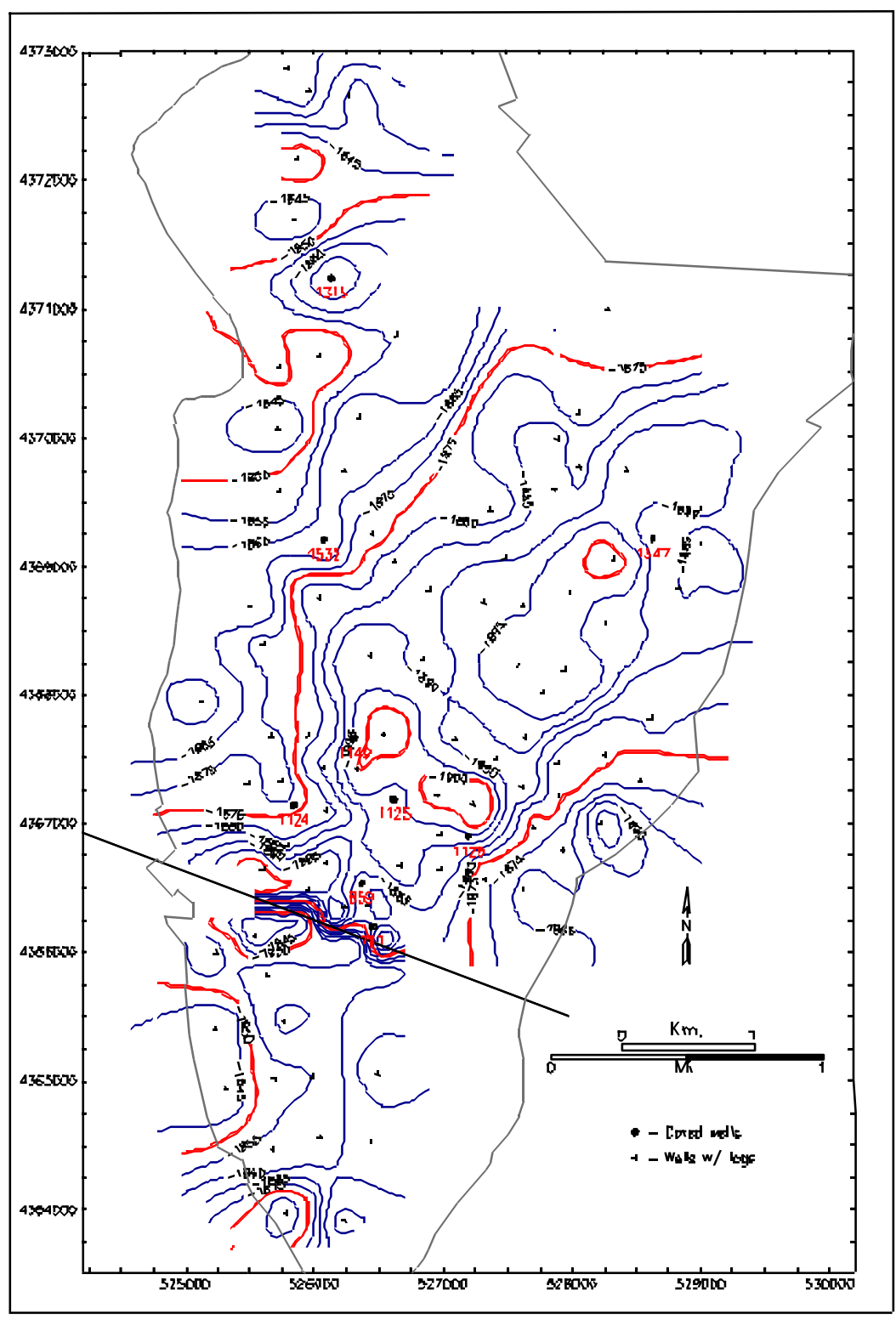

Figure 2.7. Structure contour map for top of Gordon. Position of inferred fault is shown. 20 


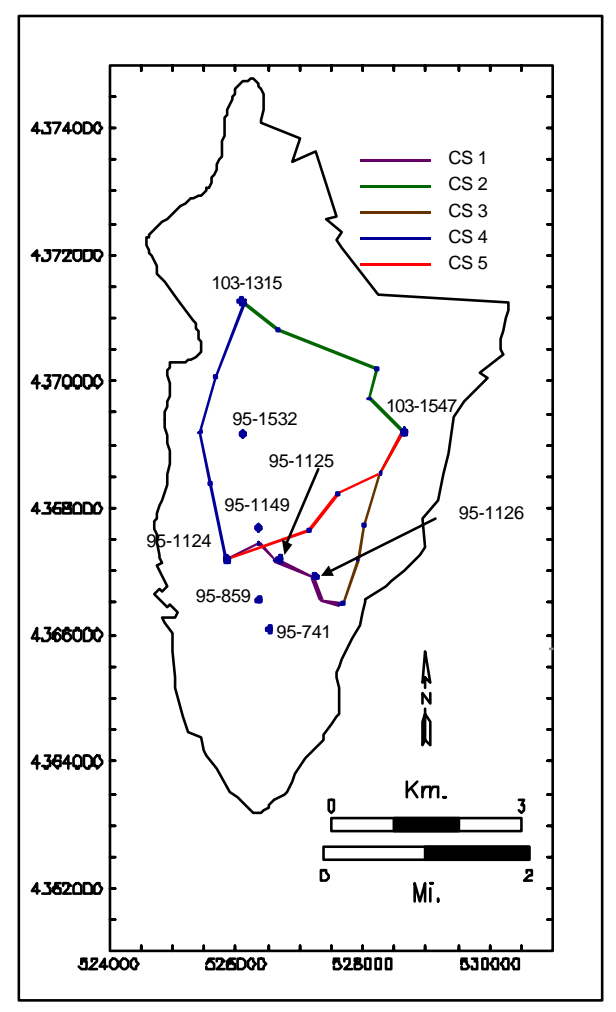

Figure 2.8. Location of cores and cross sections within the Jacksonburg-Stringtown oil field.

\subsubsection{Stratigraphy}

The Gordon comprises five different lithofacies stacked into (at least) three parasequences. General characteristics of each lithofacies are provided in Table 2.1. Only one of the lithofacies (Fss) displays characteristics of pay. Lithofacies descriptions are based on observations of six cores from the field (Figure 2.8).

TABLE 2.1. Lithofacies characteristics

\begin{tabular}{llcccc}
\hline \multicolumn{1}{c}{ Lithofacies } & $\begin{array}{c}\text { How } \\
\text { Identified }\end{array}$ & Symbol & $\begin{array}{c}\text { Thickness } \\
(\mathrm{ft})\end{array}$ & Grain size & $\begin{array}{c}\text { Average } \\
\text { Permeability } \\
(\mathrm{mD})\end{array}$ \\
\hline Shale & Core and Log & Sh & $1-20$ & clay/silt & 2.81 \\
\hline Heterolithic bioturbated & Core and Log & Hb & $1-5$ & clay to sand & 0.18 \\
\hline Laminated sandstone & Core and Log & Lss & $5-15$ & fine sand & 3.48 \\
\hline Conglomeratic sandstone & Core & Css & $5-8$ & fine sand to granule & 3.84 \\
\hline "Featureless" sandstone & Core and Log & Fss & $1-10$ & fine sand & 41.29 \\
\hline
\end{tabular}




\subsubsection{Core Description}

Five lithofacies can be recognized: "Featureless" sandstone (Fss), Laminated sandstone (Lss), Conglomeratic sandstone (Css), Shale (Sh) and Heterolithic bioturbated $(\mathrm{Hb})$. Each of these lithofacies is relatively distinctive in core and has a recognizable pattern in geophysical logs. The three sandstone lithofacies (Fss, Lss, and Css) are the most common. Where present, the Sh lithofacies is useful for field-scale correlation. The Hb lithofacies lies above the reservoir and is useful for paleoenvironmental interpretations and correlation.

Shale (Sh) is dark gray and laminated. Thin bands of siderite are present in some samples. The shale is commonly bioturbated. The thickest shale beds are found in the lower part of the Gordon and are known only from log, as core was not available for the lowest intervals. Thin shales are found interbedded with sandstones higher in the section where they are useful for correlation.

"Featureless" sandstones (Fss) are fine- to very fine-grained and very well sorted with few recognizable sedimentary structures (Fig. 2.9). Some faint horizontal lamination and scattered quartz pebbles can be observed. The lack of sedimentary structures is probably the result of the monotonous grain size rather than bioturbation. Laminated sandstones (Lss) are fine- to very fine-grained and very well-sorted with a wide variety of sedimentary structures. Horizontal laminations and low-angle crossbedding are common. In some cases, the crossbedding is bidirectional, perhaps herringbone. Sedimentary structures are clearest when clay laminae are present. Single quartz pebble layers are limited to a few per core. Bioturbation is rare; when present, it is often in the form of large single burrows. Some rooted zones have been observed but are not common. Brachiopod, bivalve, and echinoderm fossil fragments are apparent in Lss sandstones.

The differences between Lss and Fss are obvious in core; the sandstones can also be clearly distinguished on wireline log (Fig. 2.10). In core, Lss appear denser than Fss. This observation is confirmed on the logs. Lss sandstones have a density of around $2.5 \mathrm{~g} / \mathrm{cm}^{3}$, whereas Fss sandstones have a density of around $2.3 \mathrm{~g} / \mathrm{cm}^{3}$. Combined with a standard gamma-ray signature, Fss are easy to distinguish and are the primary reservoir with the field. Studies using a minipermeameter have shown that the differences in density are associated with a distinct difference in permeability. For the Gordon as a whole, permeabilities range from over $100 \mathrm{mD}$ to less than $25 \mathrm{mD}$. This range is probably the result of depositional heterogeneity combined with diagenetic modification. The highest permeabilities are consistently found in the Fss lithofacies, which corresponds to the primary reservoir in the field.

Conglomeratic sandstone (Css) displays a bimodal distribution of grain size (Fig. 2.9), fine- to very fine-grained sandstone, similar to that comprising most of the Gordon, and gravel-sized clasts. There is little material of intermediate grain size. Texture varies from matrix-supported to clast-supported. Scour surfaces are common and many of the conglomerate beds appear to be lags deposited upon such surfaces. Other sedimentary structures found in the conglomeratic beds include low-angle, bi- and uni-directional crossbeding, high-angle (up to $45^{\circ}$ ) crossbeding, 
reverse grading, rare ripple beds, shale rip-up clasts, and occasional fossils (including a single orthocone cephalopod).

Css has a variable log signature (Fig. 2.10). Gamma-ray signatures indicate that the clay content of this facies is low. Gamma-ray values are low throughout the field and do not display much variation. The density curve varies to a much greater extent. Both Css and interbedded sandstones display a wide variety of density signatures. This variability is, in general, related to the extent of cementation. Several, thin, pay zones occur within Css but can not be correlated throughout the field.

The Heterolithic bioturbated $(\mathrm{Hb})$ lithofacies is found at the top of the Gordon in all the cores. It was deposited as interbedded sandstone and shale; however, extensive bioturbation following deposition has resulted in a well-mixed combination of siltstone, sandstone, shale and conglomerate (Fig. 2.9). The most readily observable sedimentary structures in this facies are trace fossils. While most trace fossils are indistinct or unidentifiable in cross section, Chondrites sp. and Teichichnus sp. have been identified. Siderite clasts and occasional 1-2 cm siderite beds are present. The interbedded sandstones display ripple cross beds and thin brachiopod, bivalve and crinoid fossil fragments. Log signatures for this facies vary depending upon the dominant lithologies present (Fig. 2.10) as indicated by a serrated pattern.

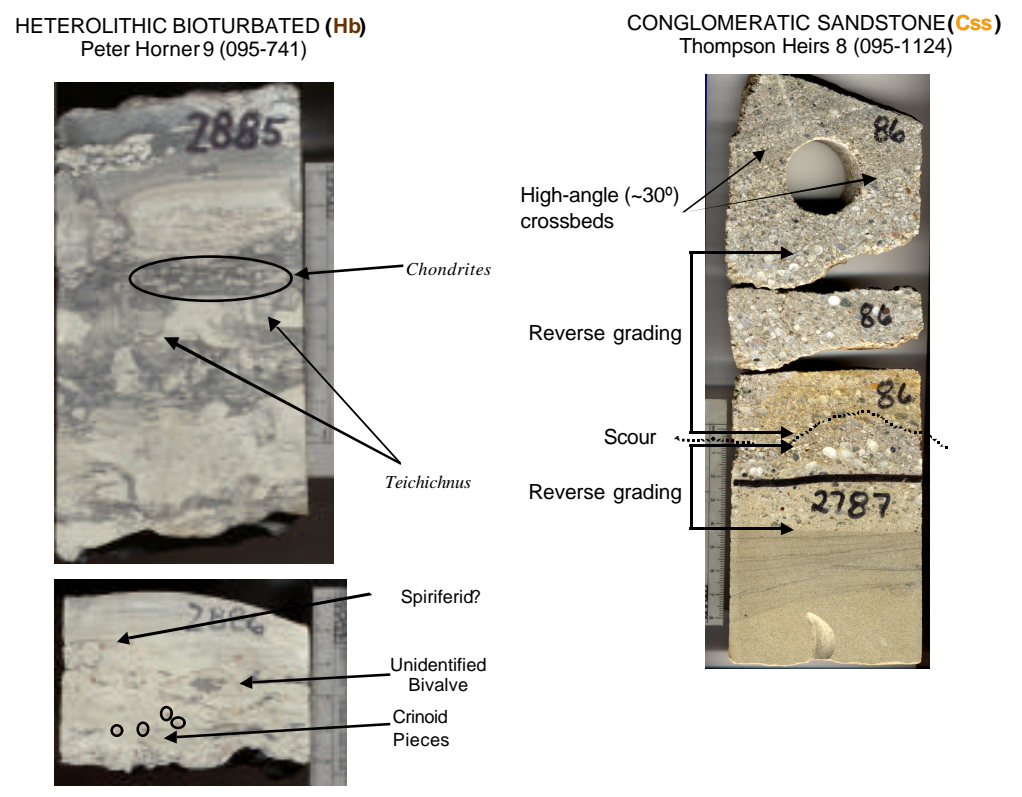

The Hblithofacies is composed of mixed shales, siltstones and sandstones. Bioturbation is abundant: Chondrites and Teichichnus sp. are present. Siderite clasts and siderite beds $1-2 \mathrm{~cm}$ thick are common. The sandier portions of the shale beds display ripple crossbeds and cross-sections of thin brachiopod and bivalve fossils.
The Css lithofacies displays a bimodal distribution of grain sizes: fine-grained sand and gravel. Texture varies between matrix and clast support. Scour surfaces are common and many of the conglomerate beds appear to be lags. Other sedimentary structures include low angle bi- and uni-direction crossbeds, reverse grading, limited ripple beds, crossbeds, reverse grading, limited ripple beds,
shale rip-up clasts, and marine fossils. Fossils include brachiopods and orthocone cephalopods.

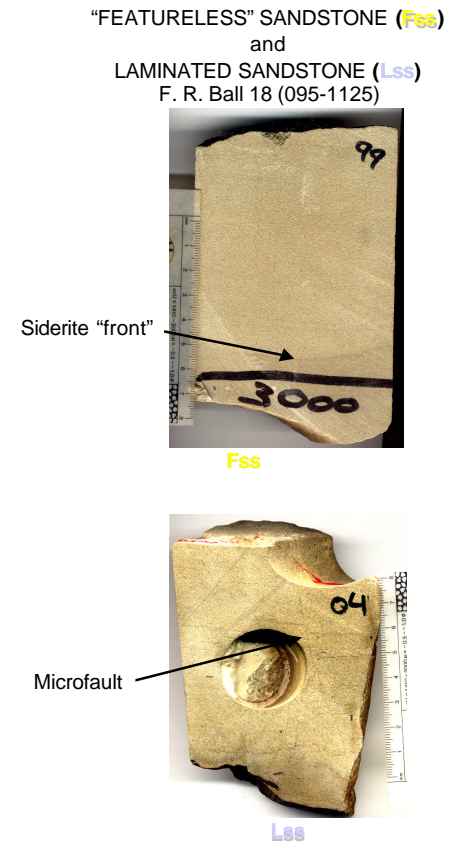

All sandstones are fine-to very fine-grained and very well-sorted. Two different lithofacies can be discerned in core, one that displays sedimentary structures (Laminated sandstone) and one that displays no sedimentary structures ("Featureless" sandstones). The reason for the lack of structure in one and not the other is unknown. Horizontal laminations and low-angle cross bedding have been discerned, and single quartz pebble layers are common. 
Figure 2.9. Definitions of lithofacies.
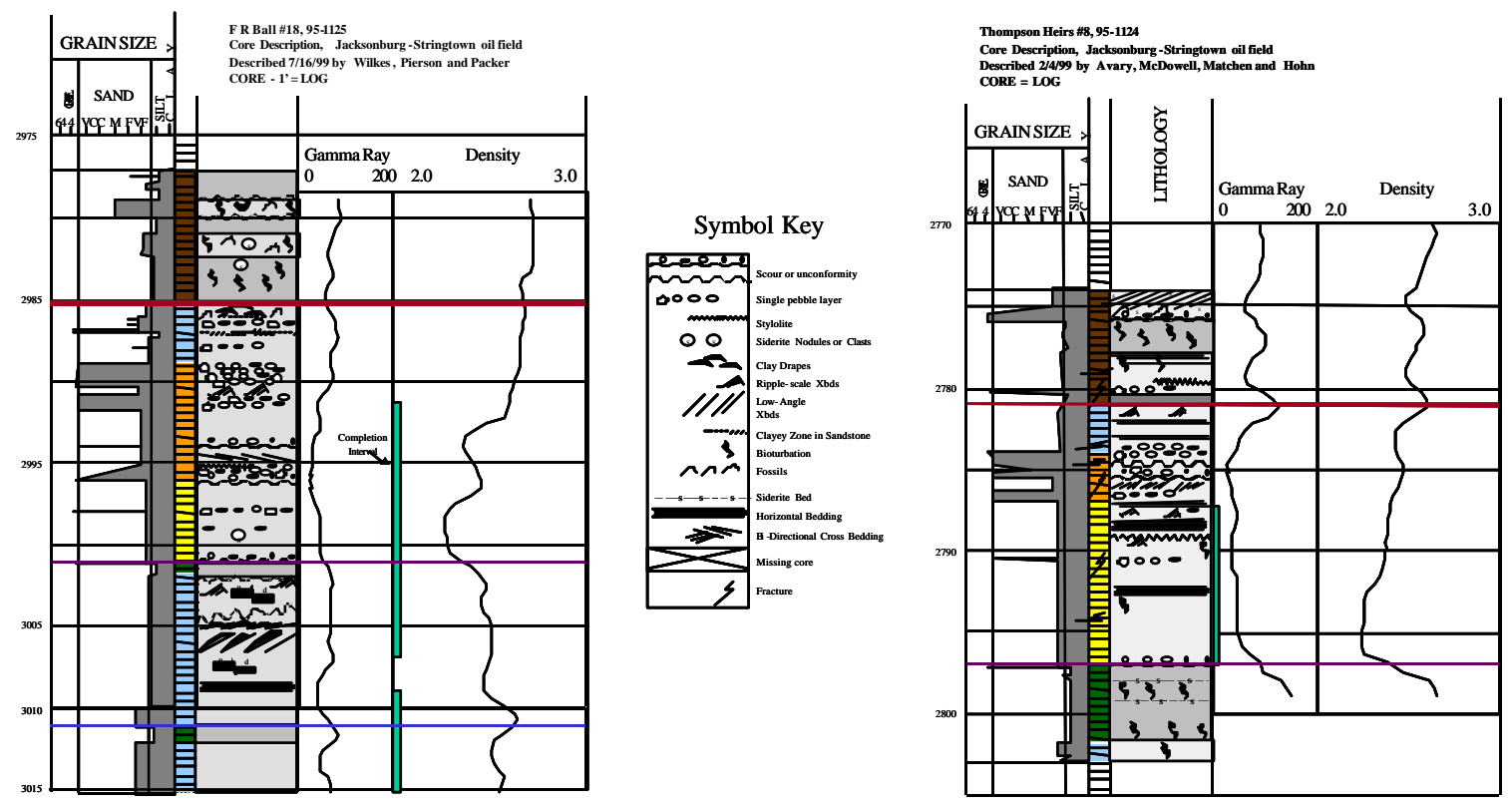

Figure 2.10. Correlation of core to log. Colors correspond to scheme used in Fig. 2.9.

\subsubsection{Stratigraphic Framework}

The primary reservoir in the field comprises three parasequences. Overall, the Gordon and each individual parasequence coarsen upward - a regressive pattern. The boundaries between parasequences are placed at the top of thin shales interbedded with the sandstone. Additional markers within the Gordon include the $\mathrm{Hb}$ lithofacies and the thin sandstones at the bottom of the section. These three markers help define the Gordon and allow for correlation throughout the field.

\section{Parasequence Boundaries}

The parasequence boundaries are placed at the top of the thin shale beds noted in core and interpreted from geophysical logs. These shales represent local flooding of the shoreface and are succeeded by regressive sediments of the shoreface. Shales can be seen in most cores and logs within the field, however, in some cases they have been removed (Figs. 2.11 and 2.12; F.R. Ball 19 well), particularly between psA and psB. In these cases, the parasequence boundary is speculative, as neither the core nor log provide unequivocal evidence for the position of the boundary. For logs in which the boundary is ambiguous (Ball 19), the position of the boundary was estimated by using the supplemental markers described above. Using these markers, it is clear that the reservoir sandstone in Ball 19 occupies a lower stratigraphic position than the 
equivalent reservoir sandstones in the other cores. Two possibilities for the lack of shale are: 1) shales were never deposited (sandstones were deposited in place of shale) or, 2) they were removed by later events (incision on the shoreface). At the interval in question in the Ball 19 core, there is a stylolite overlain by a thin pebble layer instead of shale. This suggests scour at the approximate boundary; the evidence is not conclusive. The other option is simply that this area experienced continuous deposition of sand across the boundary.

\section{Parasequences: Post-Gordon}

The section above the Gordon has little effective porosity, but does provide some assistance in stratigraphic correlation. The most prominent lithofacies of the post-Gordon is the Hb. This unit has little porosity and lies above the productive interval. The sandstones within this interval are not reservoir quality, but their distinctive log signature is used as a supplemental datum throughout the field. The contact with psA is sharp and marked by a transition from the Css below to the $\mathrm{Hb}$ above.

Parasequence A (psA)

The lower boundary of psA is placed at the top of the field-wide shale bed observed in five of the six cores (Figs. 2.11 and 2.12). psA is composed of all previously described sandstone lithofacies, is 17-20 feet thick; and displays a coarsening upward pattern on wireline logs. Css is most prevalent in the upper part of psA (Figs. 2.13 and 2.14). Lss and Fss occupy the lower part of psA, and generally grade from Lss in the east to Fss in the west. The reservoir sandstones reach their greatest extent in this stratigraphic unit and are oriented along a north-south trend in the central and western portions of the field (Figure 2.15). 


$\begin{array}{cccccc}\text { Thompson } & \text { Peter Horner \#9 } & \text { I Reilly \#13 } & \text { F R Ball \#18 } & \text { F R Ball\#19 } & \text { Lemasters O-13 } \\ \text { Heirs \#8 } & (95-741) & (103-1315) & (95-1125) & (95-1126) & (103-1547) \\ (95-1124) & & & \end{array}$

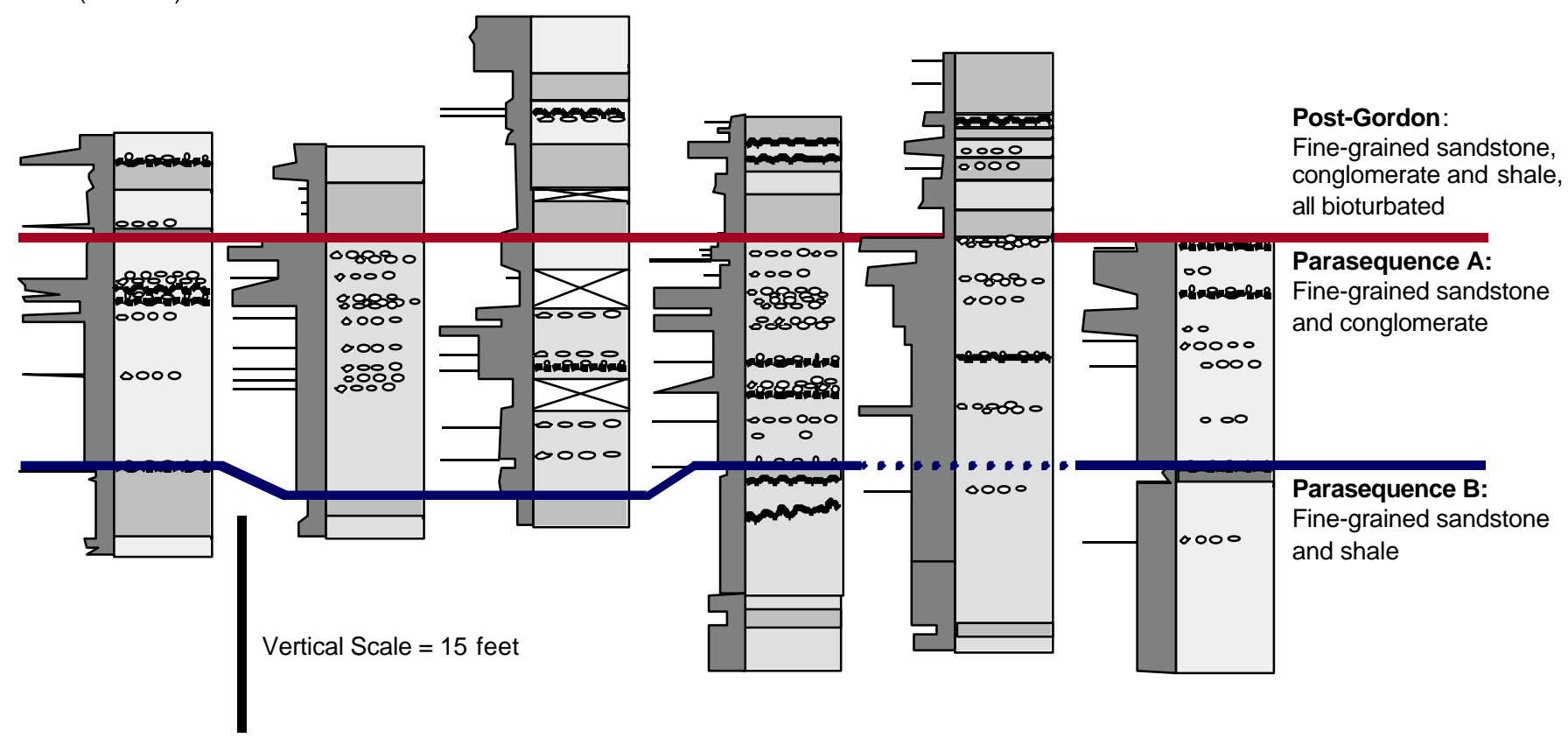

Figure 2.11. Correlation of all available cores, ordered roughly from east to west. No horizontal scale. Core locations are shown on Fig. 2.8.

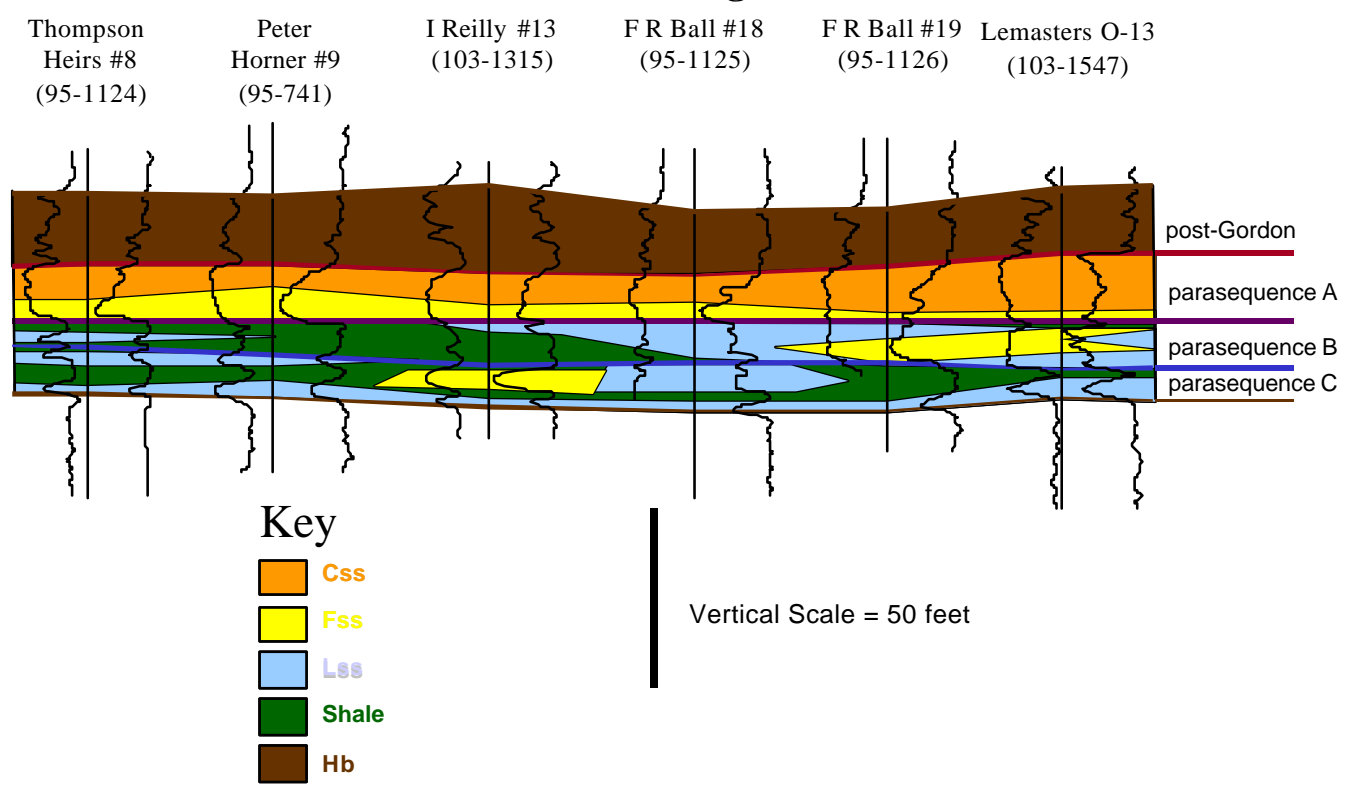

Correlation of wireline logs for cored wells. Logs are ordered roughly from east to west. Gamma Ray is on the left, Density is on the right. There is no horizontal scale for this diagram. Location of core provided by map on first panel.

Figure 2.12. Correlation of wireline logs for cored wells; for each well the gamma ray log is on the left, and the density log on the right. No horizontal scale. Core locations are shown on Fig. 2.8. 


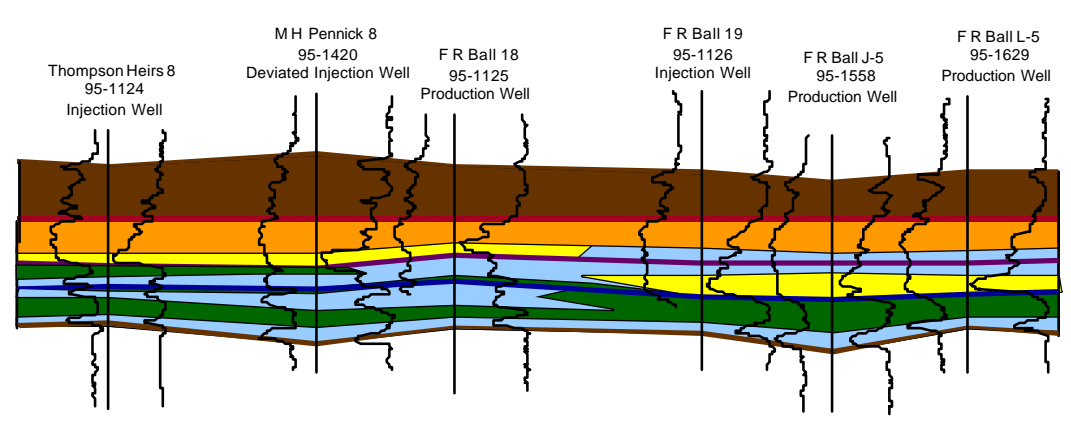

Cross Section 1

(CS1)
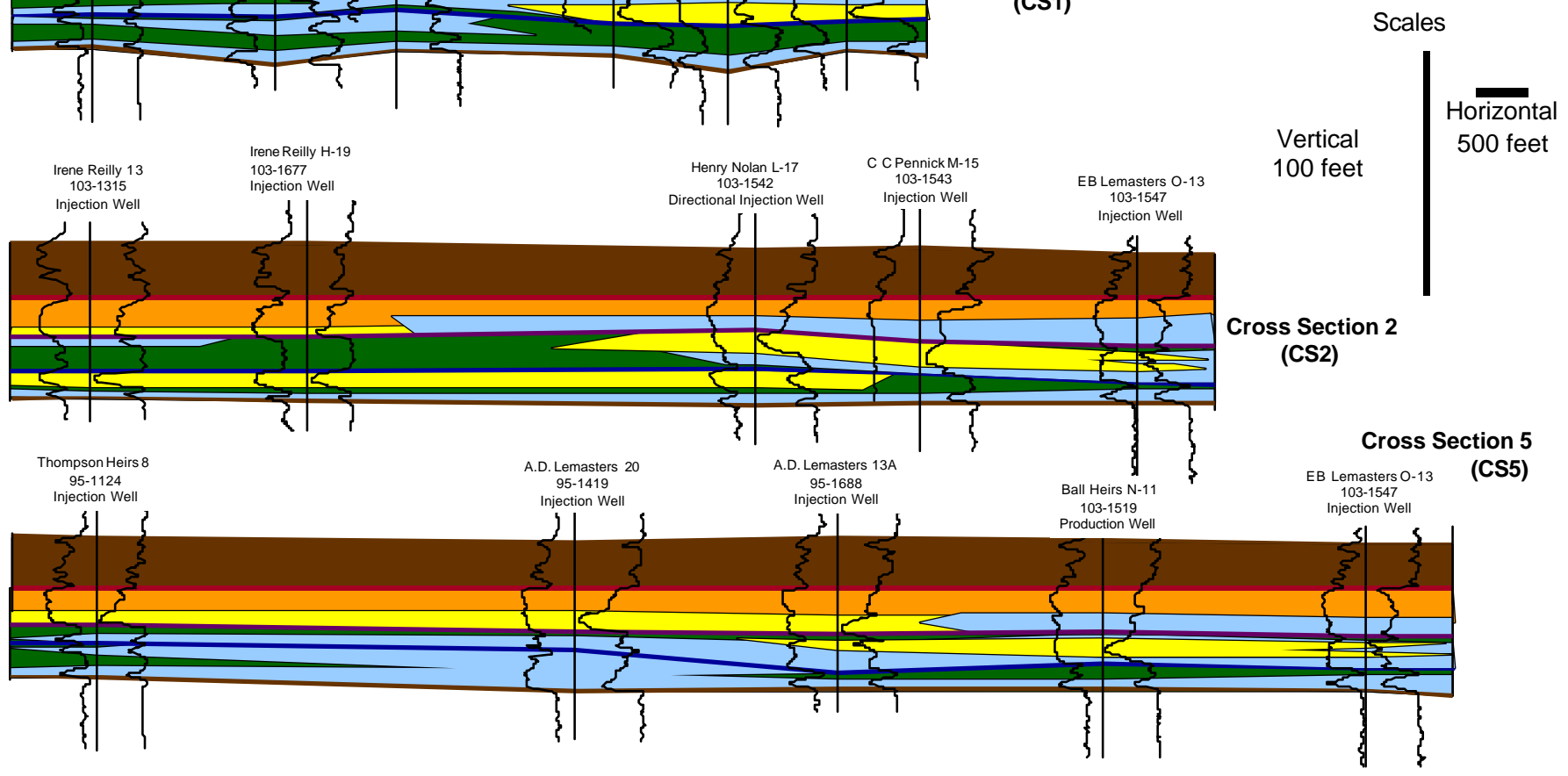

Figure 2.13. East-west stratigraphic cross sections. Locations of cross sections are shown in Figure 2.8.
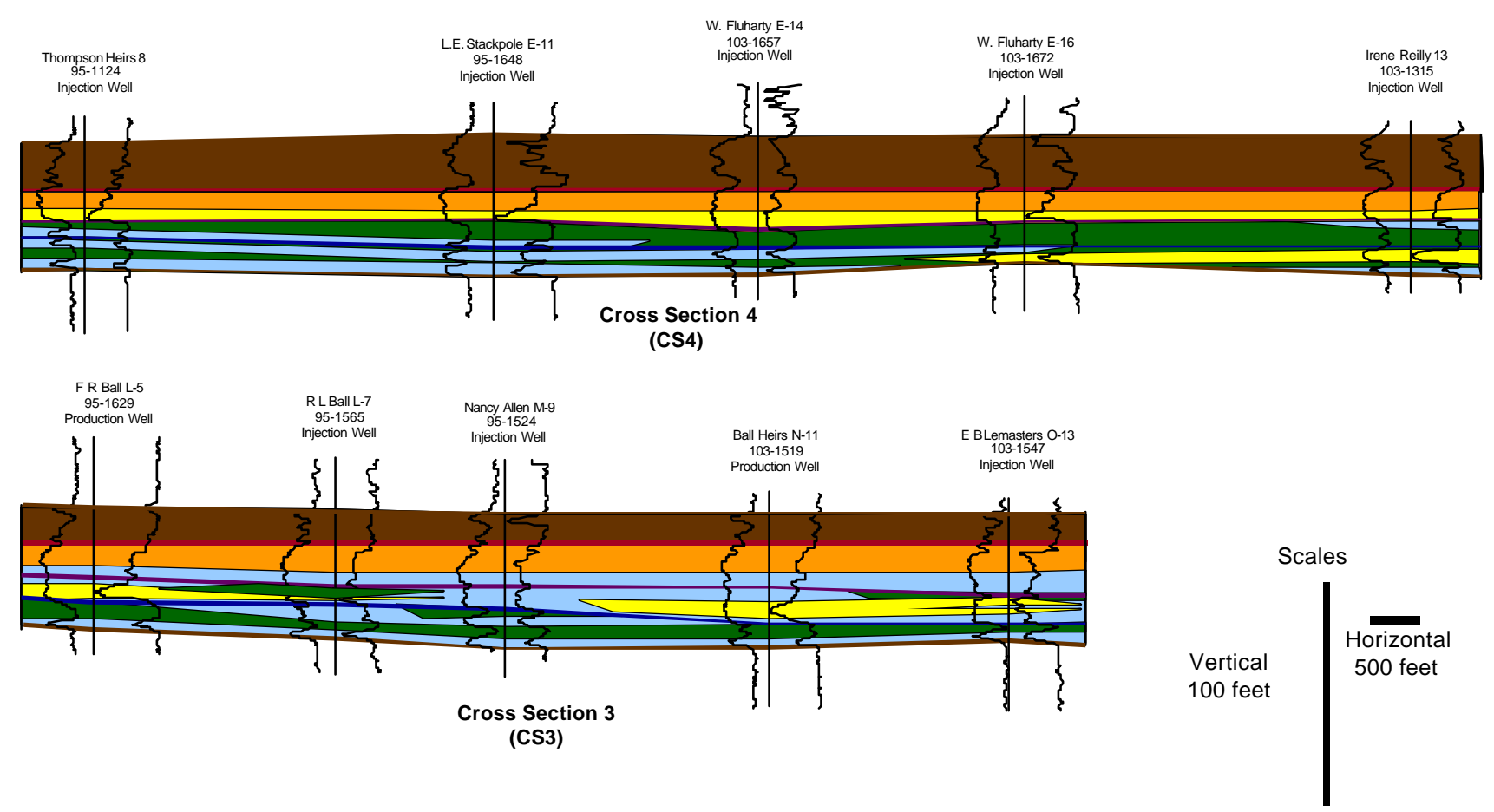

Figure 2.14. North-south stratigraphic cross sections. See Fig. 2.8 for locations. 


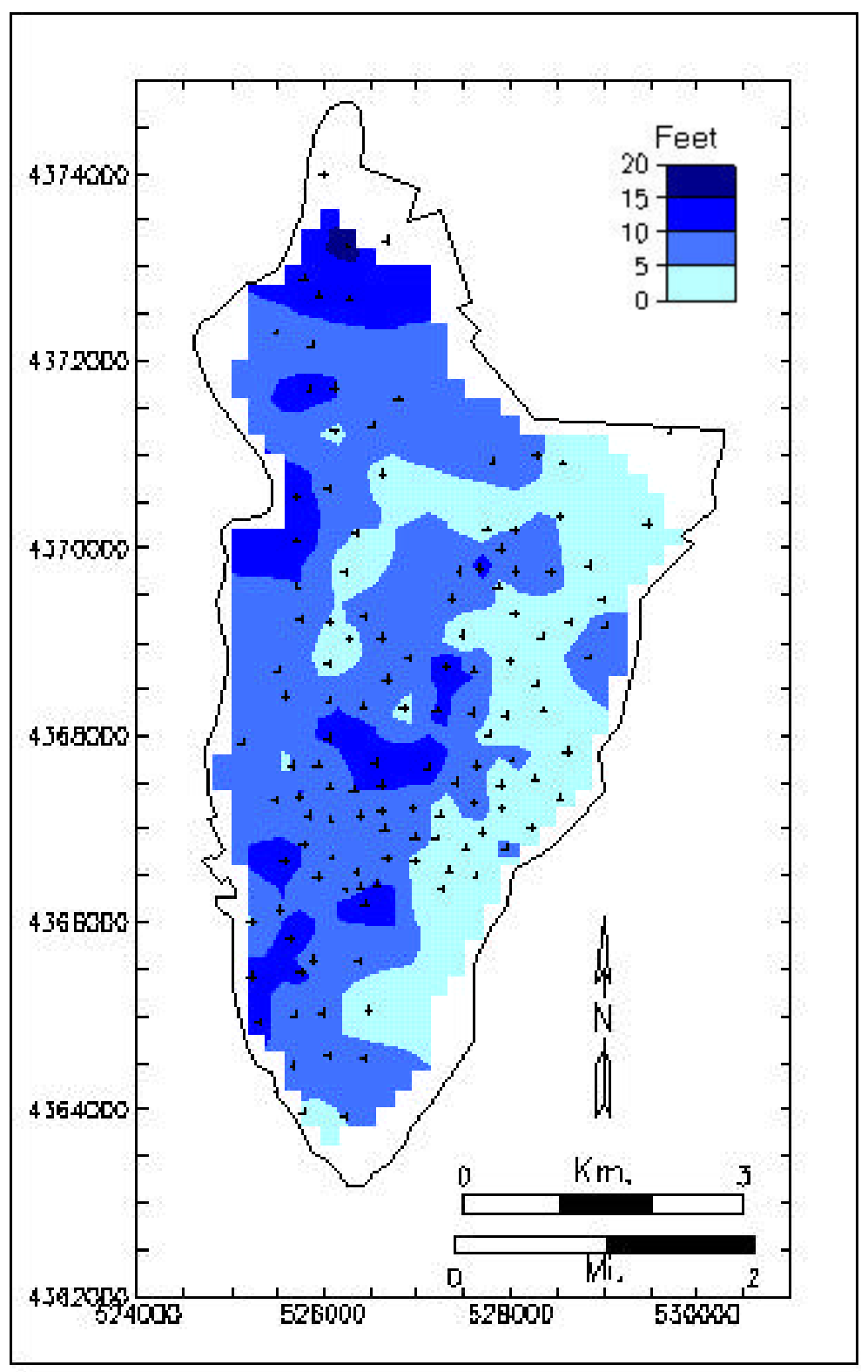

Figure 2.15a. Thickness of featureless sandstones (Fss) in parasequence A (psA). 


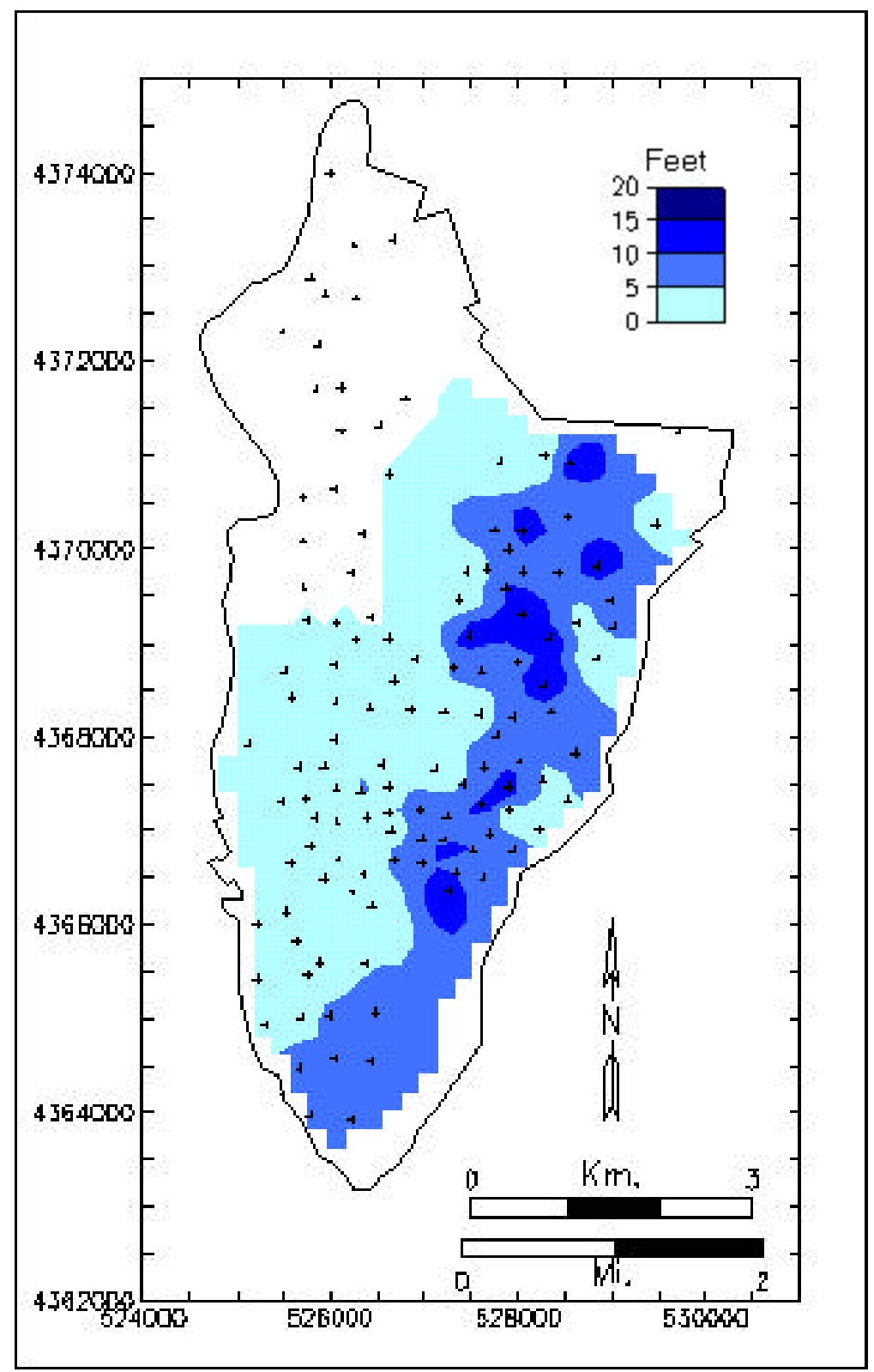

Figure 2.15b. Thickness of featureless sandstones (Fss) in parasequence B (psB). 


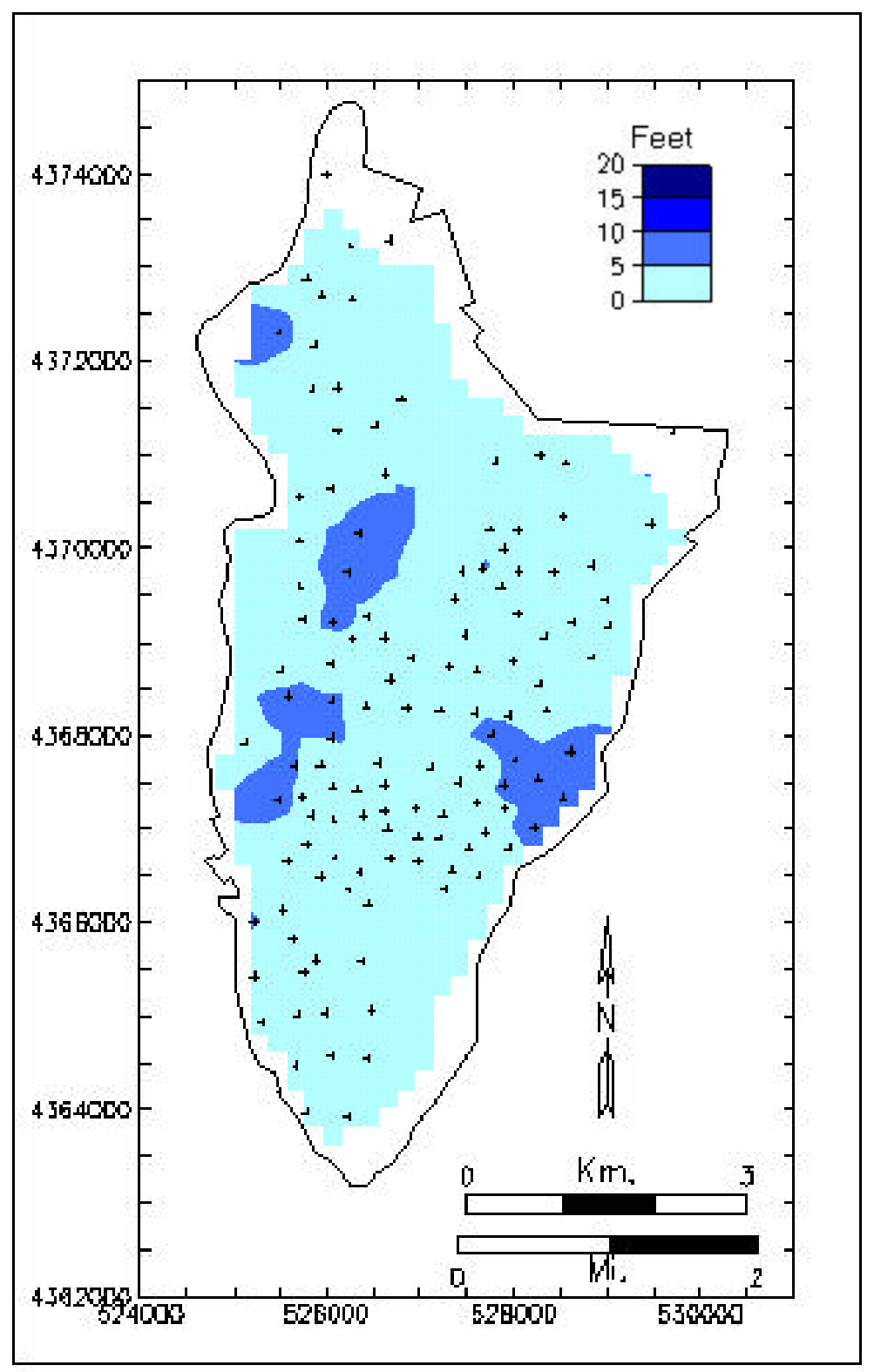

Figure 2.15c. Thickness of featureless sandstones (Fss) in parasequence $\mathrm{C}$ (psC). 


\section{Parasequence B (psB)}

Parasequence B (psB) is complete in the three eastern cores and is partially represented in the three western cores (Figs. 2.11 and 2.12). The upper boundary of psB matches the lower boundary of psA and the lower boundary of psB is placed at the top of the lower shale bed in the Ball cores (Ball 18 and 19). The lower shale bed is only observed in those two cores. In the Lemasters O-13 well, the lower boundary is placed at the base of the lower fine-grained sandstone where it overlies a shale bed. In the Reilly well, this boundary is placed at the top of the pay sandstone near the base of the Gordon interval. In the western wells, identification of this boundary is difficult as psB is predominantly shale and was not cored.

The lithology of psB is sharply divided between Fss and Lss in the east and Sh in the west; most of the sandstones are Lss with some interbedded Fss. No Css has been observed in psB. If coarser material is present, it is in the form of isolated pebbles or single pebble layers. In Ball 18, psB is composed of Lss; in Ball 19, the unit is split between Lss and Fss. The western part of the field, psB is dominated by Sh; there is little core from this area so few conclusions can be drawn. The transition between shale and sandstone is sharp (Fig. 2.15).

\section{Parasequence $C(p s C)$}

The upper boundary of $\mathrm{psC}$ is equivalent to the basal boundary for $\mathrm{psB}$. The basal boundary for psC is placed at the base of a thin sandstone that can be found throughout the field and is very simple to pick on logs. Shale and Lss dominate psC. No core was taken in this unit so conclusions about lithology are inferred from wireline logs. Except for the basal sandstone, most of these sandstones are thin and discontinuous and can rarely be traced between more than a few wells before pinching out. Fss is limited to thin zones in the eastern and northern portions of the field although one extensive pay unit occurs in the north (Fig. 2.15). The northern pay in psC is known as the "Irene Reilly Zone"(IRZ) after the cored well (Dennis Young, PennzEnergy, 1999, verbal communication). The IRZ has been completed locally for oil production; however, permeability is too low for effective water flood. The IRZ occupies a narrow, north-south trend in the northwestern part of the field.

\subsection{Stratigraphy and Production}

Presence of multiple pay units represents an important heterogeneity within the Gordon. The previous section established that each pay unit underlies only part of the field, and that some portions of the field have multiple pay intervals. In fact, each parasequence is present throughout the field.

Jacksonburg-Stringtown field can be partitioned into five areas representing four combinations of stratigraphic and structural relationships (Fig. 2.16). The west-northwest to east-southeast fault in the southern part of the field appears to have sufficient throw to isolate reservoir rocks on either side. 
The northern part of the field can be partitioned based on apparent presence of significant pay interval in each of the three parasequences. Area " $\mathrm{A}$ " is characterized by relatively thick intervals of inferred reservoir sandstone in psA. Parasequence A (psA) accounts for the northsouth trend in the western part of the field, an area of high production in the central part of the field that appears to be part of the north-northeast production trend, and the pilot study area discussed later in this report.

Parasequence $B(\mathrm{psB})$ has relatively thick reservoir rock in the two areas labelled $\mathrm{AB} @$ and corresponds to part of the north-northeast trend in production.

Most wells in area " $\mathrm{C}$ " penetrate reservoir sandstone in psC. Reservoir rock in this parasequence is also penetrated by several wells in other parts of the field. Nevertheless, area " $\mathrm{C}$ " is characterized by an absence of relatively thick reservoir sandstone of psA and psB.

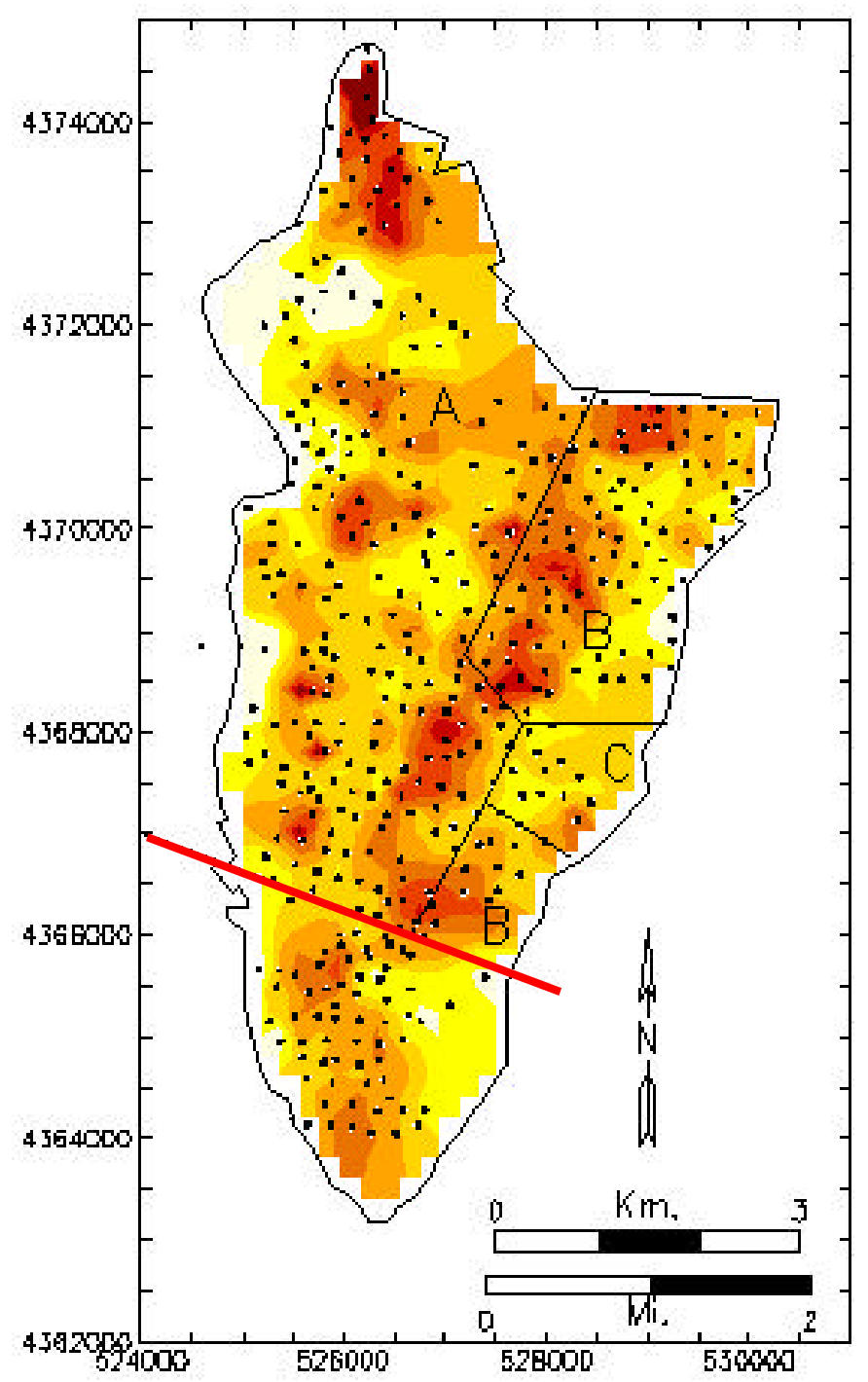

Figure 2.16. Inferred presence of reservoir sandstone related to estimated cumulative production and structure. Areas A, B, and $\mathrm{C}$ have significant thickness of featureless sandstone (Fss) - the inferred reservoir - within the corresponding parasequences psA, psB, and psC. Reservoir sandstones south of the fault (red line) across the southern portion of the field may be isolated from those to the north.

\section{Barrels of Oil \\ (Thousands)}

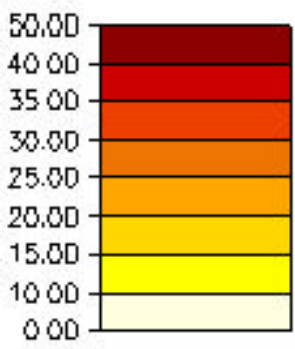




\subsection{Petrology}

Forty-two, standard $(27 \mathrm{~mm} \times 46 \mathrm{~mm})$ thin sections were prepared from samples taken from selected intervals in Gordon core and from outcrop. Because of the abandonment of the outcrop portion of the Project (see Section 3), no further discussion of outcrop materials will be presented here. Core samples were selected from F. R. Ball \#18 (095-1125), F. R. Ball \#19 (095-1126), Peter Horner \#9 (095-741), Irene Reilly \#13 (103-1315), E. B. LeMasters O-13 (103-1547), and Thompson Heirs \#8 (095-1124) based the presence of sedimentary or diagenetic structure or notably high or low permeability (as measured with minipermeameter - see Section 2.5). All thin section materials were impregnated with blue epoxy to aid in the recognition of porosity and were given a permanent glass cover.

Finished thin sections were subjected to observation and point count. Grain size and sorting estimates were made by observation and recording of grain dimensions for 50 grains in each slide (unless a bimodal distribution was encountered in which case both fractions were counted to 50 points). Observations for grain size and sorting were taken perpendicular to bedding in order to be representative of the entire thin section. Grain composition and porosity were recorded during an additional count of 300 grains for each slide.

Statistical comparisons (bivariate correlation) were performed between permeability, grain size, sorting, and percentage grain compositions. The results of these comparisons are presented graphically in Figure 2.17. As expected, there is a strong ( $99 \%$ confidence) positive correlation between permeability and primary porosity. A weaker ( $95 \%$ confidence ) positive correlation exists between permeability and secondary porosity, as well. Perhaps of more interest is the strong ( $99 \%$ confidence) negative correlation between grain size and sorting this means that as sorting gets better and better, the associated grain size decreases. Strong ( 99\% confidence) positive correlations exist between sorting and the amount of feldspar and mica present in thin section - better-sorted rock materials are significantly higher in their feldspar and mica content. Conversely, coarser-grained rock materials contain a significantly ( $99 \%$ confidence) higher amount of polycrystalline quartz grains probably derived from a high-grade metamorphic or igneous source area.

Primary porosity observed in thin section is intergranular; secondary porosity appears to occur in association with dissolved or partially dissolved potassium feldspars. Cements in Gordon samples consist of clay (kaolinite associated with dissolved feldspars; otherwise, "unspecified" mineralogy), calcite, silica, and siderite. Figure 2.18 presents a graphical interpretation of the inferred cementation history for the Gordon in the Jacksonburg-Stringtown field. It should be noted, however, that not all parts of the Gordon have received the same types of cement - the cements associated with various Gordon lithofacies will be discussed later. In general, calcite and clay cements occur in an early, post-burial setting within the Gordon. The formation of clay cement continues with deeper burial and diagenesis as associated clays and feldspars are altered. Later in diagenesis, secondary quartz in the form of euhedral overgrowths and pore-filling chert is precipitated. Finally, and overprinting or replacing earlier cements, siderite (frequently euhedral) cement fills remaining porosity in many Gordon samples. 


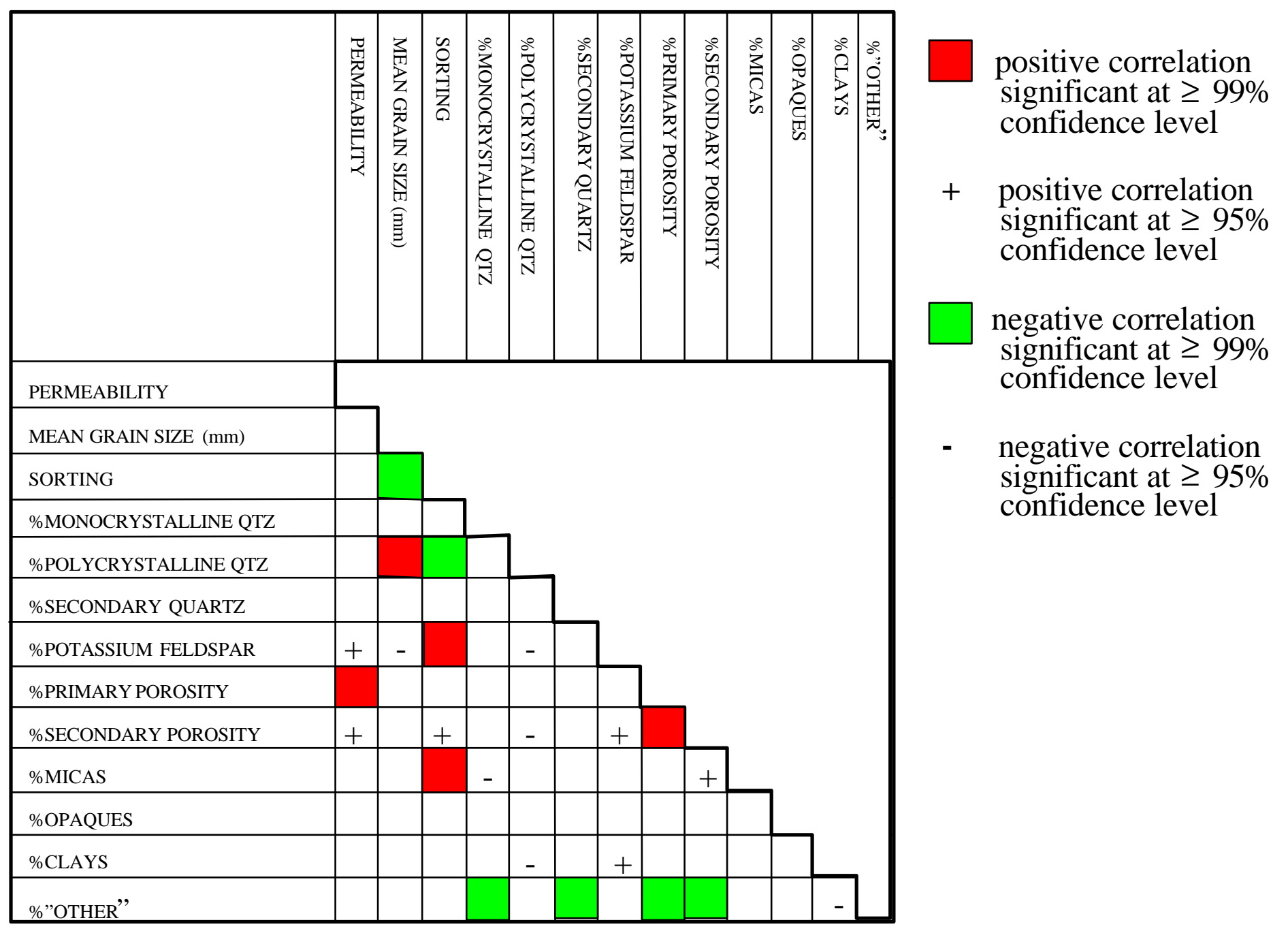

Figure 2.17. Bivariate correlation matrix illustrating significant statistical correlations between petrophysical and petrographic features observed in thin section. Of particular interest is the strong (> 99\%), negative correlation between sorting and mean grain size - finer-grained sediment is better sorted. Well-sorted sediment also contains higher amounts feldspar and mica; more poorly sorted sediment, which is also usually much coarser-grained, contains higher amounts of polycrystalline quartz (probably of high-grade metamorphic or igneous origin). 


\begin{tabular}{|c|c|c|}
\hline & $\begin{array}{l}3 \\
\frac{3}{0} \\
\frac{1}{4} \\
\frac{1}{\infty} \\
\frac{1}{\infty}\end{array}$ & $\begin{array}{l}\text { DEEPER BURIAL - COMPACTION } \\
\text { AND DISSOLUTION OF FELDSPARS }\end{array}$ \\
\hline CALCITE & 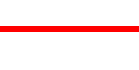 & \\
\hline CLAY & & \\
\hline SILICA & & 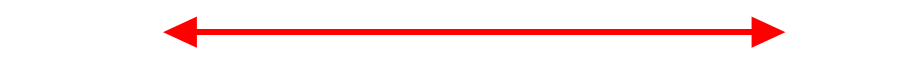 \\
\hline SIDERITE & & 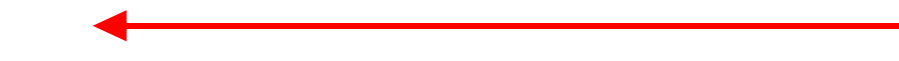 \\
\hline
\end{tabular}

Figure 2.18. Cementing history inferred for Gordon sandstones from thin sections.

\subsection{Petrophysics}

A TEMCO MP-401 minipermeameter was used to sample permeability in core, core plug, hand sample, and outcrop. For the sake of consistency, the same minipermeameter probe tip (inside diameter $=0.125 "-3.2 \mathrm{~mm}$ ) was used for all readings. When repeated readings were taken at the same spot, the reported and recorded value represents either the mean (two readings) or median (more than two readings). All measurements were made using dry nitrogen gas; the software controlling the minipermeameter automatically corrected for changes in temperature and atmospheric pressure.

All cores were sampled with the minipermeameter at a $0.25^{\prime}(7.6 \mathrm{~cm})$ interval. This allowed a direct comparison to the digitized geophysical logs for each well. Figure 2.19 shows a graphical comparison of the gamma ray and density log signature to permeability for F. R. Ball \#18 (0951125). Since the Gordon cores from the Jacksonburg-Stringtown field had previously been subjected to whole core or core plug analysis of porosity and permeability, it was also possible to compare the results of minipermeameter permeability acquisition to these other types of analysis. Figure 2.20 shows the results of such a comparison of permeability for Peter Horner \#9 (095741). For this and the other cored wells in the field, minipermeameter readings show considerably more variability that do either permeabilities taken from core plugs or from whole core analysis. This is to be expected due to the greater frequency of sampling with the minipermeameter. Also of note is the fact that for permeabilities $>10 \mathrm{mD}$, minipermeameter permeabilities generally are greater than whole core values and less than core plug values. Because whole core analysis samples a significantly larger volume of rock and may 


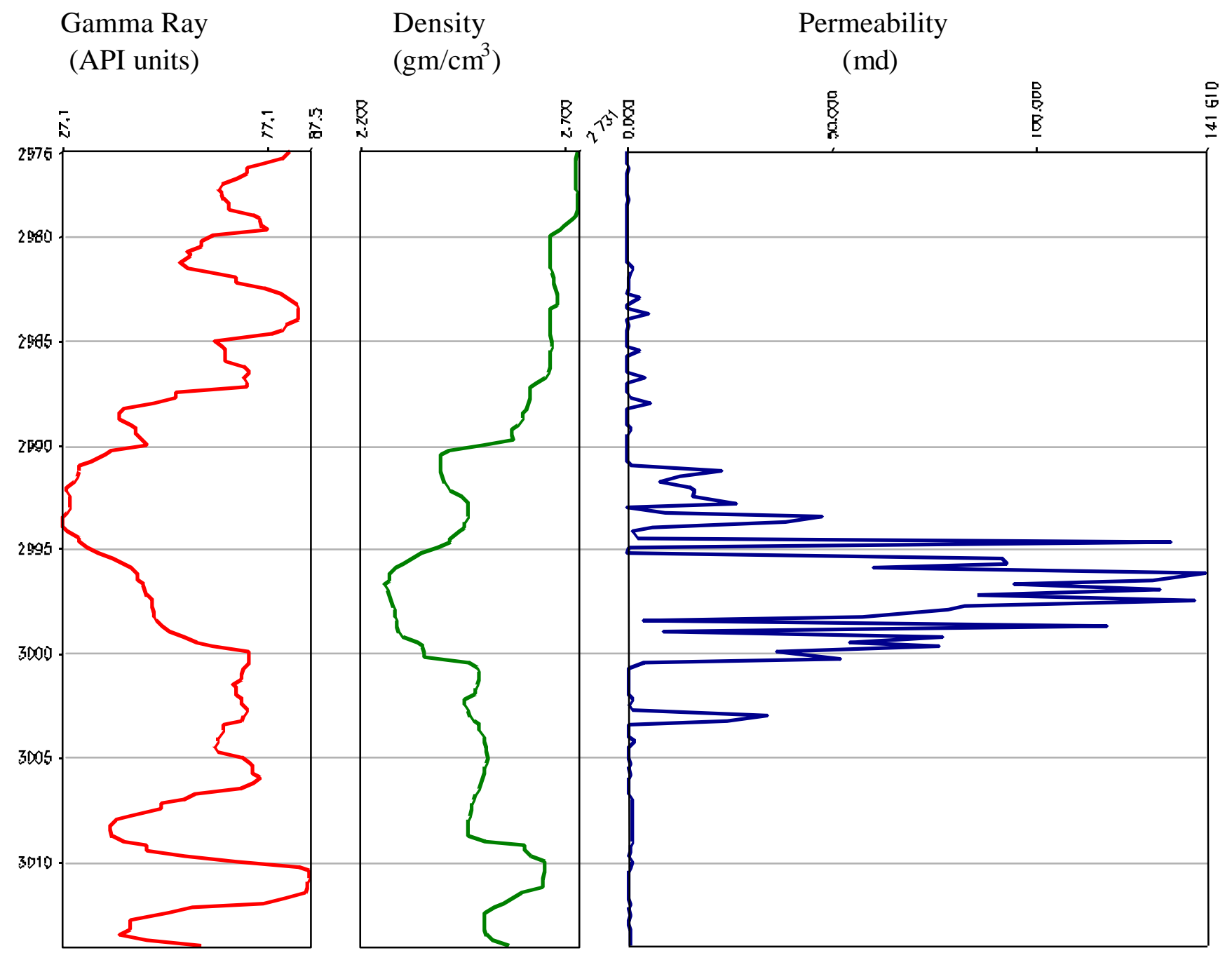

Figure 2.19. Permeability logs were created for all cored wells by sampling permeability with the minipermeameter at the same 0.25 ' interval used when digitizing geophysical logs. Shown above is a plot of gamma ray, density, and permeability for F. R. Ball \#18 (0951125).

include sedimentary barriers to flow such as interbedded shales or stylolitic horizons, it is not unexpected that whole core permeabilities may be lower than "spot" permeabilities taken with the minipermeameter. The consistently higher permeabilities seen in core plugs are more difficult to explain but it should be noted that the typical preparatory procedure for core plugs involves solvent cleaning of the rock material. No such preparation of slabbed core was undertaken prior to sampling with the minipermeameter. It is also worthy of note that in several instances a "rind" of lower permeability was detected along the exterior of core material (Figure 2.21). The Project's engineers suggest that this is the result of infiltration of drilling fluids into the outermost few millimeters of the core. Thin-section examination of this material was unable to determine any distinctive mineralogy associated with the lower permeabilities. 


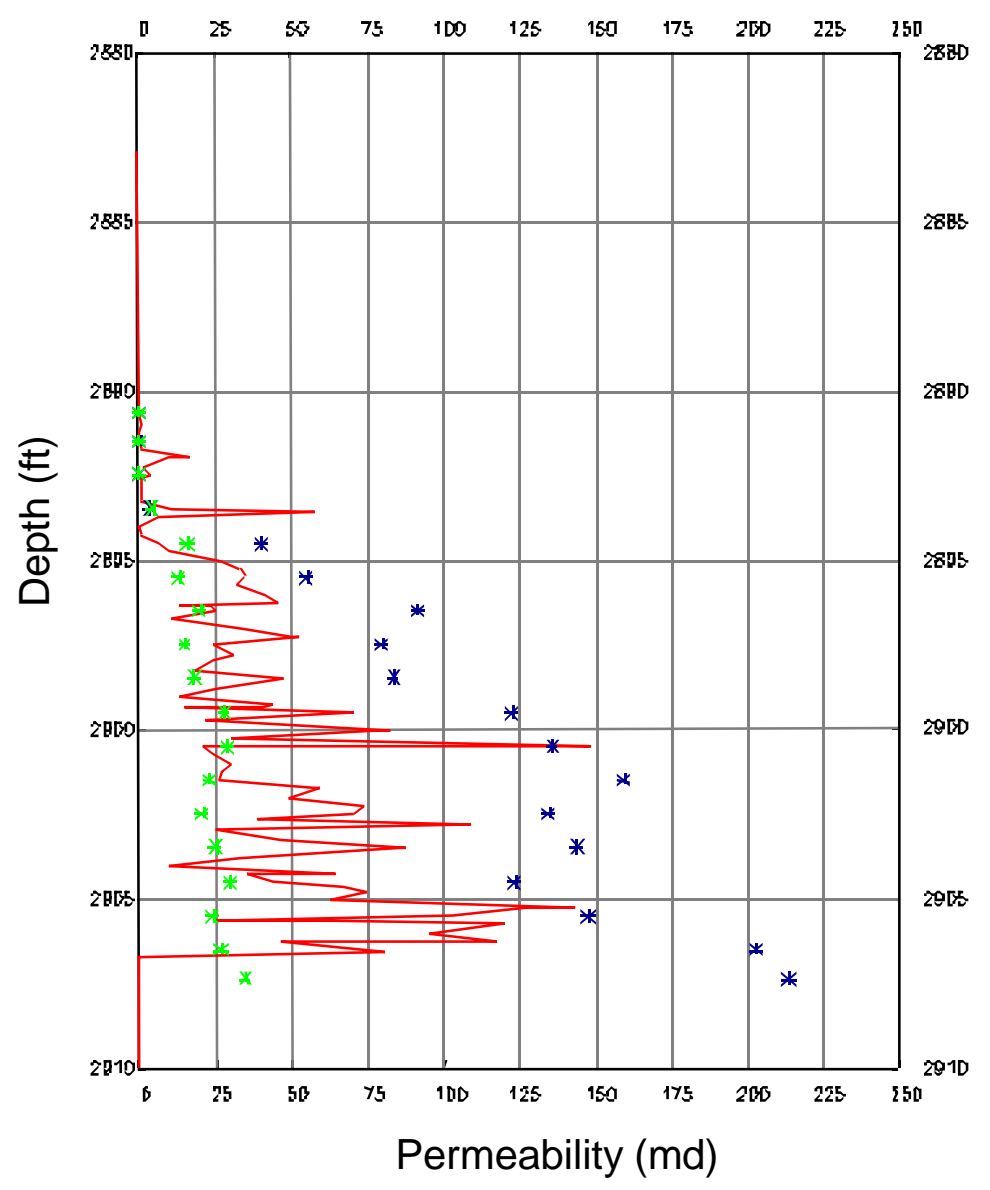

Figure 2.20. Graph of permeability vs. depth for Peter Horner \#9 (095-741). Permeability from minipermeameter is shown in red; permeability from core plugs is shown in blue; permeability from whole core shown in green. In general, for permeabilities $>\mathbf{1 0}$ $\mathrm{mD}$, minipermeameter readings were found to lie between analytical values taken from whole core and those from core plugs.

Next, the minipermeameter was used to investigate variations in permeability at the scale of depositional fabric and sedimentary structures observed in core, namely, a few millimeters. "Regular" (generally rectangular or square grids with a consistent 0.25 " $-6.35 \mathrm{~mm}$ spacing between grid nodes) sampling grids were laid out on cut core surfaces and permeability was measured at each grid node (Figure 2.22a). On vertical core slices, grids were rotated so that one axis of the grid was parallel to any bedding observed in the core segment. For vertical slices, measured permeability at each grid node represents $k_{h}$ (but not necessarily $k_{\max }$ ).

Variography was performed for each permeability grid. Because of the constraints of grid sampling, we were able to generate two variograms for each grid (Figure 2.22c); one representing the variance with distance along bedding horizons and a second representing variance with distance at right angles to bedding (i. e., with core depth). In general, less variability in permeability was found along bedding horizons; this was not always the case, especially when crosscutting sedimentary structures were encountered when sampling permeability or (we speculate) where diagenetic effects such as cementation are heterogeneously expressed in the core segment. Finally, at selected core intervals, the core was cut parallel to bedding, regular grids were laid out on the cut surface, and permeability measured at each grid node. For these horizontal slices, measured permeability at each grid nodes represents $k_{v}$. 


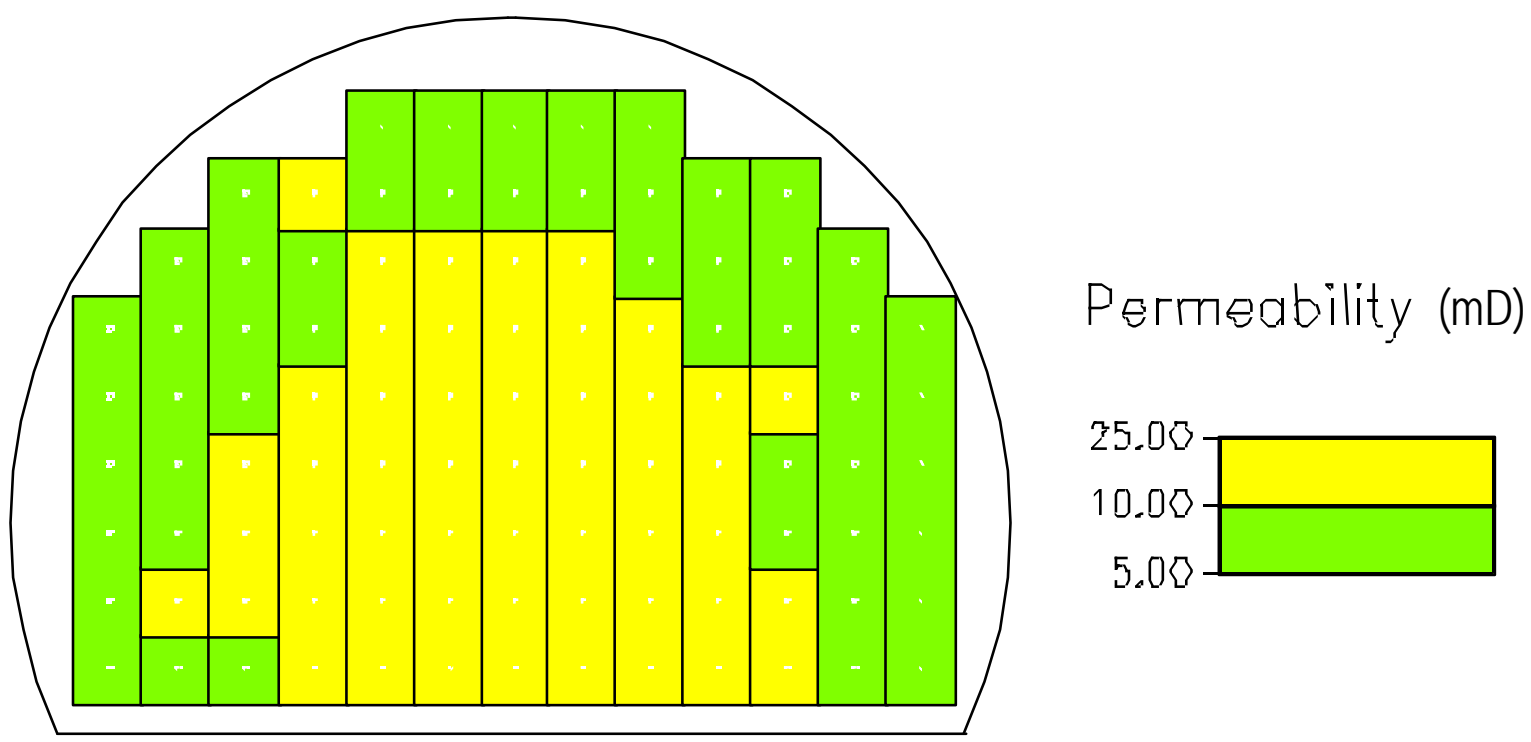

\section{Grid 21}

Figure 2.21. Permeability map for Thompson Heirs \#8 (095-1124) - 9x13 grid at 2795.0'. pay sandstone; horizontal slice. Fairly uniform distribution of permeability in pay sandstone. Notice the "rind" of low permeability around the exterior of the core. NOTE: analysis of core plugs gives $k_{v}$ of $31 \mathrm{mD}$ for this interval.

Because of the time involved in measuring the permeability for each of the minigrids (between 1-5 minutes per grid node $x$ 90-120 nodes), the entire length of the core could not be analyzed in this manner. It was decided to measure permeability on minigrids for selected portions of each core. To maximize the utility of the data recovered from these analyses, we turned to the core classification scheme developed by the Project's stratigrapher based on geophysical logs. Using density and gamma ray signature, intervals within each core were classified as either pay sandstone, non-pay sandstone, or conglomerate. Minigrids were laid out at core positions corresponding to each of these units and detailed permeability measurements were taken. Where appropriate (when it would not jeopardize or destroy remaining core material), the core was cut horizontal to bedding, a minigrid was superimposed, and permeability measured. In total, 35 minigrids were created and sampled for permeability.

To display the results of permeability measurements for individual minigrids, we created a software add-on for our existing computer mapping and contouring program that allowed us to display the permeability value at each grid node as a color chosen from a spectrum of colors. The resulting maps of permeability (Figure 2.22b) were produced with no averaging or interpolating of values between grid nodes as might be the case if we had simply contoured the values. Perhaps more importantly, these permeability maps allowed us to directly observe the 
distribution of permeability for each minigrid, to look for "patterns" or trends in this distribution, and to easily compare permeabilities for multiple minigrids. Figures $2.23 \mathrm{a}, \mathrm{b}, \mathrm{c}, \mathrm{d}, \mathrm{e}, \mathrm{f}$, and g are a representative samples of permeability maps for our 35 minigrids.

The following observations were made after the examination of permeability maps and variograms for all minigrids: 1) core materials classified as pay sandstone based on log signature were found to have permeabilities ranging from 10 to $200 \mathrm{mD}$; 2) other, non-pay sandstones identified by $\log$ signature were found to have permeabilities ranging from 0 (below level of instrumental detection) to $5 \mathrm{mD} ; 3$ ) the distribution of permeability within pay sandstones was fairly uniform (Figure 2.23a); 4) the distribution of small amounts of permeability within nonpay sandstones was usually either zoned parallel to bedding (Figure 2.23b) or "patchy" (Figure $2.23 \mathrm{c})$; 5) the conglomeratic material was always problematic in that it could take on the permeability characteristics of enclosing materials (Figures $2.23 \mathrm{~d}$, e); 6) conglomeratic material was also found with permeabilities exactly the opposite of enclosing materials, e. g., extremely low permeability conglomerate in pay sandstone (Figure 2.23f) and high permeability conglomerate in non-pay or low permeability pay sandstone (Figure 2.23g). The last two observations are particularly troubling for the Gordon reservoir because they imply that conglomeratic materials, often difficult to pick on geophysical logs because of their thinness, can provide either an unexpected barrier to vertical flow or an unexpected path for horizontal flow ("thief zone"). 

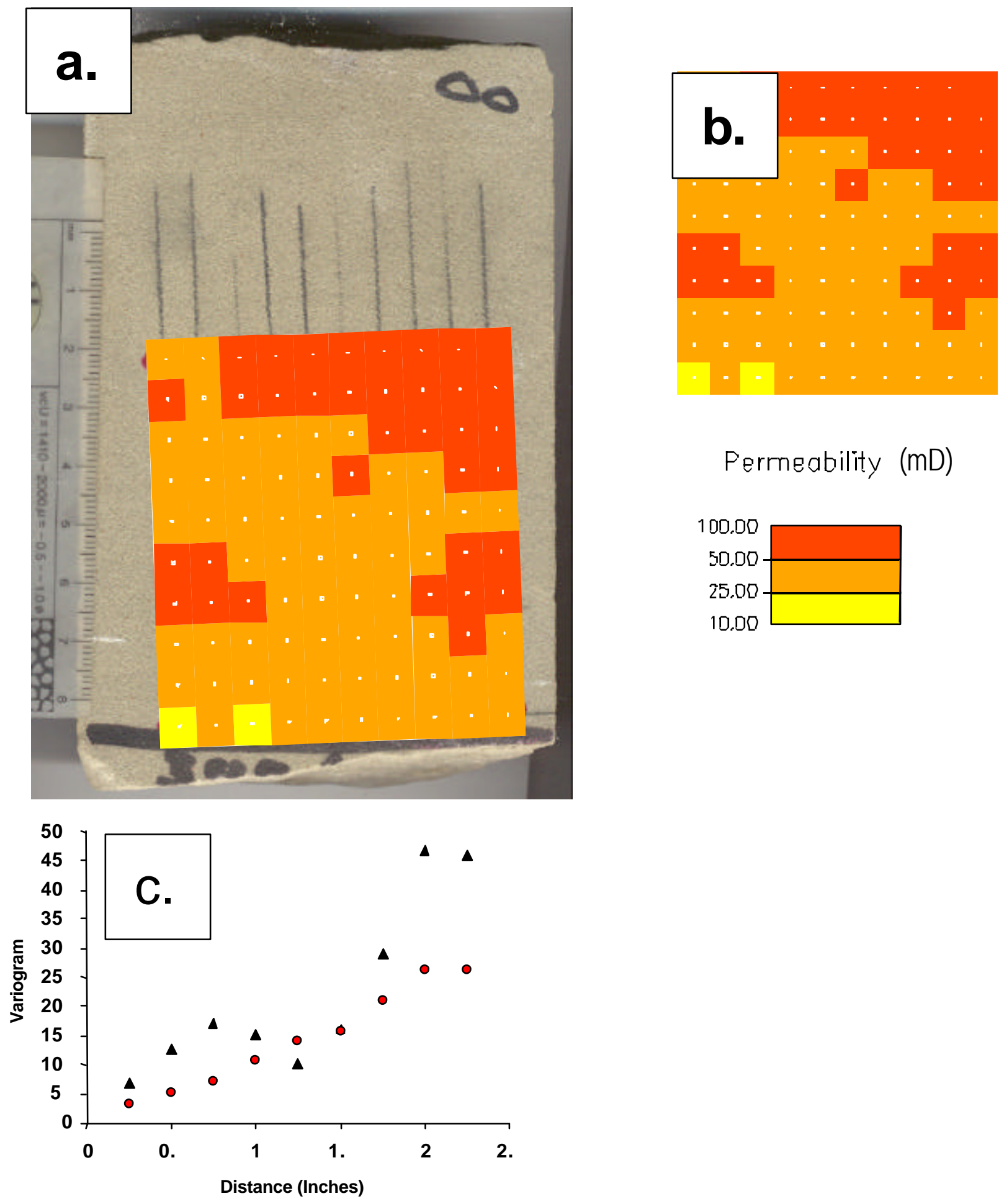

- Within $\quad \Delta$ Across

Figure 2.22. Regular $10 \times 10$ grid (0.25" node spacing), taken at the 3101' interval from $F$. R. Ball \#18 (095-1125). a - core segment with superimposed grid and permeability map. Note: grid has been rotated approximately $2^{\circ}$ counter-clockwise to parallel bedding in the core. $b$ - permeability map and legend. $c$ - variogram quantifying variance in permeability parallel to bedding (circles) and across bedding (triangles). 


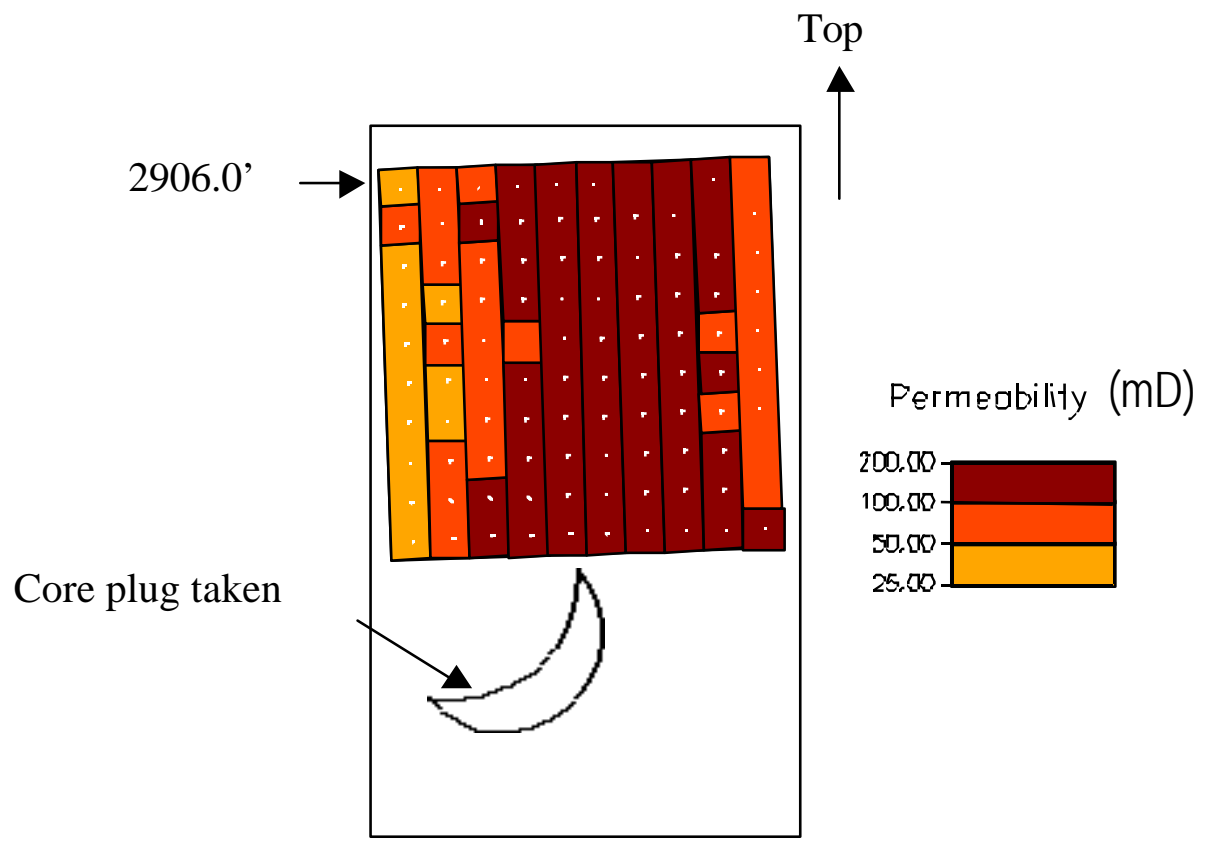

Grid 13

Figure 2.23a. Permeability map for Peter Horner \#9 (095-741) - 10x10 grid starting at 2906.0'. Pay Sandstone; vertical slice; grid rotated $2^{\circ}$ to parallel bedding. Fairly uniform distribution of permeability in pay Sandstone. Notice the "rind" of lower permeability along the exterior margins of the core. NOTE: analysis of core plugs gives $k_{h}$ of $203 \mathrm{mD}$ for this interval; analysis of the whole core gives $k_{h}$ of $27 \mathrm{mD}$.

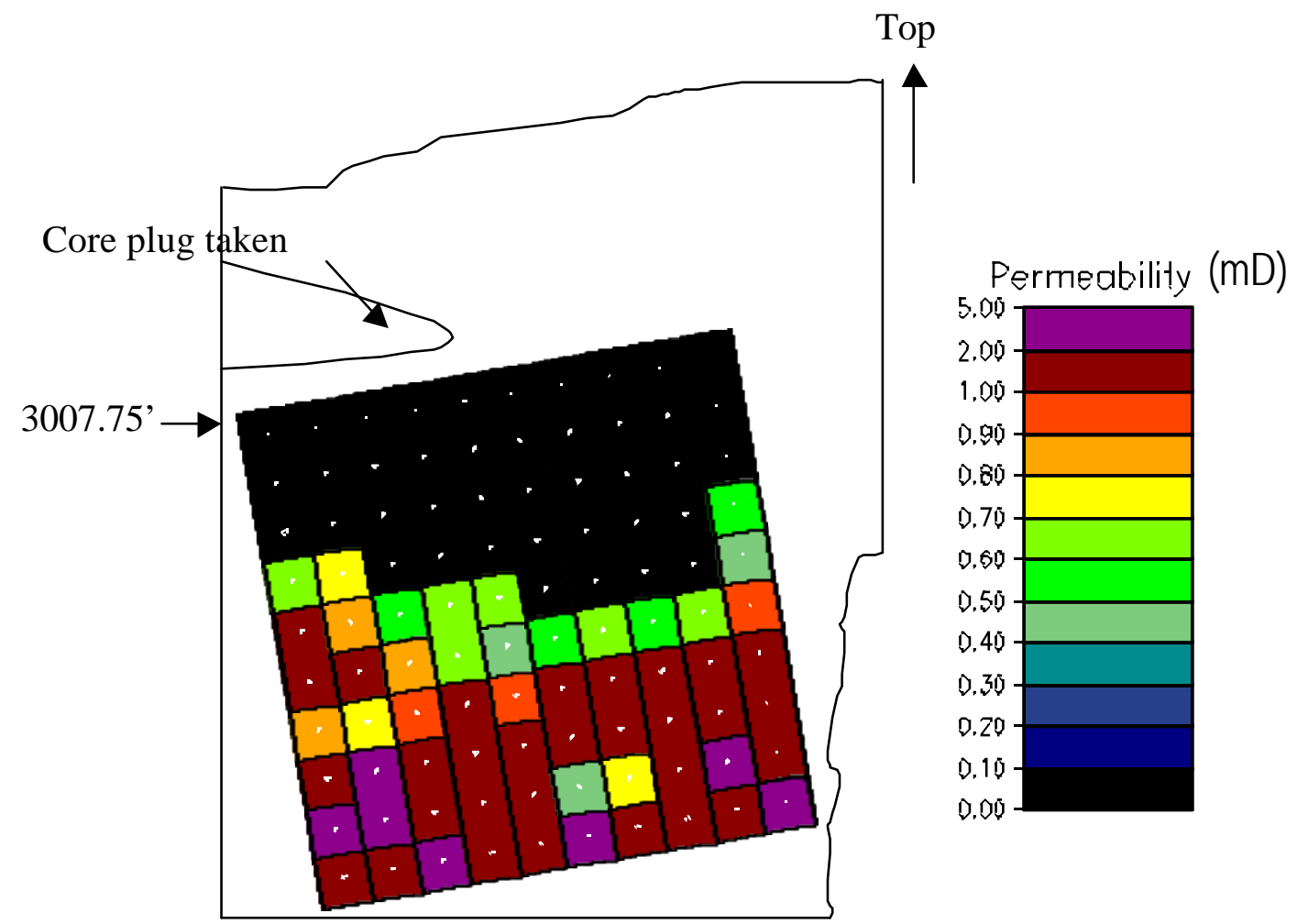

\section{Grid 19}

Figure 2.23b. Permeability map for F. R. Ball \#18 (095-1125) - 10x10 grid starting at 3007.75'. Non-Pay Sandstone; vertical slice; grid rotated $10^{\circ}$ to parallel bedding. "Zoned" distribution of permeability in Non-Pay Sandstone. NOTE: analysis of core plugs gives $k_{h}$ of $0.07 \mathrm{mD}$ for this interval. 


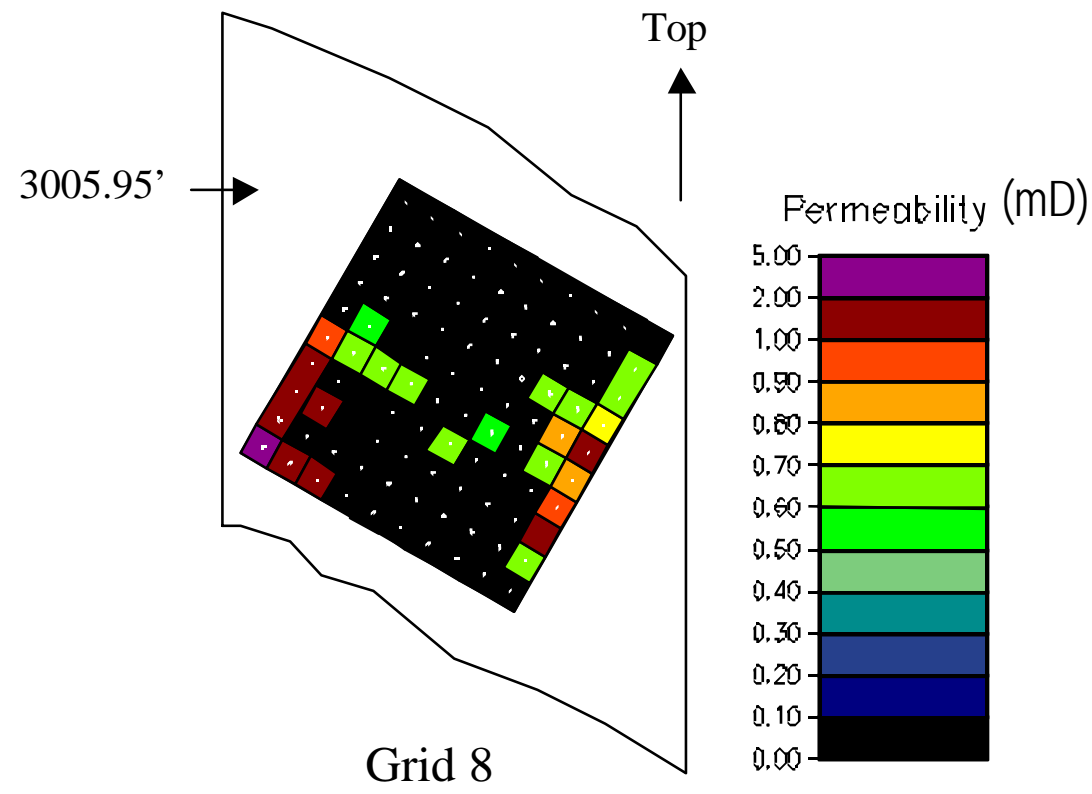

Figure 2.23c. Permeability map for F. R. Ball \#18 (095-1125) - 10x10 grid starting at 3005.95'. Non-Pay Sandstone; vertical slice; grid rotated $30^{\circ}$ to parallel bedding. "Patchy" distribution of permeability in Non-Pay Sandstone. NOTE: analysis of core plugs gives $k_{h}$ of $0.26 \mathrm{mD}$ for this interval.

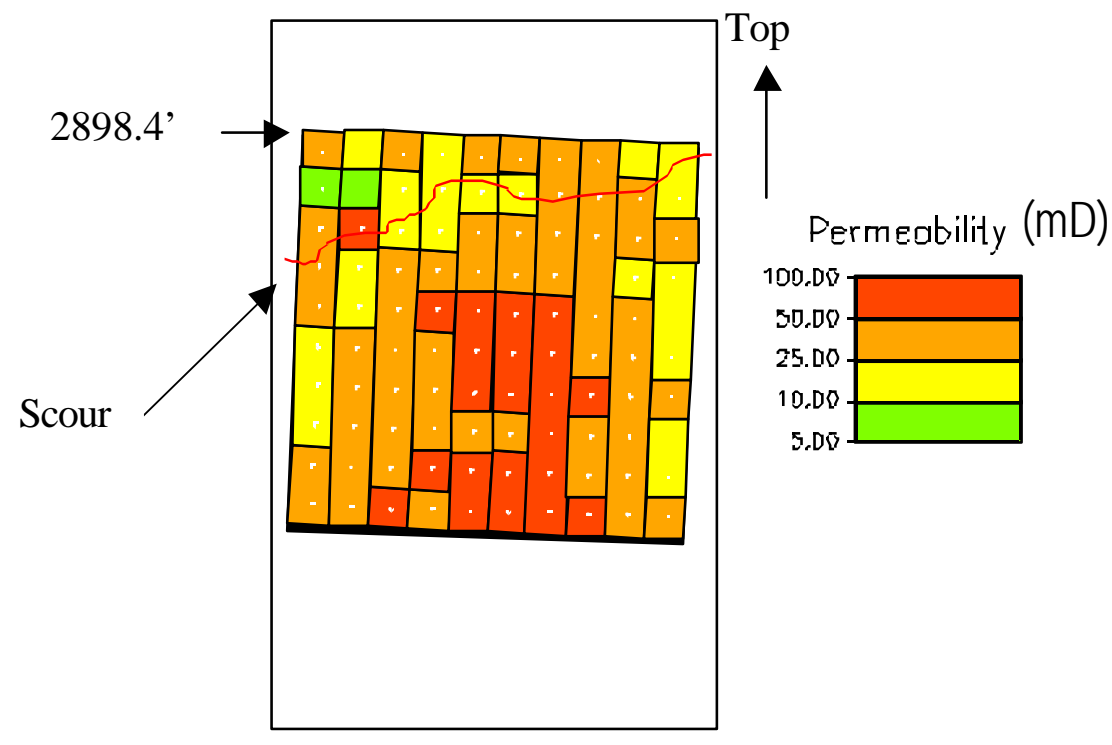

Grid 12

Figure 2.23d. Permeability map for Peter Horner \#9 (095-741) - 10x10 grid starting at 2898.4'. Conglomerate interbedded with pay sandstone separated by a scour; vertical slice; grid rotated $2^{\circ}$ to parallel bedding. High permeability in Conglomerate. There appears to be a good "connection" between the pore space of the conglomerate and pay sandstone in this interval. NOTE: analysis of core plugs gives $k_{h}$ of $84 \mathrm{mD}$ for this interval; analysis of the whole core gives $k_{h}$ of $18 \mathrm{mD}$. 


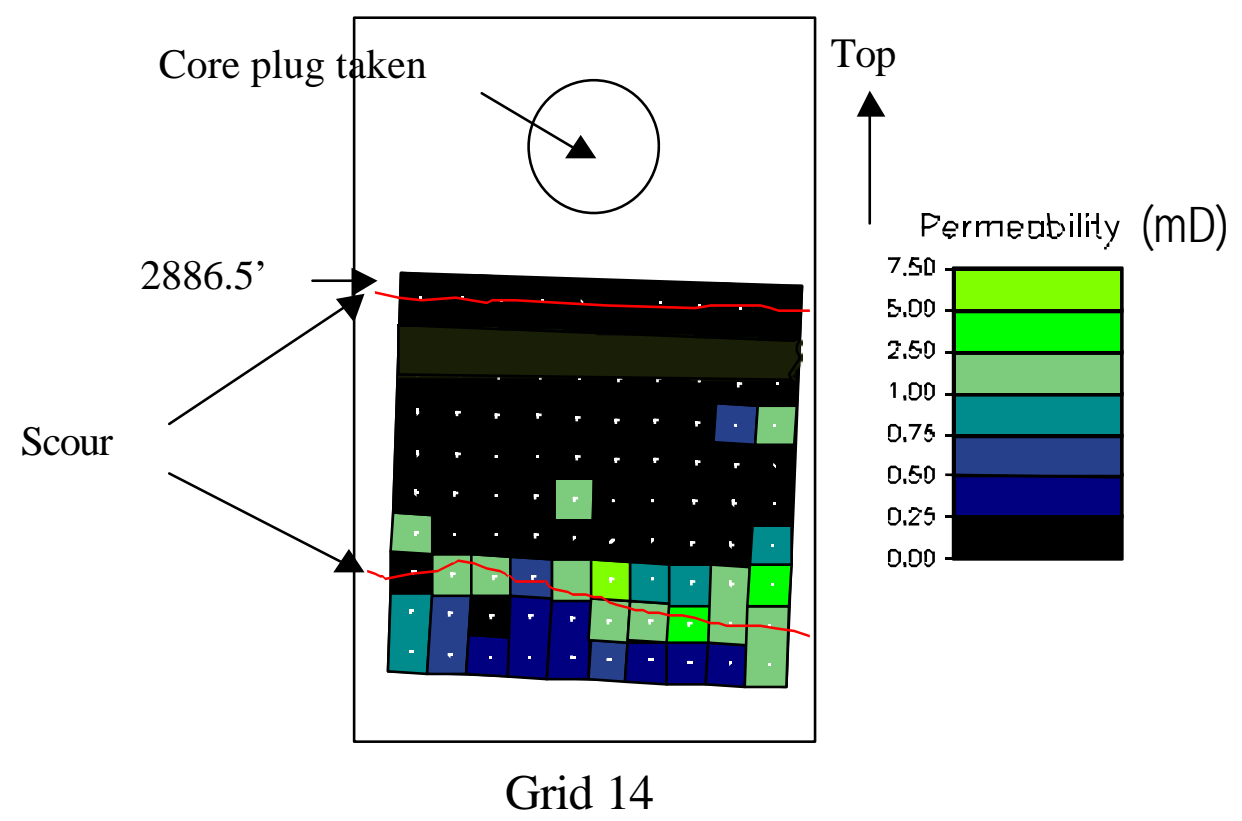

Figure 2.23e. Permeability map for Irene Reilly \#13 (103-1315) - 10x10 grid starting at 2886.5 '. Conglomerate; vertical slice; grid rotated $2^{\circ}$ to parallel bedding. Low permeability restricted to a zone associated with a scour surface in conglomerate. NOTE: analysis of core plugs gives $k_{h}$ of $0.4 \mathrm{mD}$ for this interval; analysis of the whole core gives $k_{h}$ of $0.5 \mathrm{mD}$.

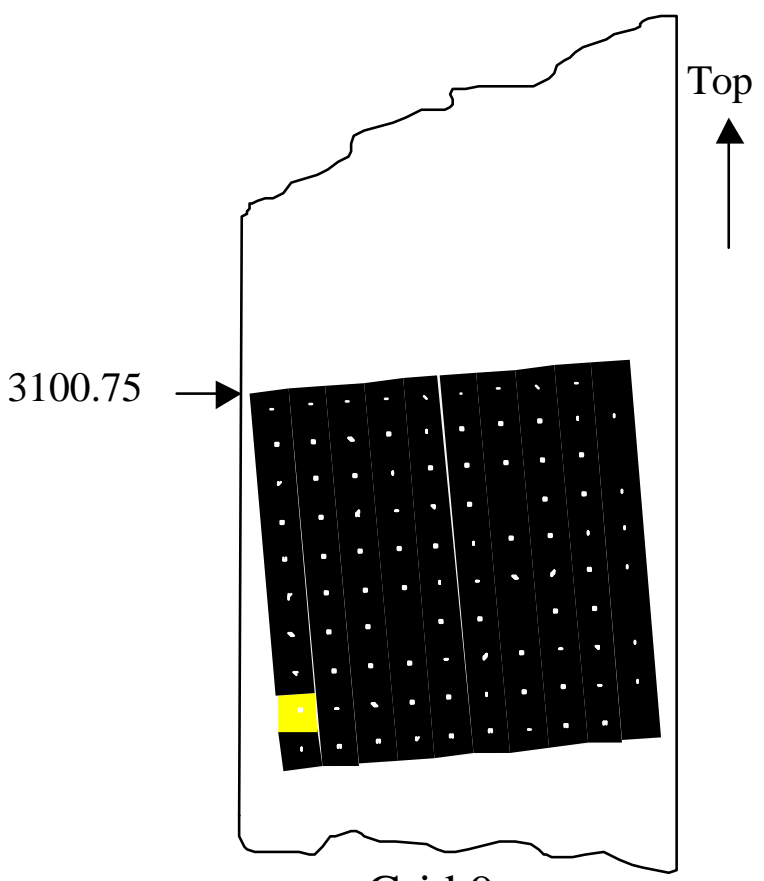

Permeability (mD)

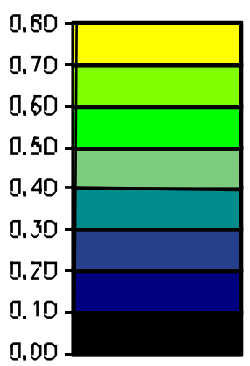

Grid 9

Figure 2.23f. Permeability map for F. R. Ball \#19 (095-1126) - 10x10 grid starting at 3100.75 '. Conglomerate; vertical slice; grid rotated $5^{\circ}$ to parallel bedding. Extremely low permeability conglomeratic material overlies sandstone with permeabilities ranging from 0 to $27 \mathrm{mD}$. 


\section{Top}
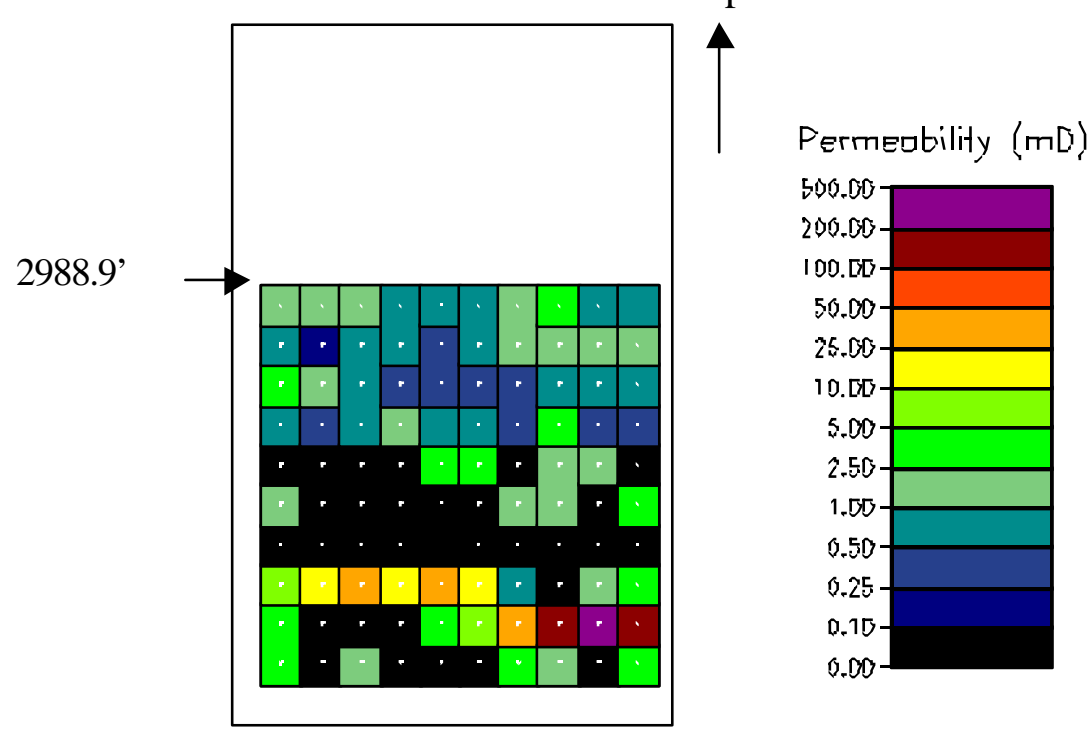

\section{Grid 6}

Figure 2.23g. Permeability map for F. R. Ball \#18 (095-1125) - 10x10 grid starting at 2988.9'. Conglomerate; vertical slice; no rotation. Zoned (parallel to bedding), high permeability in conglomeratic material interbedded within low permeability sandstone and shale. Average permeability of 5' of Gordon overlying this interval is $0.8 \mathrm{mD}$; average permeability of 5' of Gordon underlying this interval is $11 \mathrm{mD}$.

\subsection{Electrofacies}

Reference wells were selected using the criteria that they must be cored and have all of the following data: gamma ray, density, permeability, and grain size logs, all on a 0.25 ' sampling spacing - all four types of data must be available at each 0.25 ' sample point. This reduced the number of acceptable reference wells to seven (095-741, 095-1124, 095-1125, 095-1126, 095-

$1532,103-1315$, and 103-1547). LAS files were created for each of these wells by first adjusting core depths to match log depths and then merging permeability (minipermeameter) and grain size data into existing digitized geophysical logs for the wells. Data within the LAS files were further restricted to only the depth interval specified by the Project's stratigrapher (the Gordon reservoir interval). Next, depths for all wells were corrected to sea level by subtracting the drilling depth from the kelly bushing or drilling platform elevation. One of the reference wells (095-1124) was selected as the "super well" and the elevations for each of the other reference wells were adjusted up or down so that their "top of Gordon" matched that of the super well. Finally, all depths were converted to metric units (subsea) so that they were compatible with the metric UTM coordinates used for geographical well locations.

A single data file was created containing: depths, gamma ray, "scaled" gamma ray, density, permeability, and grain size (millimeters) from all reference wells. The entire range of gamma 
ray responses for the Jacksonburg-Stringtown field were scaled into the range [0,1] so that these values were of the same order of magnitude and range as the density values. Two additional data elements (county code and permit number) were added to this file for "bookkeeping" purposes. The file was analyzed using the $k$-Means Clustering technique in the SPSS statistical software package. This technique requires the user to specify the number $(k)$ of groups or "clusters" expected to be present within the data and to choose which data variable or combination of variables are to be used to establish the clusters. The technique proceeds to calculate "central" (mean) values for each cluster and to iteratively modify the Euclidean distance between cluster centers until cluster centers are "equidistant." If this process cannot be completed in 10 iterations for every cluster, the process is considered to have failed to produce a stable or convergent solution. Additionally, cluster membership for every data point is saved.

The clustering process was repeated specifying 2, 3, 4, 5, and 6 clusters using a variety of variables and combinations of variables. Once all data points had been assigned to a cluster, electrofacies logs were reconstructed for the reference wells and displayed in the form of an electrofacies cross section. The Project's stratigrapher examined each of these cross sections and by comparison to his correlations done independently using gamma ray and density logs, decided that four electrofacies most closely resembled his work. In addition, he concluded that four electrofacies based on a linear combination of density and scaled gamma ray best matched his correlations.

Cluster membership, density, and scaled gamma ray values for every point in the reference data set were subjected to SPSS's Discriminant Analysis technique. This technique was used to confirm the statistical significance of the clustering solution and to generate a set of Fisher's linear coefficients that could be used to classify other geophysical log values from the Jacksonburg-Stringtown field into the same four electrofacies. Each cluster (electrofacies) was described by a different set of Fisher's coefficients $(0,1,2, \ldots, n)$; where $n=$ number of variables used to create the clusters). Cluster or electrofacies group membership is then determined for any set of data values by computing a "test" statistic (T) using the Fisher's coefficients for each one of the electrofacies. The data values are "plugged" into a linear equation of the form:

$$
\mathrm{T}=0+{ }_{l}\left(\text { variable }_{1} \text { value }\right)+{ }_{2}\left(\text { variable }_{2} \text { value }\right)+\ldots \ldots \ldots \quad{ }_{n}\left(\text { variable }_{\mathrm{n}} \text { value }\right)
$$

Data values are assigned to the electrofacies whose computed test statistic is the largest.

Once it was determined that the four cluster - density and scaled gamma ray model was a statistically significant solution, the scaled gamma ray and density values from the Gordon interval for all geophysical logs in the field were extracted, their depths converted to subsea elevations in meters, and their top elevations adjusted to match the "top of Gordon" in the super well (095-1124). Scaled gamma ray and density values for each well were run through a computer program that determined the maximum test statistic based on Fisher's coefficients for four electrofacies. An electrofacies membership (integer values 1, 2, 3, or 4) was assigned to each pair of data values. Next, a three-dimensional electrofacies dataset was created by taking the depth, scaled gamma ray, density, and electrofacies for every data point in the Gordon 
interval from every logged well in the field and adding the UTM coordinates appropriate to each well. This information was placed into a single file that could be "sliced" to produce electrofacies maps and cross sections. Figure 2.24 shows the petrophysical characteristics of each electrofacies and their relationship to lithofacies within the Gordon identified by the Project's stratigraphers (see Section 2.2.3).

Figure 2.25 shows a series of horizontal slices through the Gordon reservoir in the JacksonburgStringtown field area. Starting at the top of the reservoir, each map within the Figure represents a progressively deeper horizon, generally taken at 1 meter intervals. The electrofacies encountered at this horizon in each of the 88 wells in the data set is shown with a color-coded symbol matching the legend in Figure 2.24. Two trends are apparent in Figure 2.25: 1) a shallow, north-south trend along the west edge of the field corresponding approximately with the strata of Gordon psA (See Section 2.2.4); 2) a deeper, northeast-southwest trend along the east edge of the field corresponding approximately with the strata of psB (See Section 2.2.4). Because of the synclinal nature of the Gordon reservoir within the Jacksonburg-Stringtown field and because of the reservoir's structural plunge, strata of these two parasequences, although at different stratigraphic positions within the reservoir, are seen to coexist at the same subsurface elevation. In fact, in the central-southern portion of the field, these strata may be in communication.

\begin{tabular}{|l|c|c|c|c|c|}
\hline Lithofacies & Electrofacies & $\begin{array}{c}\text { Mean } \\
\text { Gamma Ray } \\
\text { (API units) }\end{array}$ & $\begin{array}{c}\text { Mean } \\
\text { Density } \\
\text { G/cm }\end{array}$ & $\begin{array}{c}\text { Mean } \\
\text { Permeability } \\
\text { mD }\end{array}$ & Mean Grain size \\
\hline Sh & 1 & 135.529 & 2.682 & 0.000 & Coarse Silt \\
\hline $\begin{array}{l}\text { CsS, } \\
\text { LSS } \\
\text { \& Hb }\end{array}$ & $\mathbf{2}$ & 79.175 & 2.555 & 2.651 & Very Fine Silt \\
\cline { 2 - 6 } & $\mathbf{3}$ & 39.576 & 2.519 & 3.154 & Medium Silt \\
\hline $\begin{array}{l}\text { FSS } \\
\text { \&CSS }\end{array}$ & 4 & 47.026 & 2.352 & 30.989 & $\begin{array}{c}\text { Very Fine Sand \& } \\
\text { Granule }\end{array}$
\end{tabular}

Figure 2.24. Chart showing the attributes of the four electrofacies defined for the Gordon and their relationship to lithofacies defined by the Project's stratigrapher based primarily on core and geophysical logs. Electrofacies are color-coded to match slice maps and electrofacies cross-sections. Sh - Shale lithofacies; Css - Conglomeratic sandstone lithofacies; Lss - Laminated sandstone lithofacies; Hb - Hetrolithic-bioturbated lithofacies; Fss - "Featureless" sandstone lithofacies. 
Figures 2.26 and 2.27 show a series of vertical electrofacies cross sections taken parallel and perpendicular, respectively, to the structural axis of the Gordon syncline in the JacksonburgStringtown field. Examination of sections taken parallel to the syncline axis (Figure 2.26) demonstrates the effects of a small fault that transects the south end of the field. The five meters of displacement across this fault is probably enough to isolate the reservoir in the southern end of the field from the remainder of the field. Sections taken perpendicular to the syncline axis (Figure 2.27) demonstrate a distinct asymmetry in distribution of electrofacies. Electrofacies 3, in particular, thickens dramatically from the center of the Gordon syncline towards the eastern margin of the field.

\subsubsection{3-D Electrofacies Cubes}

The geostatistical method of Sequential Indicator simulation (Hohn, 1998) was used to generate three-dimensional realizations of electrofacies in the region of the pilot water flood. These realizations are useful for visualizing the spatial and stratigraphic distribution and continuity of electrofacies.

One of these realizations (Fig. 2.28) shows that the electrofacies 1 through 3 show a high level of discontinuity, whereas electrofacies 4 appears to be present throughout the study area. Representing a combination of Css and Fss, this electrofacies is essentially the reservoir within the field. This meant that the flow simulations could use relatively straightforward reservoir models comprising a small number of flow units. As shown below, best results were obtained with definition of two flow units in the pilot water flood area. 

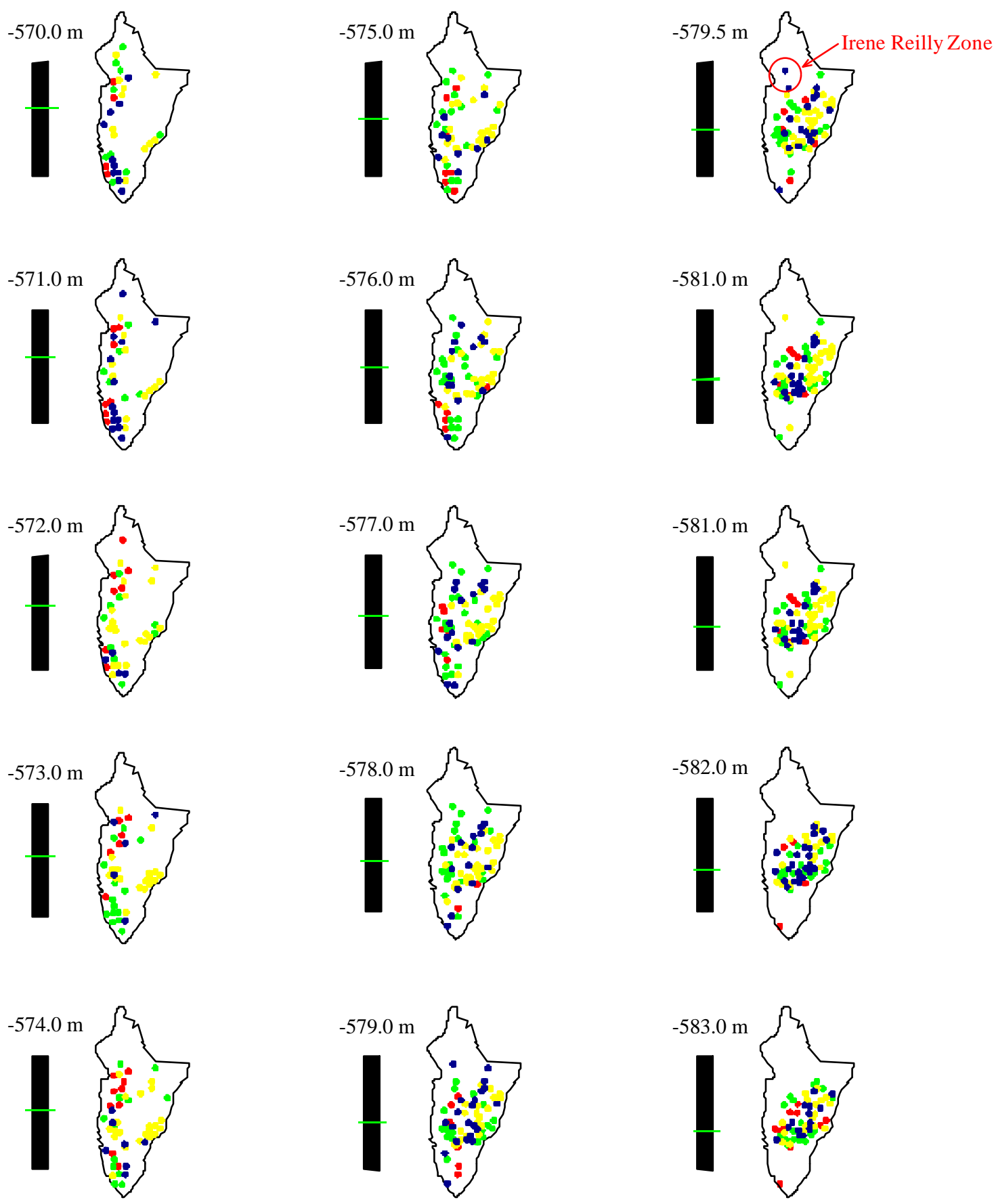

Figure 2.25. Vertical slice maps showing electrofacies at various depths within the Gordon reservoir. All depths are with respect to sea level. The electrofacies present in individual wells at each depth is represented by a dot matching the color code given in Figure 2.24. The outline of the operator's portion of the Jacksonburg-Stringtown field is shown for reference. At shallow depths $(-571$ to $-\mathbf{5 7 9} \mathrm{m})$, strata associated with psA are found in a north-south trend along the west edge of the field. At greater depths ($\mathbf{5 7 7}$ to $\mathbf{- 5 7 9} \mathbf{~ m}$ ), strata of psB form a second, roughly northeast-southwest trend along the east edge of the field. Notice that at these depths, strata of psA and psB coexist because of the synclinal nature of the field. At greater depths, only psB persists and strata of psC appear in the northwest corner of the field. 

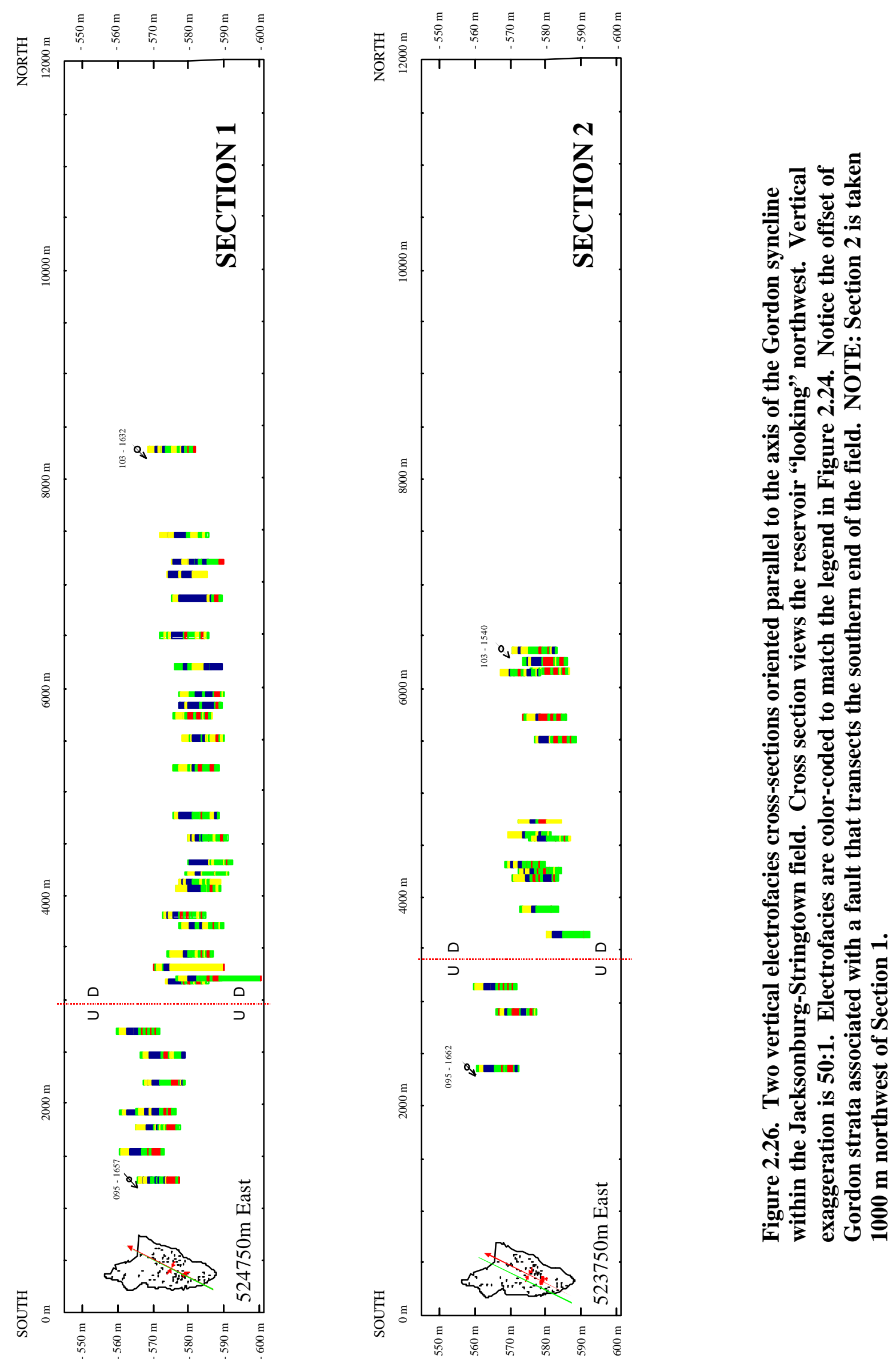

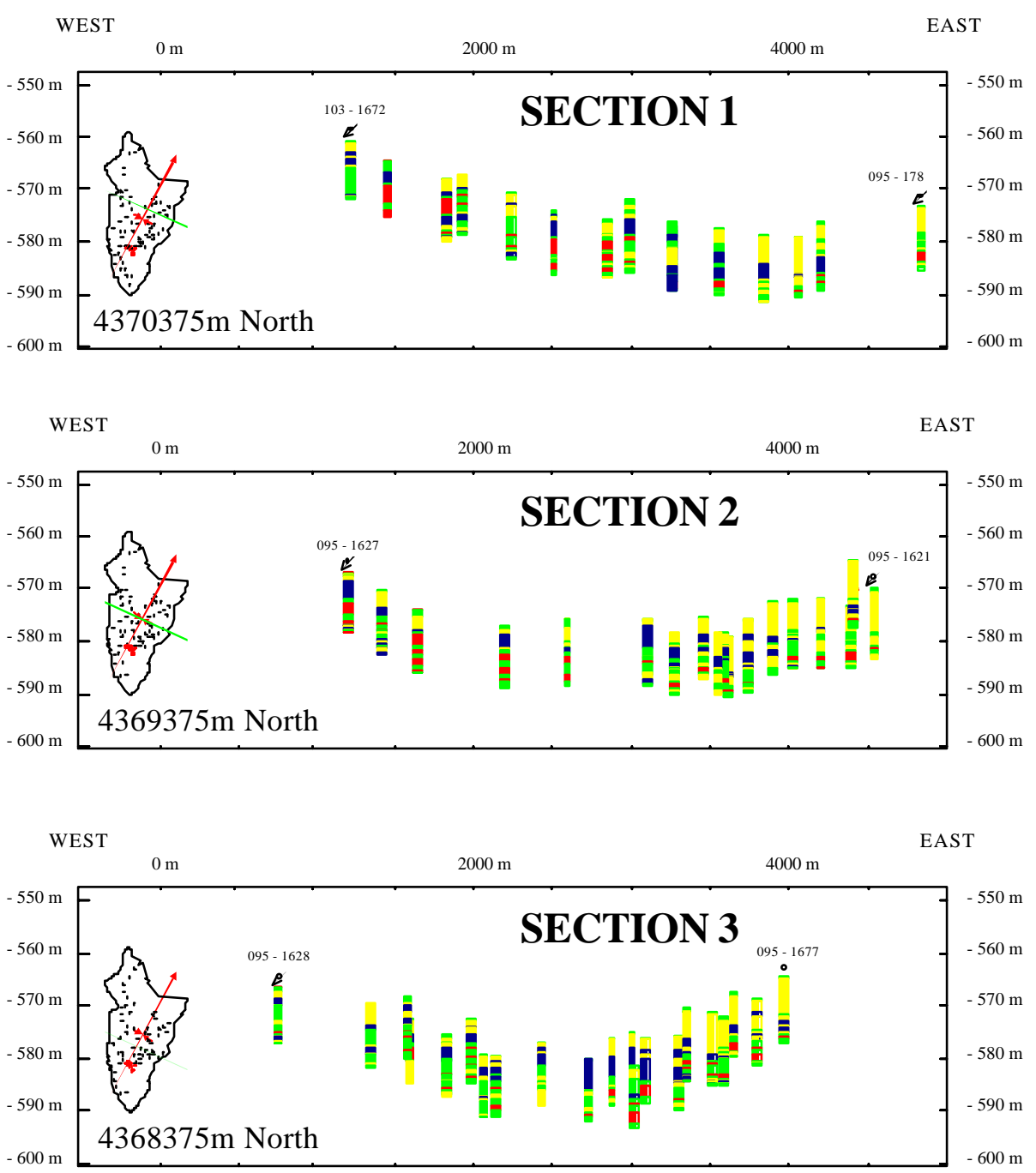

Figure 2.27. Three vertical electrofacies cross sections oriented perpendicular to the axis of the Gordon syncline within the Jacksonburg-Stringtown field. Cross-section views the reservoir "looking" northeast. Vertical exaggeration is 50:1. Electrofacies are color-coded to match the legend in Figure 2.24. Notice the asymmetrical concentration of electrofacies 3 along the east limb of the Gordon syncline within the field. NOTE: sections are taken $1000 \mathrm{~m}$ apart. 
E-W Section: 4366500 Meters North

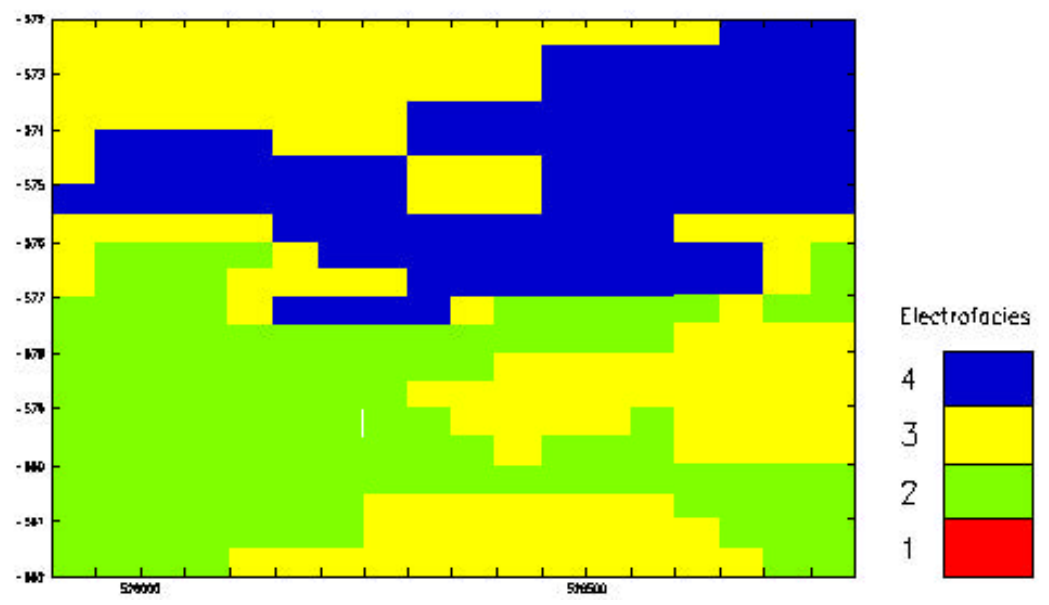

\section{E-W Section: 4366350 Meters North}
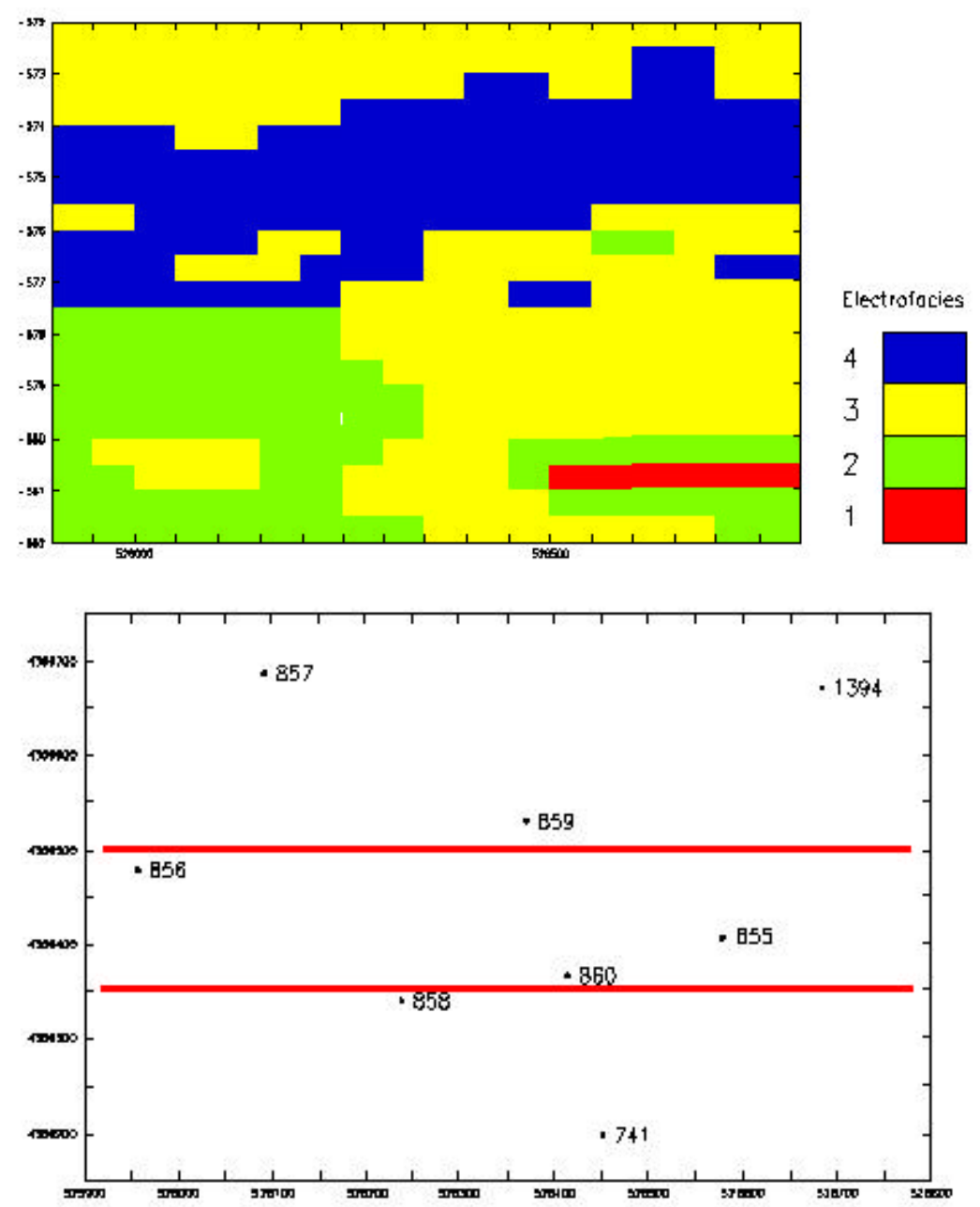

Fig. 2.28. Two east-west slices through 3-D cube of simulated electrofacies and location of slices in pilot flood area. 
Table 2.2. Petrographic and petrophysical characteristics of four Gordon lithofacies (Css - Conglomeratic sandstone; Lss - Laminated sandstone; Fss - Featureless sandstone; Hb - Hetrolithic-bioturbated). The fifth lithofacies (Sh - Shale) has not been investigated by minipermeameter or thin section. Note the distinct differences between Gordon pay sandstones (Fss lithofacies) and all other lithofacies in terms of permeability, primary and secondary porosity, grain size, and cement type.

\begin{tabular}{|l|l|r|r|l|l|l|}
\hline Gordon Lithofacies & Mean & Primary & Secondary & Mean & Sorting & Cements (in order \\
\hline & Permeability & Porosity & Porosity & Grainsize & & of abundance) \\
\hline Css & $4.042 \mathrm{mD}$ & $4.68 \%$ & $0.63 \%$ & $1.170 \mathrm{~mm}$ & Poorly sorted & Silica \& clay \\
\hline Lss & $3.889 \mathrm{mD}$ & $4.98 \%$ & $1.53 \%$ & $0.132 \mathrm{~mm}$ & Well-sorted & Clav \& siderite \\
\hline Fss (PAY) & $43.326 \mathrm{mD}$ & $15.98 \%$ & $2.25 \%$ & $0.128 \mathrm{~mm}$ & Well-sorted & Clay \\
\hline $\mathrm{Hb}$ & $0.000 \mathrm{mD}$ & $0.40 \%$ & $0.32 \%$ & $0.340 \mathrm{~mm}$ & Mod. well-sorted & Calcite. clav, \& siderite \\
\hline & & & & & & \\
\hline Gordon as a whole & $7.334 \mathrm{mD}$ & $4.95 \%$ & $0.99 \%$ & $0.541 \mathrm{~mm}$ & Mod. poorly sorted & Clay \& siderite \\
\hline
\end{tabular}

\subsection{LITHOFACIES}

Figure 2.24 shows the relationship between electrofacies defined strictly from geophysical criteria and lithofacies defined primarily based on core lithologies. Table 2.2 shows the petrophysical and petrographic characteristics of the Gordon lithofacies. It should be noted that the "Featureless" sandstone (Fss) lithofacies differs markedly from all others and from the "generalized" Gordon sandstone in terms of higher permeability, primary, and secondary porosity; smaller grain size; and predominance of clay cement. 


\section{OUTCROP PERMEABILITY STUDY}

Three outcrop localities (Rowlesburg, Aurora, and Elkins - Figure 3.1) in northern West Virginia were chosen by Project personnel as possible outcrop analogs to the Gordon sandstone NOTE: these outcrops were selected before the acquisition of permeability measuring equipment. The rocks exposed at each prospective outcrop are all within either the Devonian Hampshire or Foreknobs formation and, although chronostratigraphic control is difficult within these sparsely fossiliferous strata, are thought to be approximately the same age as the Gordon. Each of these localities exhibited lithologic and sedimentologic features similar to those observed in Gordon cores taken from the Jacksonburg-Stringtown field. The only notable difference being that the conglomeratic material seen at the top of the Gordon sequence in core is not as thick in outcrop. The Rowlesburg locality was removed from consideration because of access problems along an active railroad right-of-way.

Nineteen vertical sections were delineated at the Aurora locality, generally five feet (1.5 meters) apart (spacing varied based on outcrop conditions) along the face of the outcrop for a distance of 119 ' (36.3 meters). A bedding surface recognizable throughout the entire outcrop was chosen as a reference horizon. Each section used this horizon as a datum and $0.25^{\prime}(7.62 \mathrm{~cm})$ sampling intervals were marked off along a chalk line above and below this horizon. Lithologic description of each section was done concurrently with the acquisition of permeability data.

Acquisition of permeability data took place from August through October 1999 at the Aurora locality. The north-facing outcrop at Aurora required a variety of preparation techniques to insure that permeability readings were representative of bedrock and not of a weathering rind or other surface phenomena. Permeability acquisition at thirteen of nineteen intended sections yielded extremely low permeabilities (Figure 3.2a) - mean permeability of $1.8 \mathrm{mD}$ for 275 measurements from all sections; mean permeabilities for the thirteen completed sections ranged from $0.45 \mathrm{mD}$ to $5.77 \mathrm{mD}$. In total, from the thirteen sections at the Aurora locality, only two sample points yielded permeabilities $20 \mathrm{mD}$. The largest horizontal permeability recorded at Aurora was $27.9 \mathrm{mD}$. Because of the generally low permeability at this locality, it was deemed unsuitable as an analog to the Gordon reservoir (no lithology present in outcrop with permeability comparable to pay sandstones observed in core) and further work was abandoned at this site.

During the month of July, 2000, three vertical sections were delineated and described at the Elkins locality (Fig. 3.1). Permeability was measured with the minipermeameter at a 0.25 ' $(7.62$ $\mathrm{cm})$ spacing. Sections at Elkins were selected to maximize the exposure of specific lithologic units along the outcrop face. Consequently, sections were selected at irregular intervals along the outcrop. Elkins Section 1 was chosen because it was composed of two units - a highly bioturbated, interbedded, very fine-grained, quartz sandstone, siltstone, and shale overlying a trough-crossbedded, conglomeratic quartz sandstone. Elkins Section 2, offset approximately 20' to the southeast, was composed entirely of the bioturbated material. Elkins Section 3, offset an additional 145 ' to the southeast, was composed of a fine-grained, quartz sandstone with marine fossils and bounded above and below by shale. Section 3, selected because of an apparent lack 
of sedimentary structures, was thought to be similar to Jacksonburg-Stringtown core material with good permeability, i. e., "Featureless" sandstone.

Figure 3.2b shows histograms and descriptive statistics for all permeability readings taken at Elkins. As with the Aurora sections, permeability was extremely low - mean permeability of $0.32 \mathrm{mD}$ for 105 measurements from all sections; mean permeabilities for the three sections ranges from $0.17 \mathrm{mD}$ to $0.57 \mathrm{mD}$. No single measured permeability $5 \mathrm{mD}$ was recorded from the Elkins locality. As with the Aurora locality, this outcrop was deemed unsuitable as an analog to the Gordon reservoir.

An attempt was made to locate additional outcrops of Devonian marine sandstones that might be used as analogs. To facilitate the process, the minipermeameter was taken along during reconnaissance so that outcrop samples could be tested at each prospective locality. Three substitute outcrop localities, Huttonsville, WV, Durbin, WV, and Hightown, VA (Fig. 3.1) presented exposures of Devonian marine sandstones of the Foreknobs or Hampshire formations. The Huttonsville locality proved inaccessible because the exposed rock forms a steep cliff face a single "grab" sample of rock was tested for permeability but yielded a value of only $0.49 \mathrm{mD}$. The Durbin and Hightown outcrops were easily accessible but outcrop samples tested yielded mean permeabilities of $2.62 \mathrm{mD}$ and $1.33 \mathrm{mD}$ respectively. The maximum measured permeability at these two localities was only $5.41 \mathrm{mD}$ (Durbin).

The goal of the outcrop portion of the Project was to model outcrop permeability at a scale similar to that in the oil field. However, this modeling is contingent upon the presence of permeability in the outcrop. We concluded that insufficient permeability was observed in any of the outcrop localities investigated for permeability modeling to be performed.

Finally, in an effort to either justify the abandonment of the outcrop study or to revive it using a different approach, a total of 22, one-inch diameter cores were taken from the Aurora (13) and Elkins (9) outcrops using portable coring equipment. The recovered cores vary in length from just under 1" to approximately 6". Twelve intact cores were delivered to Project engineers to be cut to length to fit a conventional core plug porosity and permeability apparatus. Subsequent porosity analysis of these core segments yielded no porosities $1-2 \%$. Upon receiving these results, it was decided to abandon further outcrop investigation. 


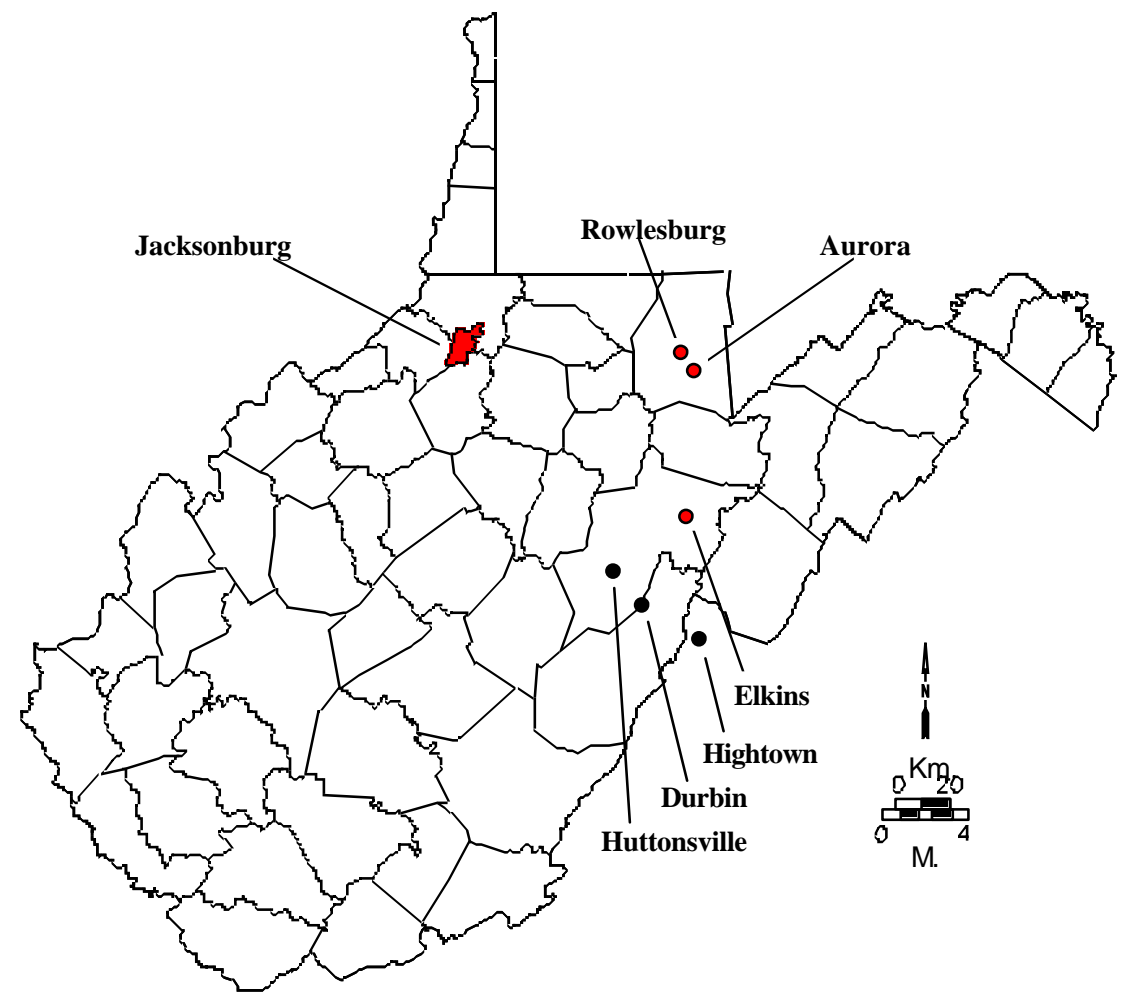

Figure 3.1. Location of outcrop exposures of the Devonian Hampshire or Foreknobs formation examined as possible outcrop analogs to the Gordon sandstone within the Jacksonburg-Stringtown field. Red circles represent initial localities chosen before the start of the Project; black circles represent localities investigated after the start of the Project. Location of the field is shown for reference.
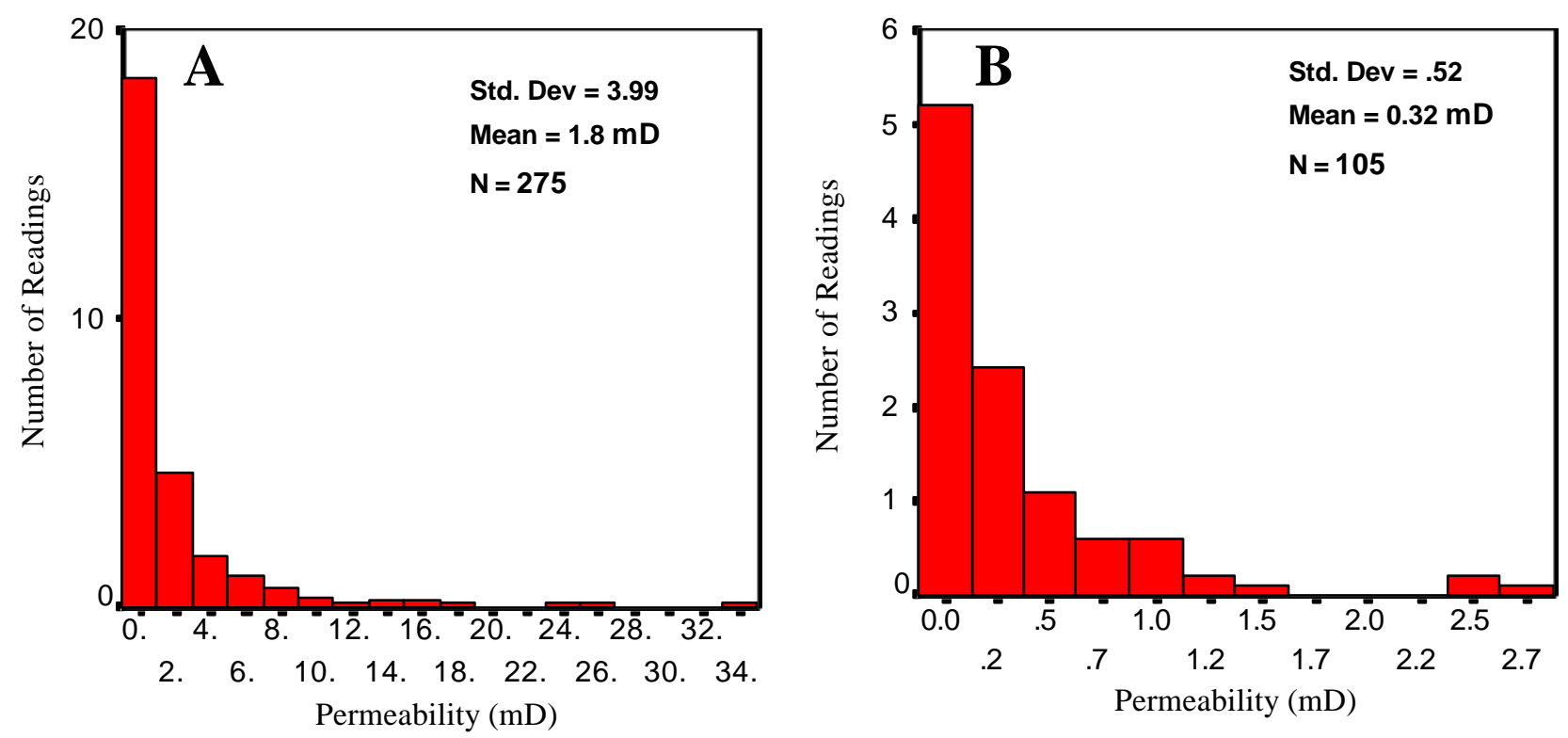

Figure 3.2. Histograms and associated statistics describing permeability data acquired at the Aurora (A) and Elkins (B) outcrop localities. NOTE: the mean, median, and modal permeability values at both localities is well below $5 \mathrm{mD}$ suggesting that neither locality is a suitable permeability analog to the Gordon reservoir in the Jacksonburg-Stringtown field. 


\section{MODELING AND SIMULATION}

Advanced computer models are available for simulating the fluid flow in increasingly complex reservoirs for the purpose of determining hydrocarbon recovery and appraising the economic success of reservoir management and development methods. However, an accurate model of the reservoir is necessary to reliably predict the production performance of the reservoir. Porosity and permeability distributions are the key formation attributes that are required for reservoir modeling. Porosity and permeability are usually determined from the analysis of the core samples. Generally, core samples are only available from limited number of wells in the reservoir because of the expenses associated with obtaining and analyzing the core samples. At the same time, geophysical well logs are commonly available for most of the wells in the reservoir. Well log data are then utilized to identify the productive intervals and to estimate the formation porosity. A correlation between core-derived permeability and log-derived porosity is often developed and utilized for permeability prediction. The use of well $\log$ data to predict permeability distribution therefore, represent a significant technical as well as economic advantage.

\subsection{Data Collection and Analysis}

Significant effort was directed toward collecting the necessary data for this study. Several trips were made to operator's office to obtain rock and fluid samples as well as other necessary data. The collected data included core analysis results, capillary pressure and relative permeability measurement results, fluid properties, fluid sensitivity study reports, lease primary production records, well records, well logs, well tests, and waterflood production-injection records. In addition, several maps and reports as wells as core samples and a fluid sample were obtained.

The results of core analysis were available on seven wells throughout the field, which eliminated the need for conventional core analysis. However, more detailed core permeability measurements were performed on all the available core samples utilizing the minipermeameter. These measurements provided detailed permeability values. The collected data were organized in a database for analysis. The data analysis was focused on determining the characteristics of the formation. The logs for the well with core analysis were interpreted to estimate the porosity.

Attempts were made to investigate the variations in fluid properties. A sample of reservoir oil was obtained by operator and was made available for analysis. However, the sample had been taken at the surface and as result was not considered a representative reservoir sample. It should be pointed out that the likelihood of obtaining a representative reservoir fluid sample is practically nil considering the age of the reservoir and the gas and water injection history. The collected fluid property data, published records, and the results of the fluid sample analysis tend to indicate that the fluid properties are generally uniform throughout the filed. The limited information on the fluid properties that were available was utilized to generate more detailed fluid characteristics for modeling studies. The collected relative permeability and capillary pressure measurements from several wells were utilized to characterize fluid-rock interactions for modeling studies. 


\subsection{Permeability Prediction}

Permeability and porosity distributions are the most critical factors in development of the reservoir model. Porosity and permeability values for individual wells are usually determined from the analysis of the core samples. However, core samples are obtained and analyzed from only few wells in the reservoir. At the same time, porosity can be directly derived from the well $\log$ data. Well logs are commonly available from the majority of the wells in the reservoir. Consequently, the porosity distribution is evaluated from well $\log$ data. Determination of permeability distribution in a heterogeneous reservoir is a complex problem. The problem stems from the fact that the available core analyses are not sufficient to develop a reliable permeability distribution. It should be noted that well $\operatorname{logs}$ do not provide a direct measurement of the permeability. Consequently, the permeability must be predicted indirectly from the well log data. This is achieved by developing a correlation between permeability and well log data. The most common form of this correlation is a correlation between core-derived permeability and logderived porosity. In a heterogeneous reservoir, however, a reliable correlation between permeability and porosity generally cannot be often established. Therefore, new and innovative approaches are necessary to establish a reliable correlation in a heterogeneous reservoir for permeability prediction. Our previous investigations resulted in development of several methodologies for determining porosity and permeability distributions in a heterogeneous formation utilizing geophysical well $\log$ data as well as pore type characteristics. These earlier studies have demonstrated Artificial Neural Networks (ANN) to be a useful tool for estimating the formation permeability using geophysical well log data as input. These methodologies were modified in this study to evaluate and predict permeability and porosity distributions. They are discussed in the following sections.

\subsubsection{Permeability-Porosity Correlations}

The analysis began with analysis of well log data to identify the productive zones and evaluate porosity values for all the wells that had core analysis available. Subsequently, the core porosity and well logs porosity values were compared. The core depths were adjusted to match the two porosity trends for each well. The final results are summarized in Figure 4.1. Finally, two preliminary correlations for core permeability-core porosity with a correlation coefficient of 0.8 and core permeability-well $\log$ porosity with a correlation coefficient of only 0.70 were developed as shown in Figures 4.2 and 4.3. The low correlation coefficient for core permeability$\log$ porosity is indicative of the heterogeneous nature of the formation.

\subsubsection{Permeability Prediction with Neural Network Model}

To predict permeability from well log data more accurately and incorporate more information data are available from well logs in addition to well log porosity, a neural network study was undertaken. ANN can identify the complex relationship between permeability and well log data without any assumption or pre-defined model. A brief introduction to neural networks is presented first. 


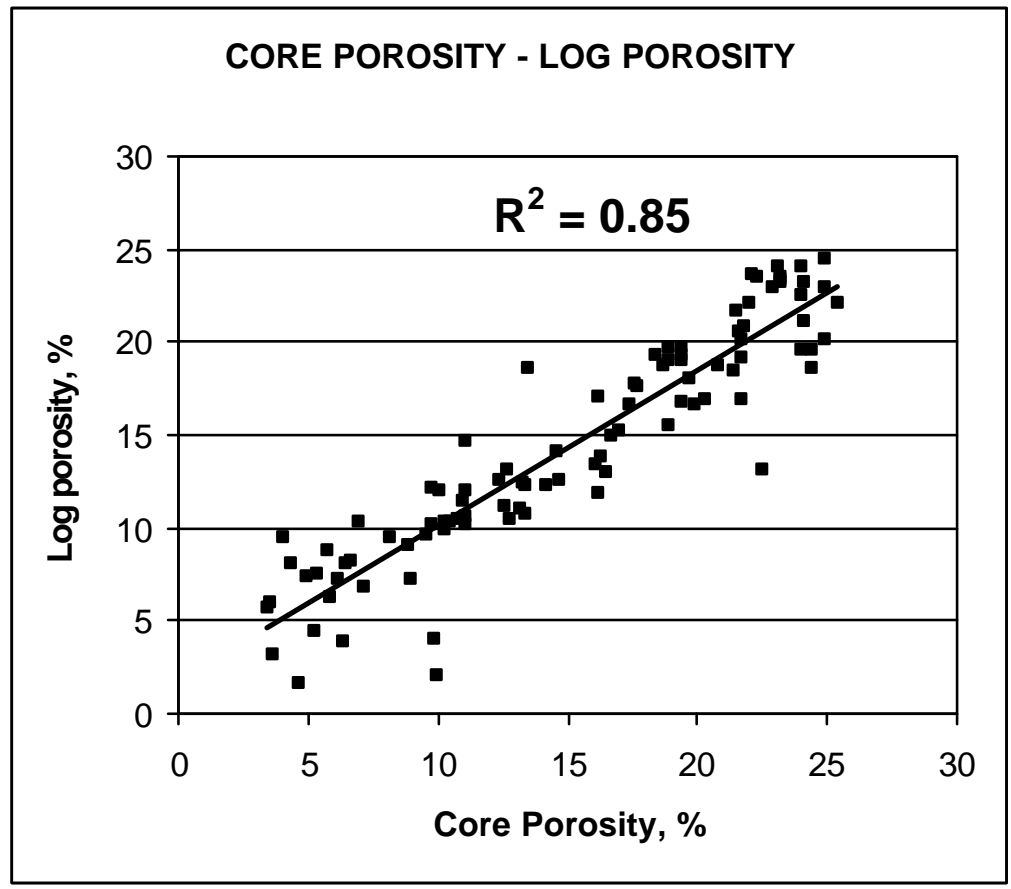

Figure 4.1. Comparison of Core and Well Log Porosity Values

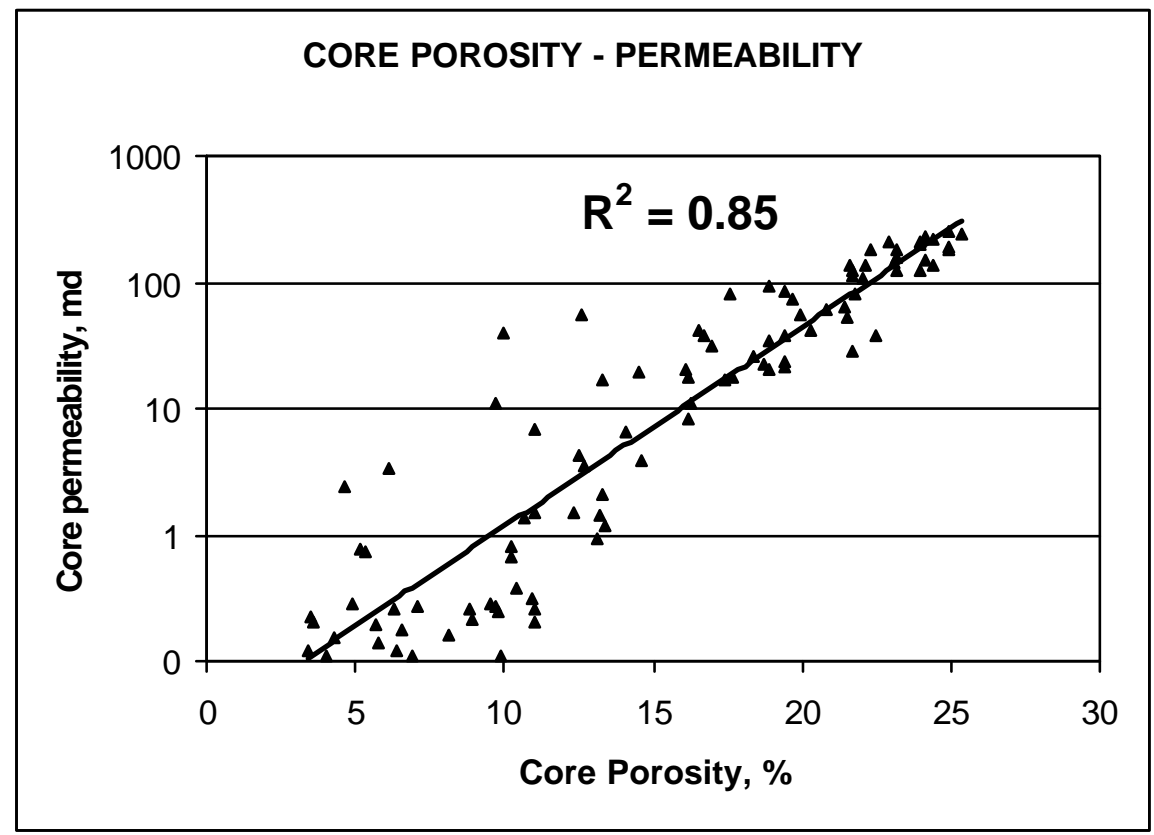

Figure 4.2. Core Permeability-Porosity Correlation 


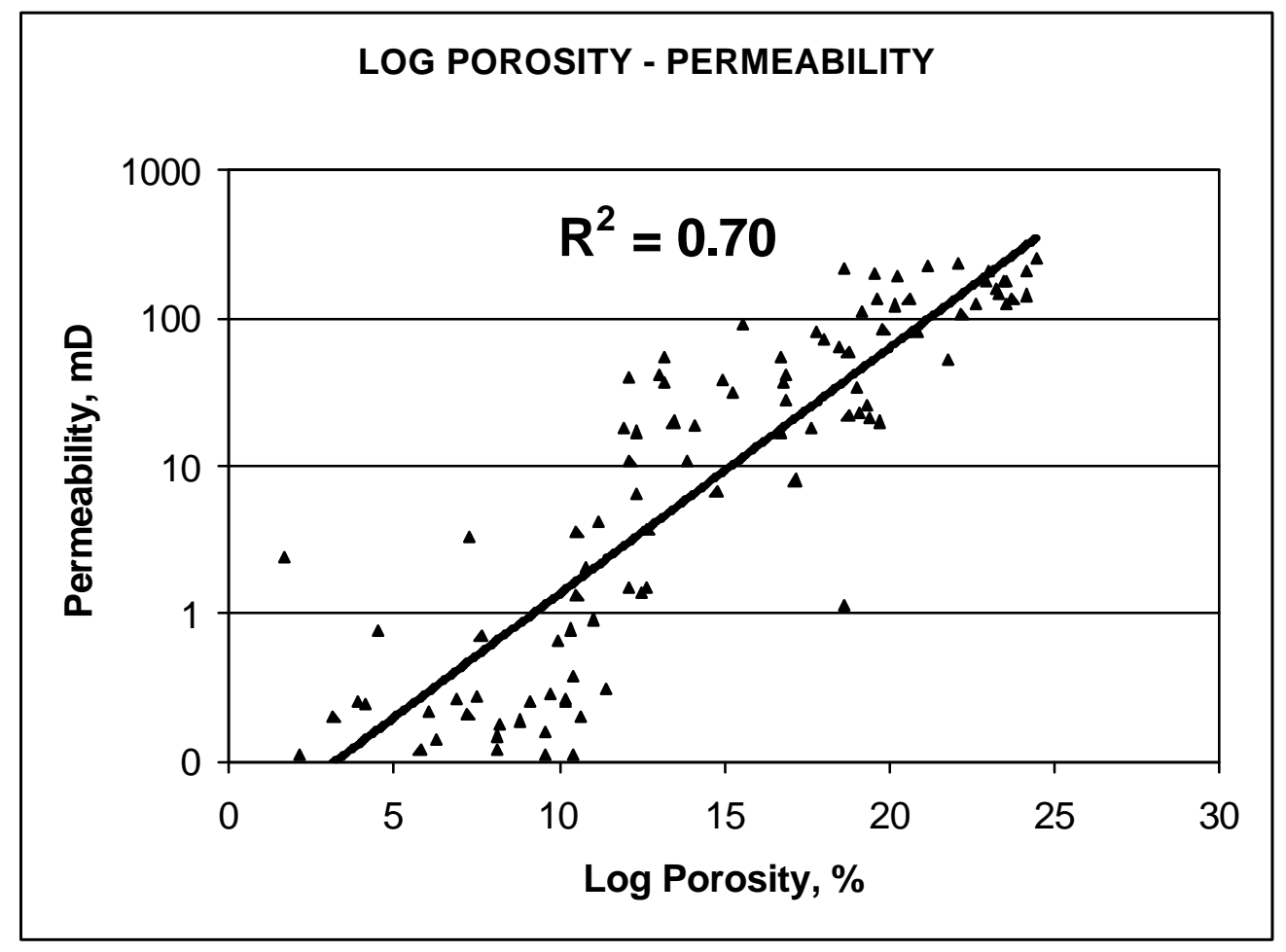

Figure 4.3. Core Permeability-Well Log Porosity Correlation

Artificial Neural Network (ANN) is an information-processing system that mimics the brain processes for solving problems. The network takes the previously solved examples to build a system of "neurons" that makes forecasts. Neural networks excel at problems where pattern recognition is important and precise computational answers are not required. The main components of a neural network are shown in Figure 4.4. The basic building blocks are the simulated neurons (depicted as a circle) that are interconnected in a network. The network processes a number of inputs from the outside to produce an output (predictions). The neurons are connected by weights (depicted as lines), which are applied to values passed from one neuron to the next. Neurons are also grouped into layers. The input layer contains the neurons that receive data from outside of the network. The output layer contains the neurons with network's predictions.

Neurons in between the input and output layers are in the hidden layer(s). A layer may contain one or more slabs - a group of neurons. 


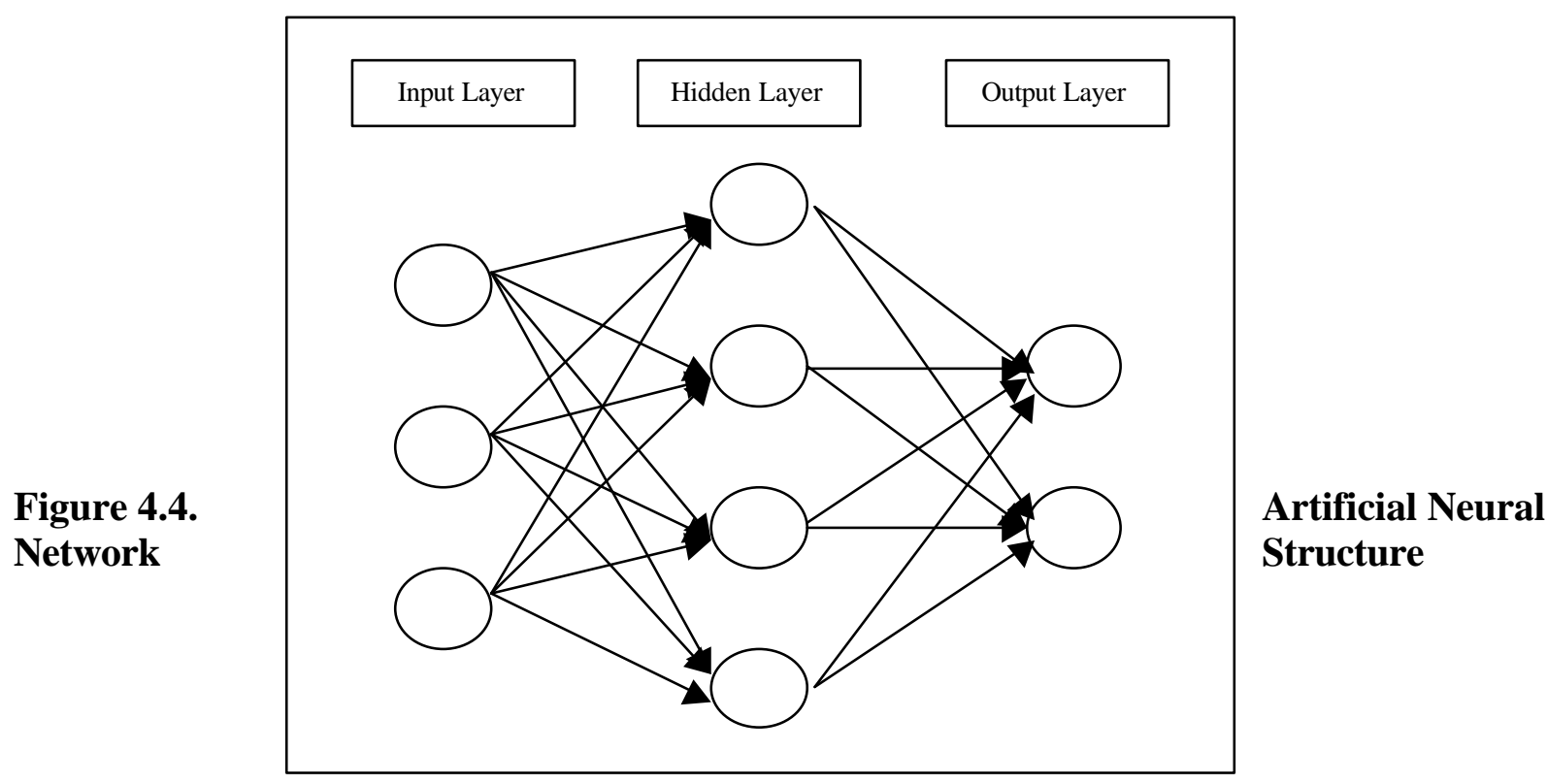

A common neural network is a back-propagation network, which usually has three layers of neurons. Neurons in the input layer produce "intermediate" outputs by applying an activation function to the sum of the weighted input values. Different activation functions may be used including linear, binary, sigmoid and probabilistic. The "intermediate" outputs then become the inputs for the middle or hidden layer. The hidden layer passes values to the output layer in the same fashion, and the output layer generates the desired results (predictions). The outputs are repeatedly compared with the correct answers, and each time the weights are adjusted slightly in the direction of the correct answers. The network "learns" by adjusting the weights between layers. Eventually, if the problem can be learned, a stable set of weights is reached. The architecture of the neural network defines the connectivity pattern among neurons the algorithm to be used in updating the weights of each connection. Various architectures are discussed in the literature. A powerful architecture is the Ward network with multiple slabs in the middle layer each with different activation function. These networks can detect different features of the input vectors. This gives the output layer different viewpoints of the data. This ANN architecture is depicted in Figure 4.5. 


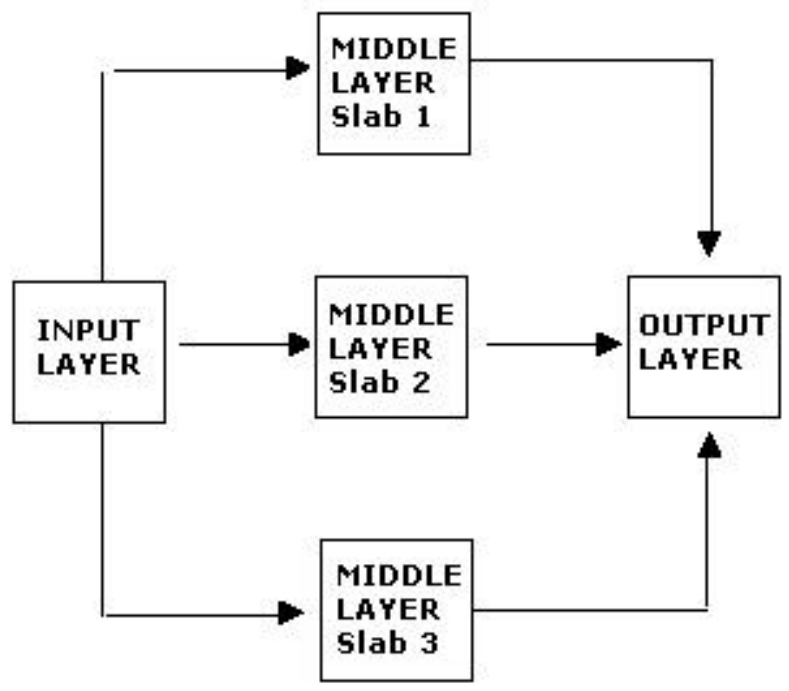

Figure 4.5. Architecture of A Neural Network

The real power of the ANN is evident when the trained network is able to produce reliable results for data that the network has never "seen" before. The main objective when applying an ANN is to achieve a balance between correct responses to training patterns and good responses to new input patterns; in other words, the network must seek a balance between memorization and generalization. To accomplish this goal, all the data are divided in two groups, the training and the test set. The training set is used to develop the ANN. In this process, the known output is used to help the ANN adjust the weights between its neurons. So, training is accomplished by modification of the weights until a small difference between "known" and "predicted" outputs is reached. The test set is a data pattern consisting of input and correct output variables used to test the network. The test patterns are used to verify how well the network is working. A test set is important because it provides a set of data not included in the training set. The weights are adjusted based on the training set, however, at intervals during training, the error is computed using the test set. As long as the error on the test set decreases, training continues. The ANN with minimum error on the test set is finally saved.

For the purpose of this study, the core data from six wells in the reservoir were utilized. The main assumption in this study was that geophysical log data could provide valuable information about formation permeability in other words a relationship between permeability and log data exists that may not be direct and explicit. The data sets selected to train the ANN consisted of several input groups. The first input group included the Gamma Ray and Bulk Density log data and corresponding depths. Bulk Density and Gamma Ray logs are available from most wells in the Jacksonburg-Stringtown Field. Although other logs, including neutron porosity and induction, are available from some of the wells, the selection of Gamma Ray and Bulk Density logs was primarily dictated by their availability for the majority of the wells in the field. The second input group consisted of the first and the second derivatives of the log data with respect to depth. This group provided useful information relative to the shape of each log curve. The final group of input data consisted of the well coordinates, and log baselines. The core permeability measurements were utilized as target outputs. 
To obtain reliable permeability predictions, several artificial neural network architectures and paradigms were considered. It was concluded that a three-layer, back-propagation network with three slabs in the middle layer (each slab having a different activation function) is the most appropriate architecture. To verify the accuracy of permeability predictions by ANN, several similar networks were trained by using the data from five of the six wells. Subsequently, the data from the sixth well was used as input for the trained network to predict the permeability values. The results of ANN permeability predictions for each well are summarized in Table 4.1. When comparing predicted with core permeabilities for all the wells, the $\mathrm{R}^{2}$ coefficient is 0.78 (if the well H-11 is not included, this coefficient would be 0.85 ).

Table 4.1. $\mathbf{R}^{2}$ Values for Permeability Prediction

\begin{tabular}{|c|c|c|}
\hline Verification Well & $\mathbf{R}^{2}$ for training + test & $\mathbf{R}^{2}$ for verification \\
\hline B-18 & 0.97 & 0.96 \\
\hline B-19 & 0.99 & 0.75 \\
\hline H-9 & 0.80 & 0.91 \\
\hline H-11 & 0.95 & 0.30 \\
\hline T-8 & 0.90 & 0.80 \\
\hline L-13 & 0.95 & 0.83 \\
\hline
\end{tabular}

\subsubsection{Porosity Prediction with Neural Network Model}

Comparison of Figures 4.1 through 4.3 leads to the conclusion that permeability has a stronger correlation with core porosity than log porosity. Further, the core porosity and log porosity have reasonable correlation. Therefore, attempts were made to predict the core porosity from well log data utilizing ANN. A back-propagation network, with three slabs in the middle layer, was trained to predict porosity using 11 inputs from logs and well information. A similar approach as permeability predication was employed to evaluate the porosity predictions. The $\mathrm{R}^{2}$ values for both training and test and for the verification well are shown in Table 4.2.

Porosity values predicted by neural network (NN porosity) clearly indicate strong correlation with core porosity values as illustrated in Figure 4.6. The significantly-improved method of predicting porosity from well log data was utilized for porosity predictions in the reservoir.

Table 4.2. $\mathbf{R}^{2}$ Values for Porosity Prediction

\begin{tabular}{|c|c|c|}
\hline Verification Well & $\mathbf{R}^{2}$ for training + test & $\mathbf{R}^{2}$ for verification \\
\hline B-18 & 0.92 & 0.90 \\
\hline B-19 & 0.94 & 0.82 \\
\hline H-9 & 0.91 & 0.96 \\
\hline H-11 & 0.92 & 0.89 \\
\hline T-8 & 0.94 & 0.83 \\
\hline L-13 & 0.95 & 0.82 \\
\hline
\end{tabular}




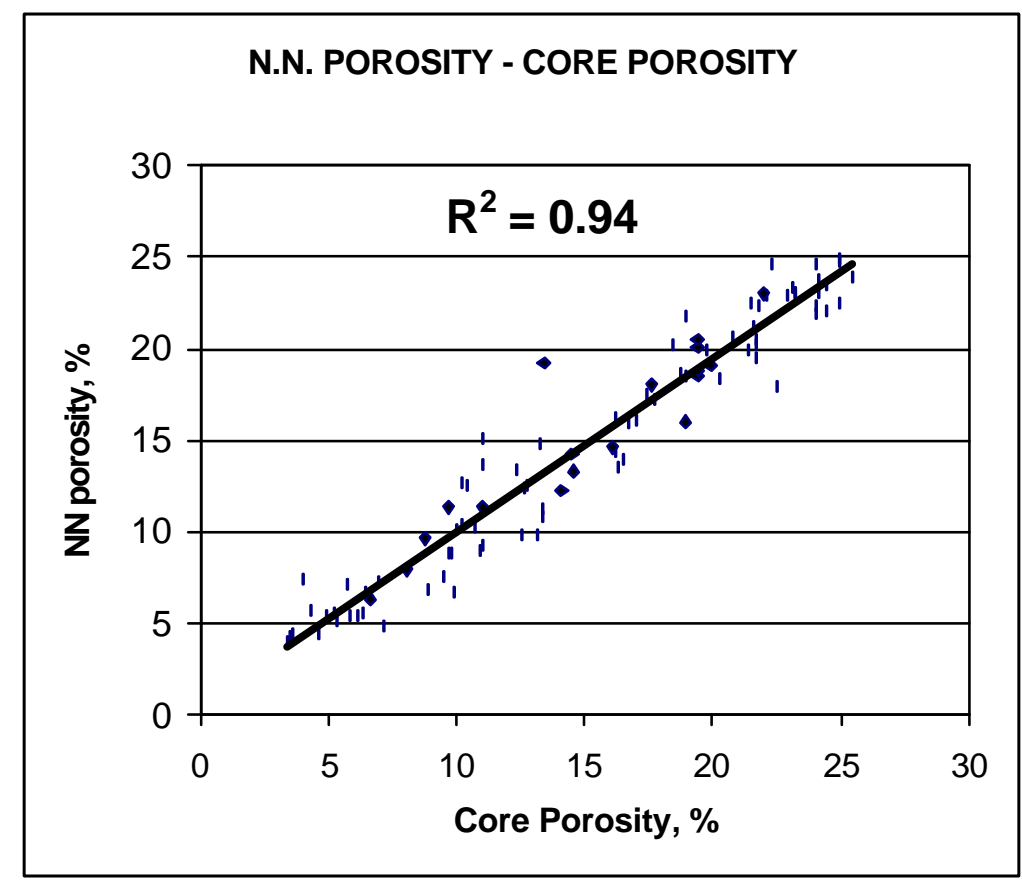

Figure 4.6. Core Porosity Prediction Results

\subsubsection{Minipermeameter Measurements}

The comparison of the core permeability distribution measured by the minipermeameter and the core plug analysis indicate very different values. The permeability values measured by the minipermeameter (mini-perms) are much lower in value and are much more variable in nature than core plug analysis. The differences are probably caused by a number of factors including damage to the core surface and the scale of measurements by the different tools. The variable nature of the mini-perm is due to scale of measurement. The minipermeameter measures the permeability at one spot on the surface of the core. This measured permeability represents an average of horizontal and vertical permeability values over a very small volume of the rock. As a result, mini-perms represent the small-scale permeability variations in the core. In a heterogeneous formation, the mini-perms are therefore more variable. However, the mini-perms are much more affected by core surface conditions since the depth of investigation is very limited. The core plugs generally represent the horizontal permeability for a somewhat larger volume (1-inch diameter by 1-inch long) of the rock. Generally, only one core plug is obtained from every foot of the core. Ideally, the plug is obtained from the best part (high porosity and permeability) of the interval.

The objective of this part of the study was to predict the small-scale permeability variation in the formation based on the measured mini-perms. To achieve this objective, a relationship between core plug permeability values, mini-perms, and geophysical well log data must be developed. It should be noted that well log data are obtained at $0.25^{\prime}$ scale, which is more representative of the 
formation than the core plugs scale. Due to good results obtained with Artificial Neural Networks (ANN) for permeability prediction, two separate ANNs were trained and tested to develop this relationship. Six wells, which had both core plug permeability values and measured mini-perms available, were utilized in this study. The first ANN utilized the data from the Bulk Density and Gamma Ray logs as wells as well location and mini-perms as input and core plug permeability as output. Due to differences in the scale, the mini-perms were first averaged out using moving average technique and then the average mini-perm and log data corresponding to the depth at which core plug were taken were used as inputs. The first network provided accurate prediction of the permeability. The training and test data sets provided R-squared values over $96 \%$ and verification sets resulted in R-squared values over $76 \%$ for all the wells. The first network was then utilized with detailed log and mini-perm data to generate a detailed permeability profile for each well. The generated detailed permeability profile was then used as target output for the second network. The second network had detailed log data and well location as input. The second network provided accurate prediction of the permeability. The training and test data sets provided R-squared values over $96 \%$ and verification sets resulted in R-squared values over $76 \%$ with exception of one well. Generally, the results were similar to those obtained without mini-perm data. Therefore, it was concluded that mini-perm data did not provide any additional information that was not already available from well log data.

\subsection{Production History Analysis: Synopsis}

The main objective of production history analysis is to evaluate the consistency of the reservoir description with known production performance. The results of the geological, petrographic, and permeability-porosity predictions are integrated to build a 3-D model for the reservoir. The reservoir model is then utilized with available pressure data to predict the production performance. This generally achieved by employing a reservoir simulator.

Reservoir simulators are complex programs that simulate multiphase displacement process in two or three dimensions. They are widely used to study reservoir performance and to determine methods for enhancing the ultimate recovery of hydrocarbons. Analytical methods of predicting reservoir performance are limited to homogeneous reservoir and cannot take into account changes in rock properties or saturations across the reservoir. In addition, numerical simulators can account for the location of the wells and the operating conditions, such as variable flow rates or pressures. The reservoir simulator can be used to assess the reservoir model (description) by determining the production performance for alternate reservoir descriptions and comparing them against the reservoir production history.

\subsubsection{Production History of the Field}

The Jacksonburg-Stringtown Field was discovered in 1895.The original oil in place is estimated to be about 80 million barrels of oil. Over 500 wells were drilled on the average spacing of 15 acres from 1897 to 1901 when the annual oil production reached over one million barrels. The initial production (IP) ranged from zero to 400 and averaged 72 barrels of oil per day. The typical well was completed open-hole at average depth of 3000 feet and was stimulated with nitroglycerine shot. By 1910, the production declined significantly and the majority of the wells 
were abandoned. The lease primary recovery ranges from 824 to 2700 and averages 1600 barrels of oil per acre. This equates to an average cumulative recovery of 23000 barrels of oil per well. The primary recovery mechanism was solution gas drive. From 1934 through the late 1960's, a limited gas injection project was operated but did not contribute significantly (less than 1 percent) to the primary recovery. The waterflood operation started with a pilot in 1981 and continued in several stages of development. The estimated waterflood recovery is 8 million barrels of oil of which approximately 2 million barrels has been already recovered.

\subsubsection{BOAST98 Simulator Overview}

In this study, a black-oil, three-phase, 3-D simulator called BOAST98 was used. This program has been developed for the U.S. Department of Energy, and is available to the public via the Internet. (www.npto.doe.gov). The BOAST98 simulates isothermal, Darcy flow in three dimensions. It assumes reservoir fluids can be described by three fluid phases (oil, gas, and water) of constant composition with physical properties that depend on pressure only. Some of the typical field production problems that can be handled by BOAST98 include: primary depletion studies, pressure maintenance by water and/or gas injection, and evaluation of secondary recovery waterflooding operations.

BOAST98 is a finite-difference, implicit pressure/explicit saturation (IMPES) numerical simulator. It contains both direct and iterative solution techniques for solving systems of algebraic equations. The well model allows specification of rate or pressure constraints on well performance, and wells can be added or recompleted during the simulation. Multiple rock and PVT regions may be defined, and three aquifer models are available as options. BOAST98 contains flexible initialization capabilities, a bubble point tracking scheme, an automatic time step control method, and a material balance check on solution stability. This simulator consists of two basic components, Edboast, used to edit the input data, and Boast98, used to make the calculations. A simulation run can be started from either the Edboast or the Boast 98 application. However, beginning with the Edboast program, the user will be able to review the input data file first and locate any mistakes that apply to the BOAST98 application.

\subsubsection{Simulation of Primary Production}

Attempts were made to predict the primary performance of the reservoir. Individual well production records are only available after 1930. Only the annual lease oil production is available for the entire life of the field. It should be noted that the available data from the primary recovery period are insufficient for simulation purposes. However, simulation runs with BOAST simulator have indicated oil recovery efficiencies similar to those obtained in the reservoir.

\subsubsection{Simulation of the Pilot Waterflood}

A pilot waterflood was initiated in Jacksonburg-Stringtown field in November 1981. The pilot area is located in southern part of the field. The pilot utilized 33-acre dual five-spot patterns. Six 
water injection and one oil producer, H-12, were drilled prior to pilot operations. The other producer, MM-1, was an old shot well drilled in 1897. The logs from the wells indicated that the reservoir thickness varies from 4 to 14 feet. The water injection rate averaged 80 barrels of water per day due to limited supply of water. The producers and injectors experienced a number of problems during the pilot operations. The producers were affected by paraffin deposition, which required stimulation to restore productivity. The injectors were also affected by interaction of the injected water and the reservoir that caused iron deposits. A fluid sensitivity analysis revealed that it is necessary to de-oxygenate and increase $\mathrm{pH}$ of the injected water. These problems resulted in lower than expected recoveries from the pilot. By January 1985, MM-1 recovered 1480 barrels of oil per acre and H-12 recovered 1065 barrels of oil per acre. The lower recovery in H-12 was attributed to casing leak from the abandoned wells nearby which had partially swept out the area prior to the installation of the pilot.

The simulation study was initially focused on the pilot area waterflood where significant amount of data was available. The collected well records, well logs, and core analysis data were utilized to construct a simple model of the pilot area. The core analysis was available for two wells in the pilot and the developed core-log correlations for permeability were utilized to estimate the permeability values in the wells without core analysis. The injection pressure-rate information was then utilized in conjunction with a reservoir simulator to predict the oil production for both center producers in the pilot. The results of the preliminary simulation studies indicated that waterflood performance could not be accurately predicted.

\subsection{5 “Flow Unit” Model}

The results of the preliminary simulation studies in the pilot area waterflood indicated that more detailed description of the reservoir characteristics and heterogeneities are necessary before the performance of the reservoir can be predicted. The Flow Unit model is the most realistic approach for reservoir simulation purposes since it incorporates a variety of geological and petrophysical characteristics of the reservoir. The Flow Unit is defined according to geological and petrophysical properties that influence the flow of fluids. Flow Unit model is more complex than geological model and the Flow Units do not necessarily correspond to stratigraphic units and may cut across these depositional intervals. Permeability and porosity distributions are the most critical factors in development of Flow Unit model.

The petrophysical studies on the core samples had revealed that the formation consists of several lithological units including sandstone (pay sand and non-pay sand), conglomerate, and shale. The pay sand and conglomerate exhibit good porosity but conglomerate permeability is very variable and generally much lower than pay sand. The formation was then subdivided into two Flow Units, pay sandstone and conglomerate. Figures 4.7 and 4.8 illustrate permeability-porosity correlations for each unit for six wells with core analysis. Comparing these figures with Figure 4.2 , it can be concluded that the pay sandstone has higher and more significant correlation than overall porosity-permeability correlation. However, conglomerate correlation is worse. This behavior is typical of conglomerate since its characteristics are extremely variable. 
The collected well records, well logs, and core analysis data were utilized to construct a model of the pilot area with two flow units, pay sandstone and conglomerate. The core analyses were available for two wells in the pilot area and the neural network models developed for porosity and permeability predictions were utilized to estimate the porosity and permeability values in the wells without core analysis. The injection pressure-rate information was then utilized in conjunction with a reservoir simulator to predict the oil production for both center producers in the pilot. The results indicated that this description of the flow units could not generate a reasonable match with the waterflood production history in pilot area.

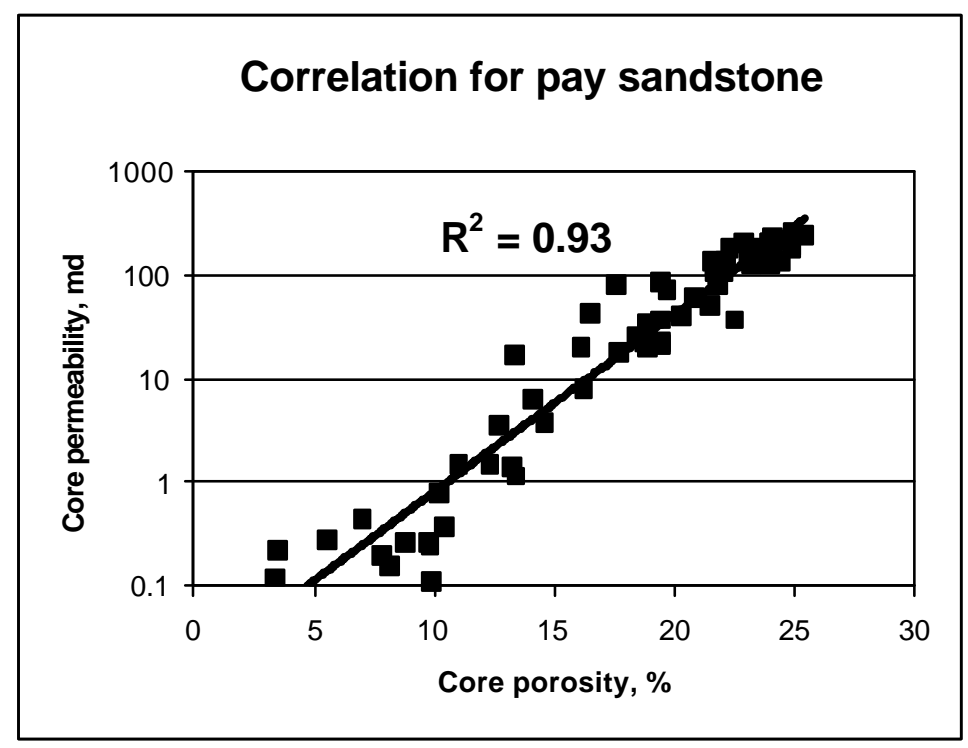

Figures 4.7 Permeability-Porosity Correlations for Pay Sandstone

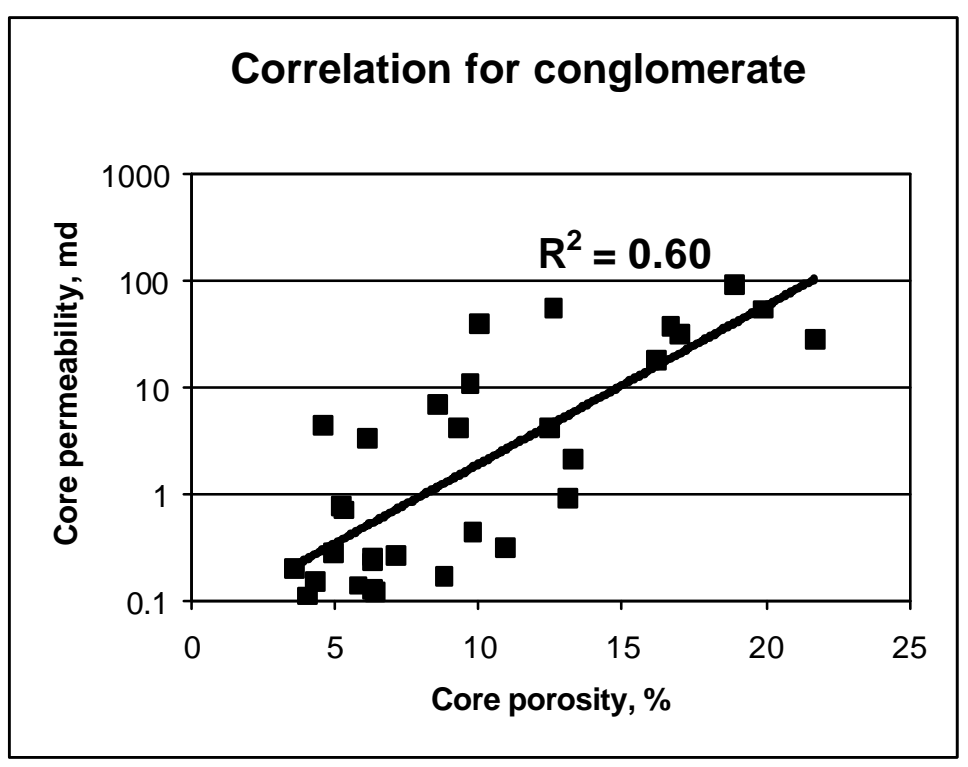

Figures 4.8 Permeability-Porosity Correlations for Conglomerate 
Further investigations revealed that the conglomerate is, in actuality, a sequence of sandstone with interbedded conglomerate. As a result, two new flow units were defined. Flow unit I consisted of the lower part of the conglomerate-sandstone sequence and the upper part of the sandstone section. This flow unit has a slightly lower porosity but much lower permeability. Flow unit II is defined as the lower part of the sandstone. Flow unit II has higher porosity and permeability. Figure 4.9 illustrate the definition of the flow units in one injection well in pilot area.

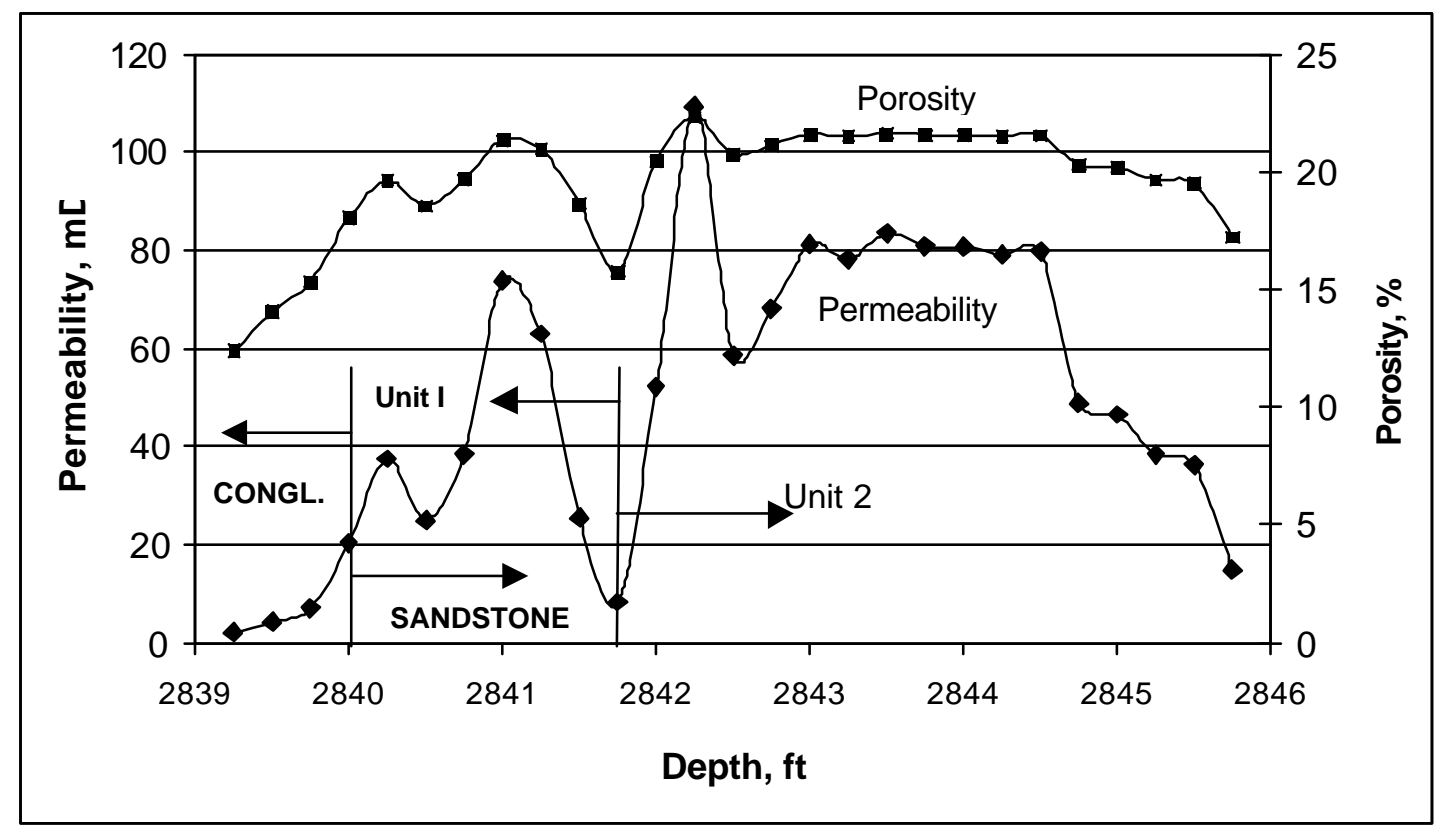

Figure 4.9 Definition of the Flow Units in Pilot Area.

Figures 4.10 and 4.11 illustrate the porosity-permeability relationship for each flow unit in the same well. The thickness of each unit was evaluated based on the distribution of permeability and porosity in each well. Figure 4.12a-f shows the distribution of unit thickness, mD-feet, and mean permeability for the each of the two Flow Units in the field using methods described in the next section. A three-dimensional reservoir description including the flow units and injection pressure-rate information were then used as inputs for the reservoir simulator to predict the oil production performance for the center producers in the pilot area. This description of the reservoir provided significantly better simulation results. Figures 4.13 and 4.14 summarize the results and compare them with pilot production history. 


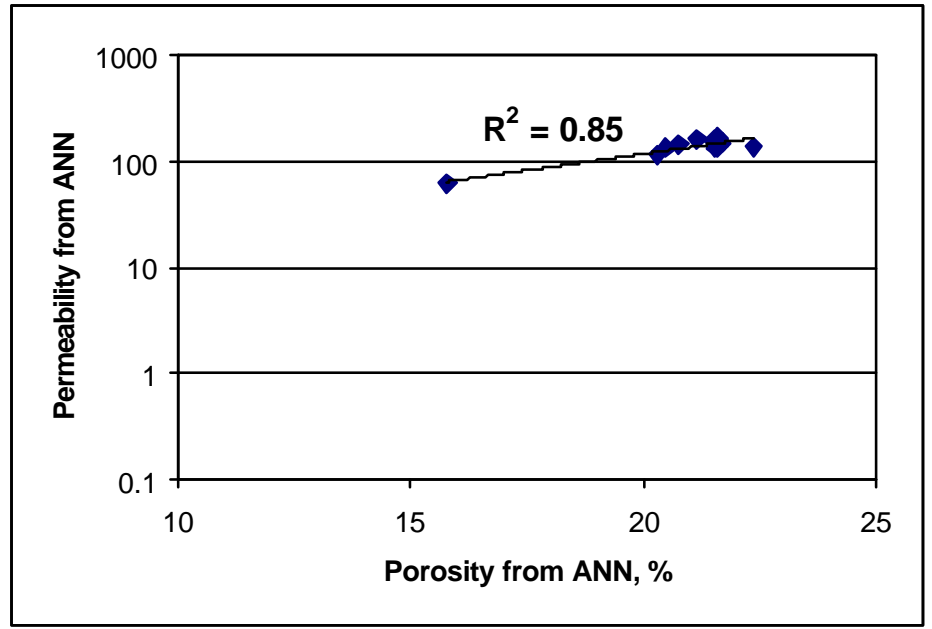

Figures 4.10 Permeability-Porosity Correlations for Unit I in the Pilot Area.

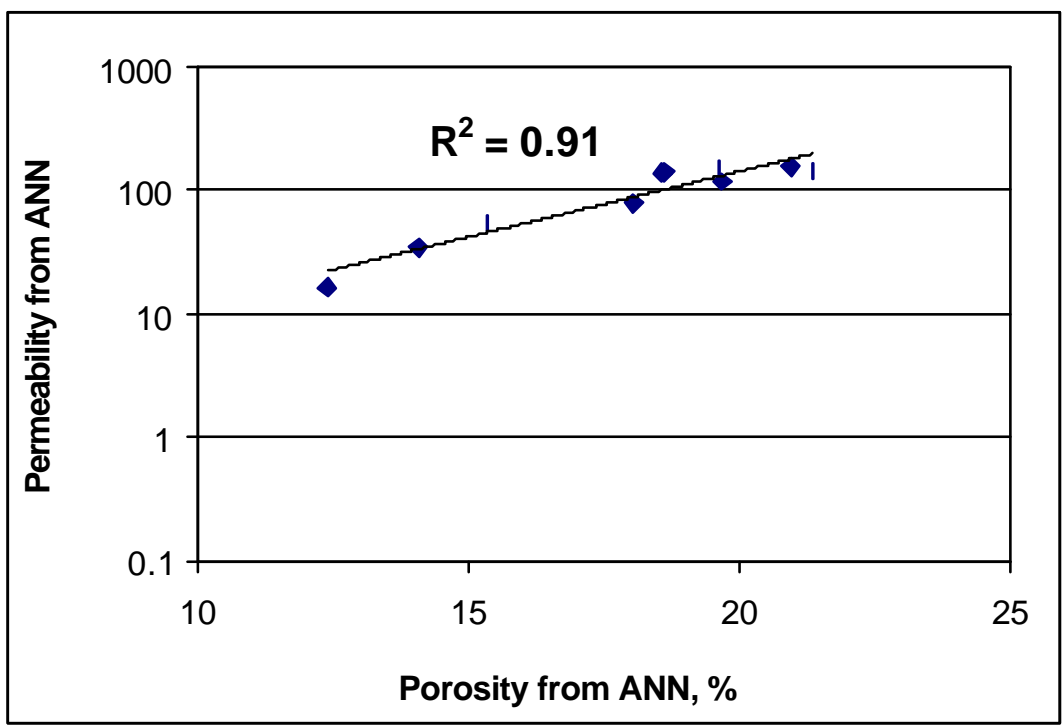

Figures 4.11 Permeability-Porosity Correlations for Unit II in the Pilot Area. 


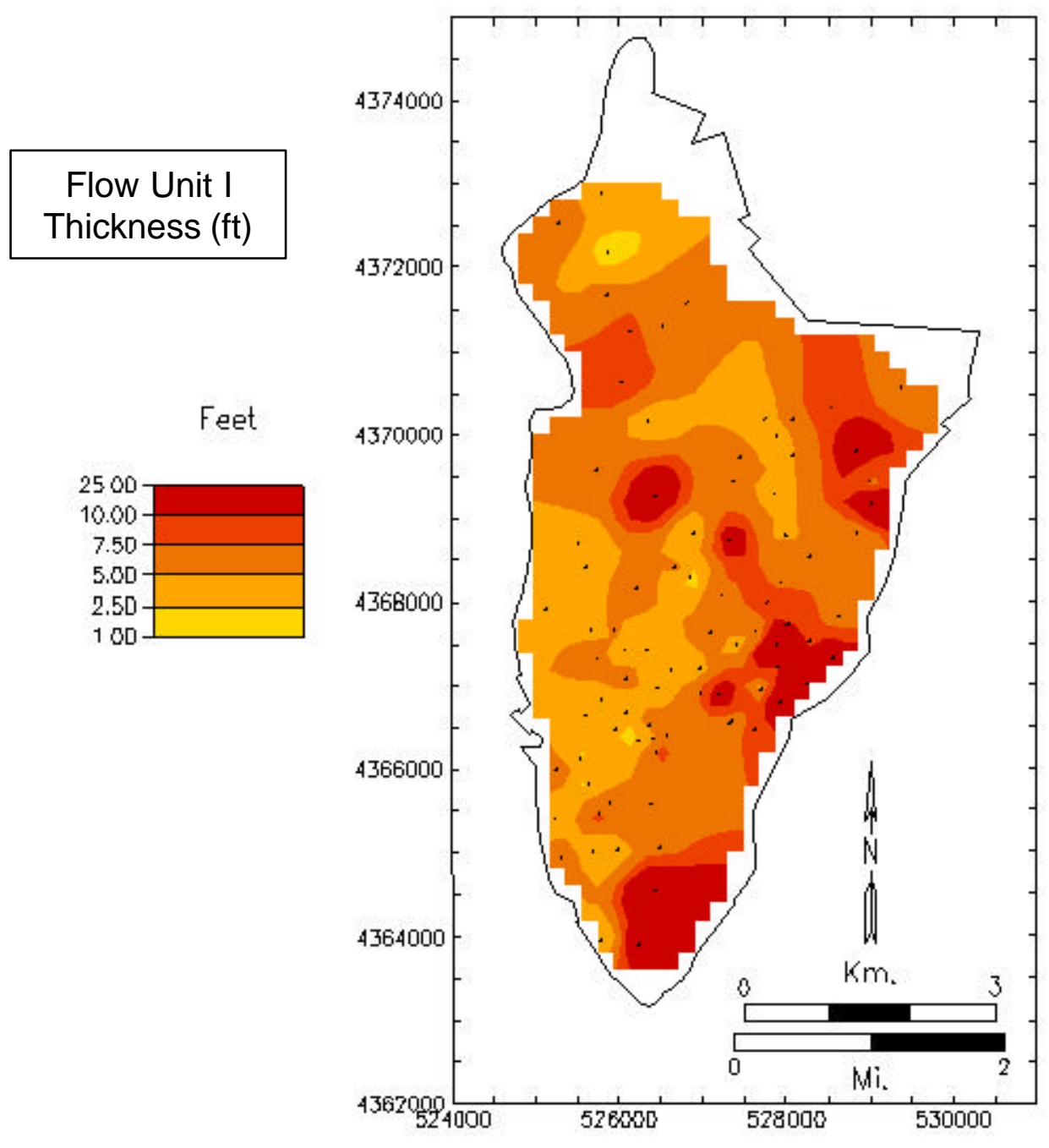

Figure 4.12a. Thickness of flow unit I. 

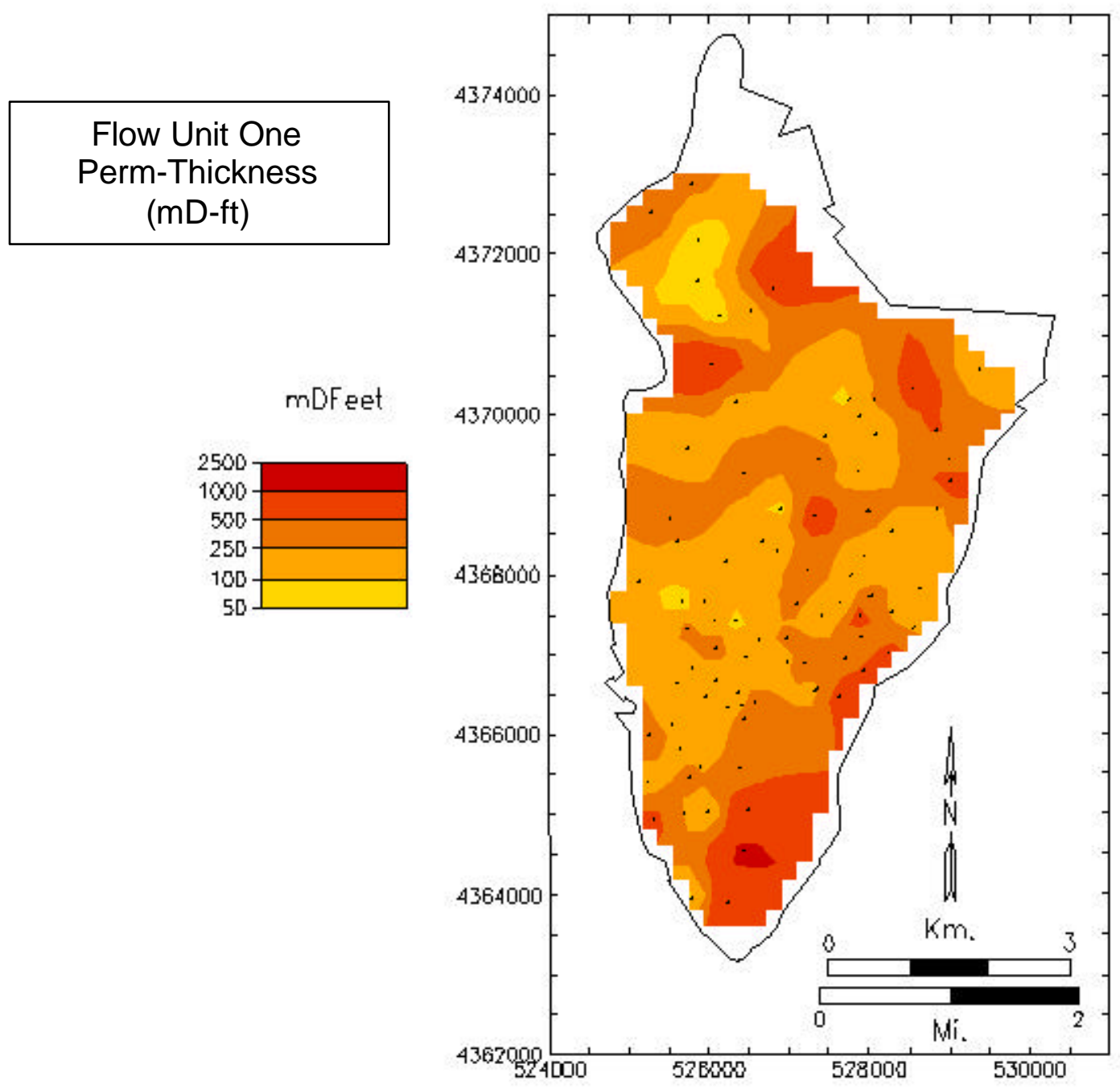

Figure 4.12b. Permeability-Thickness of flow unit I. 


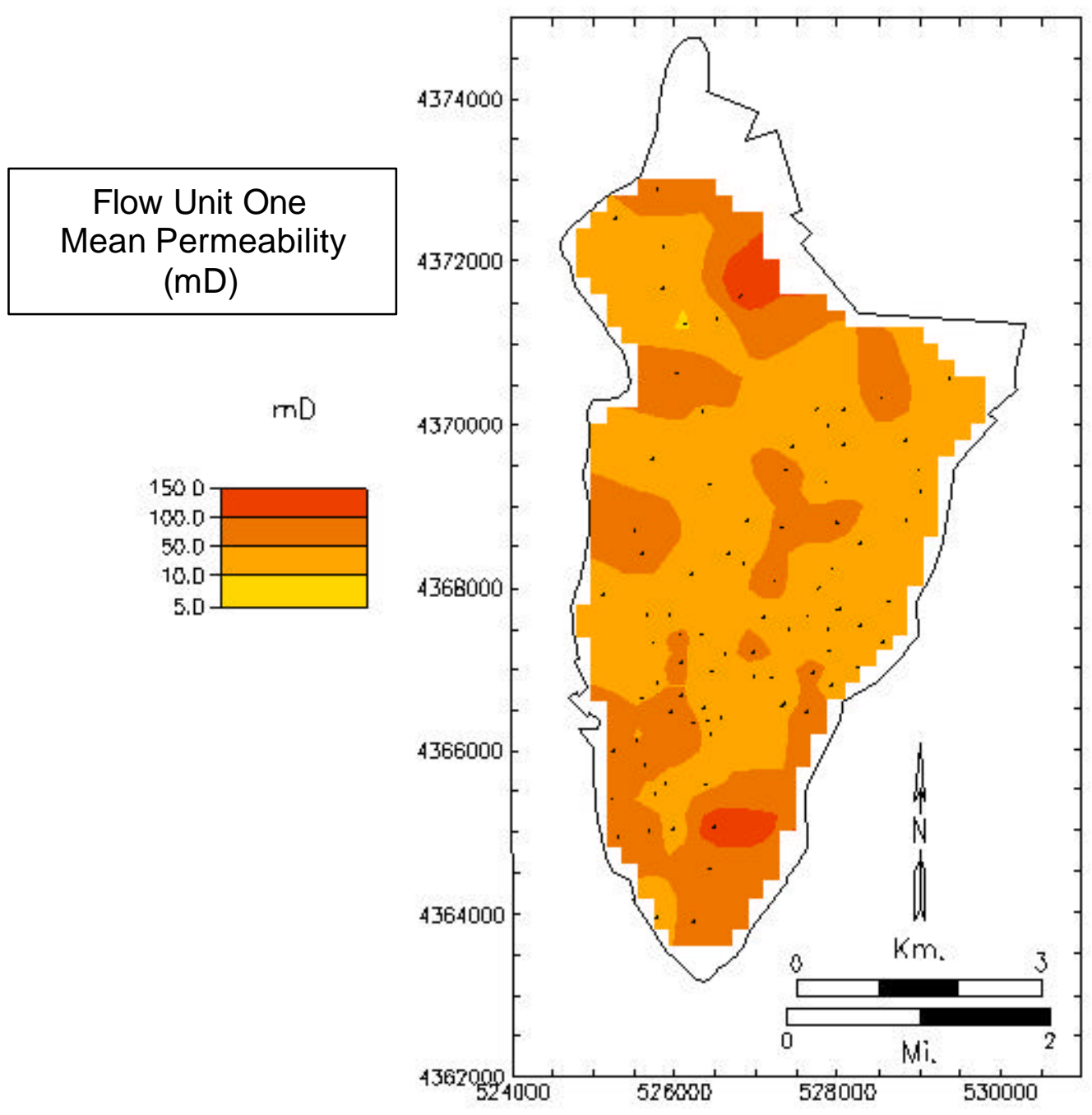

Figure 4.12c. Mean Permeability of flow unit I. 
Flow Unit II Thickness (ft)
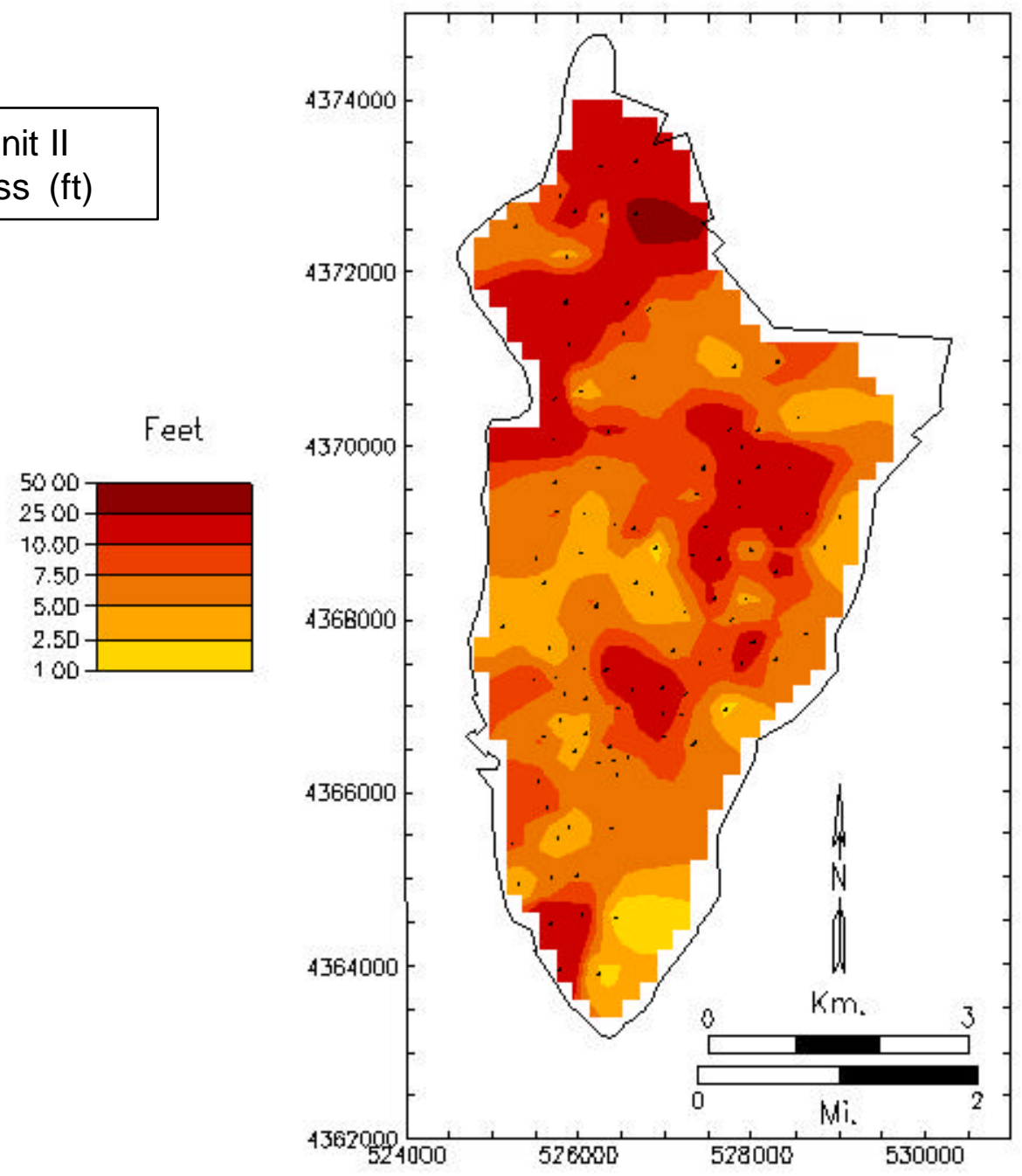

Figure 4.12d. Thickness of flow unit II. 

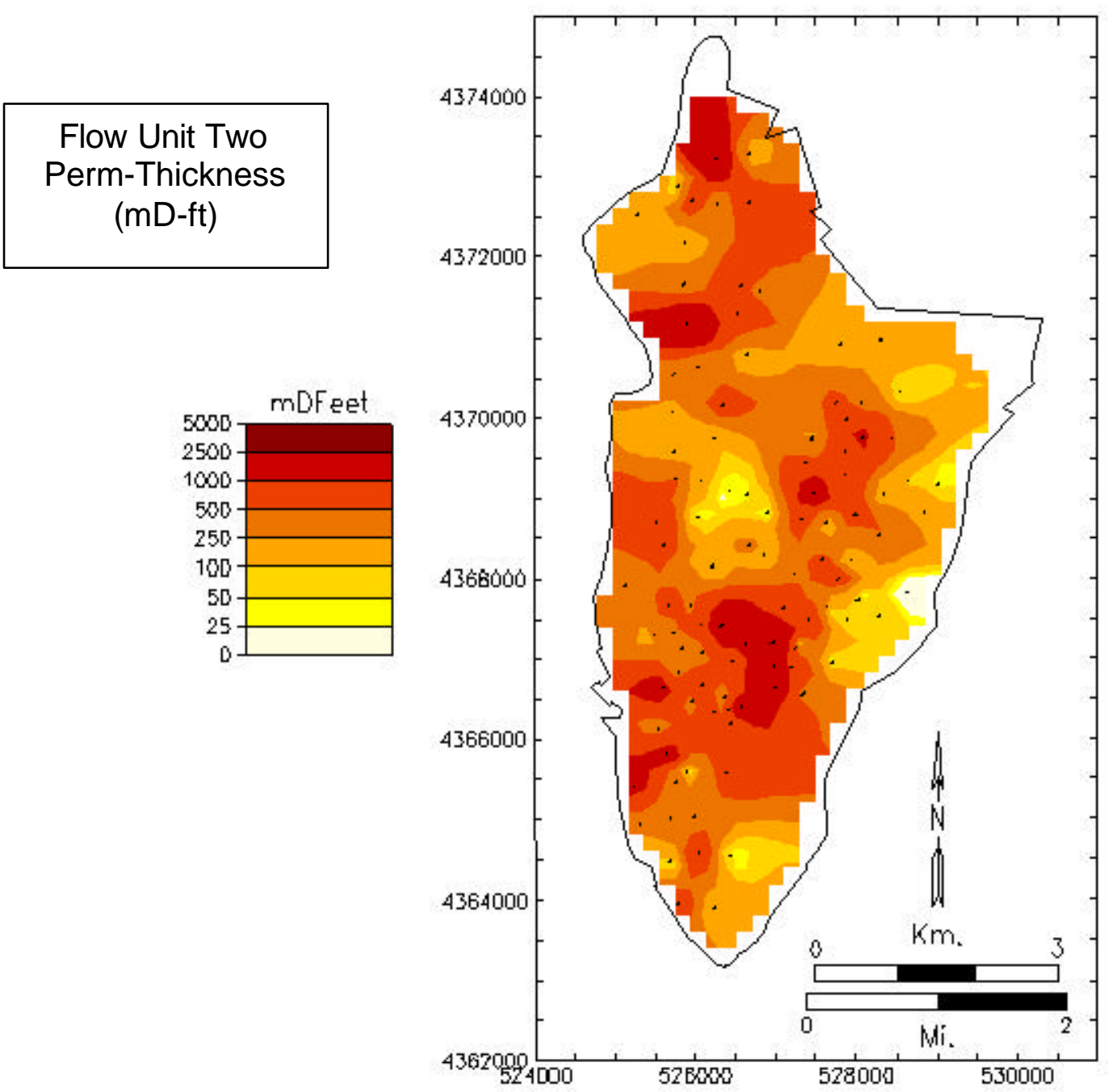

Figure 4.12e. Permeability-Thickness of flow unit II. 


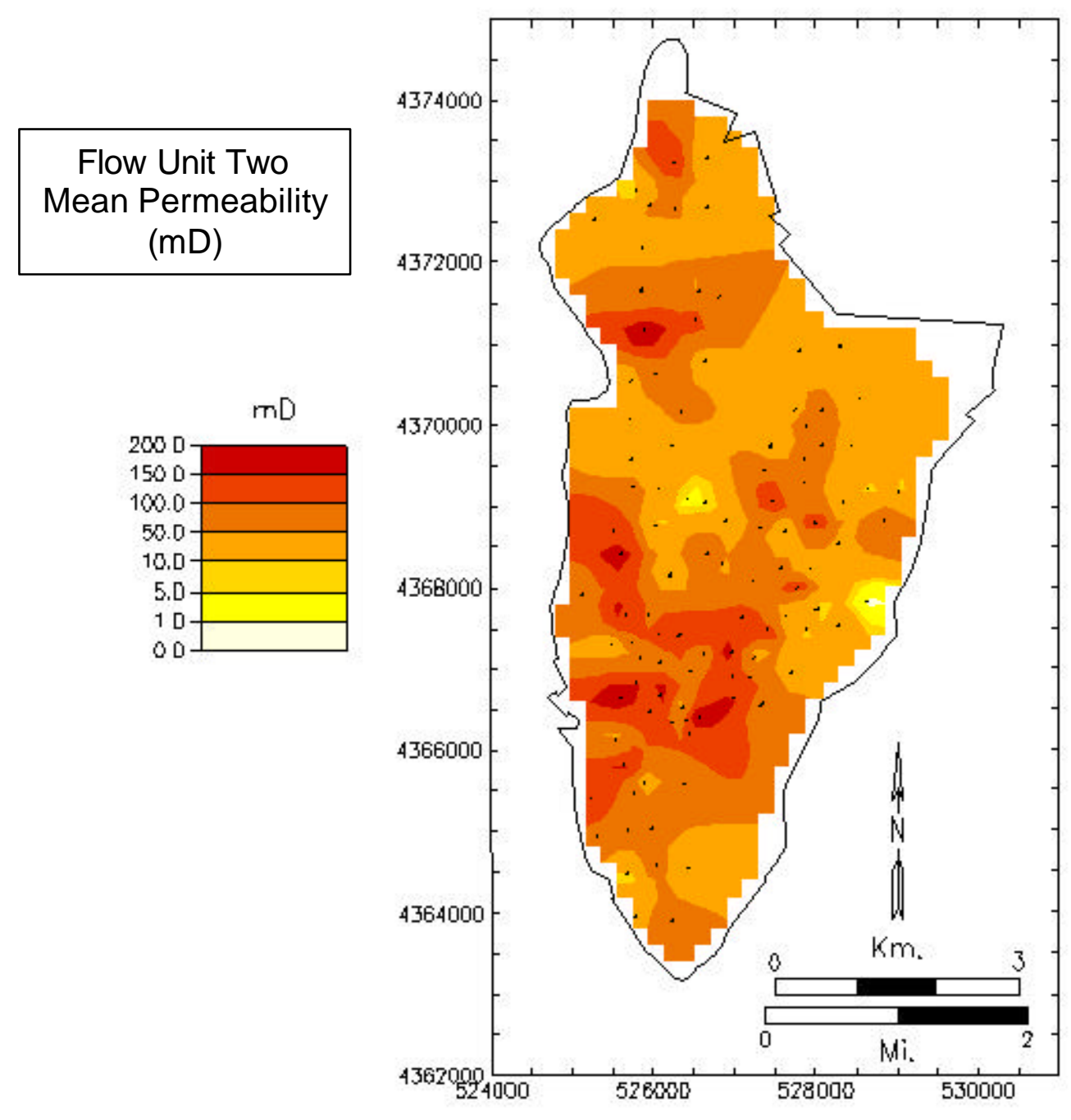

Figure 4.12f. Mean Permeability of flow unit II. 


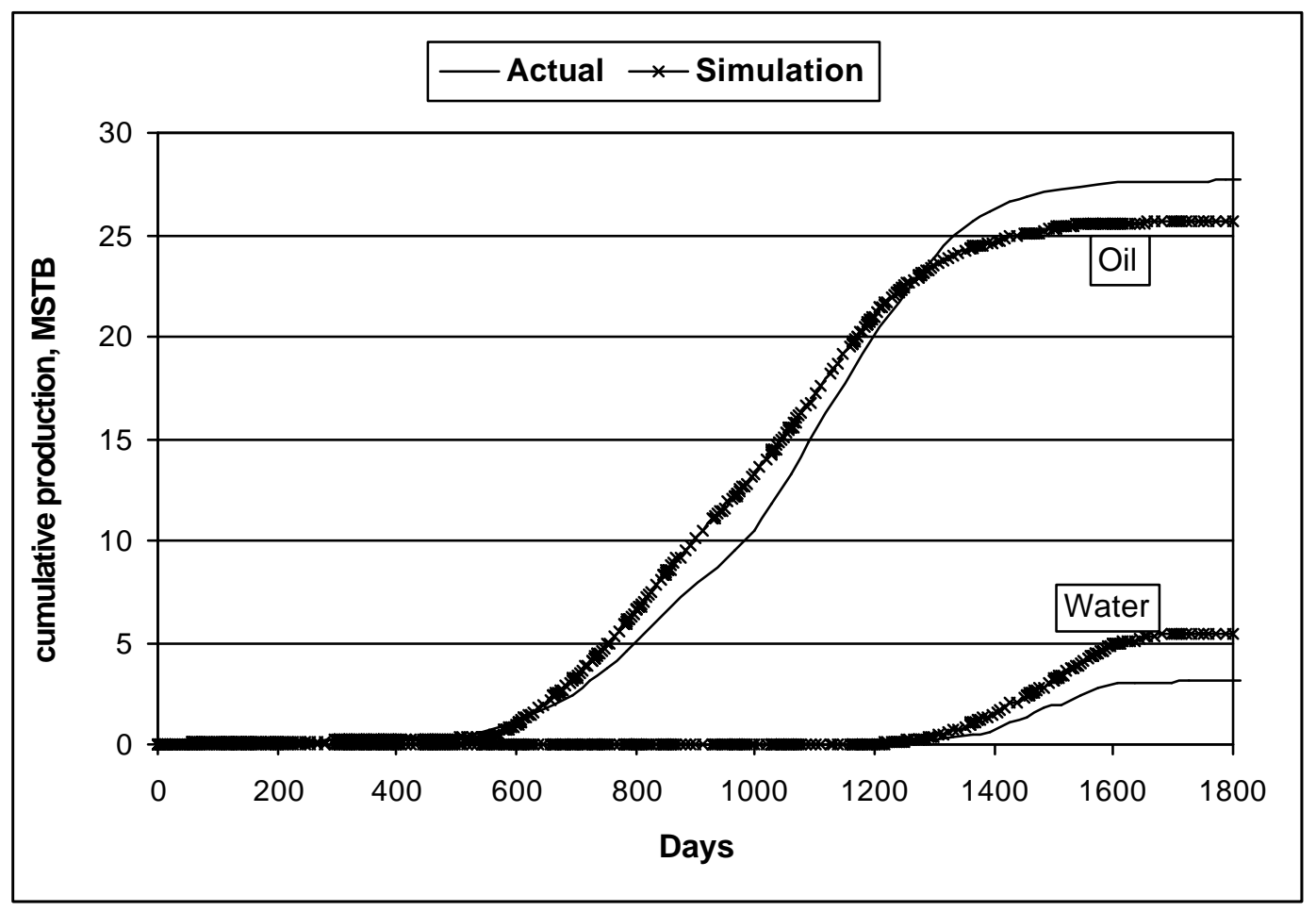

Figure 4.13. Comparison of Predicted and Actual Oil and Water Production for MM-1

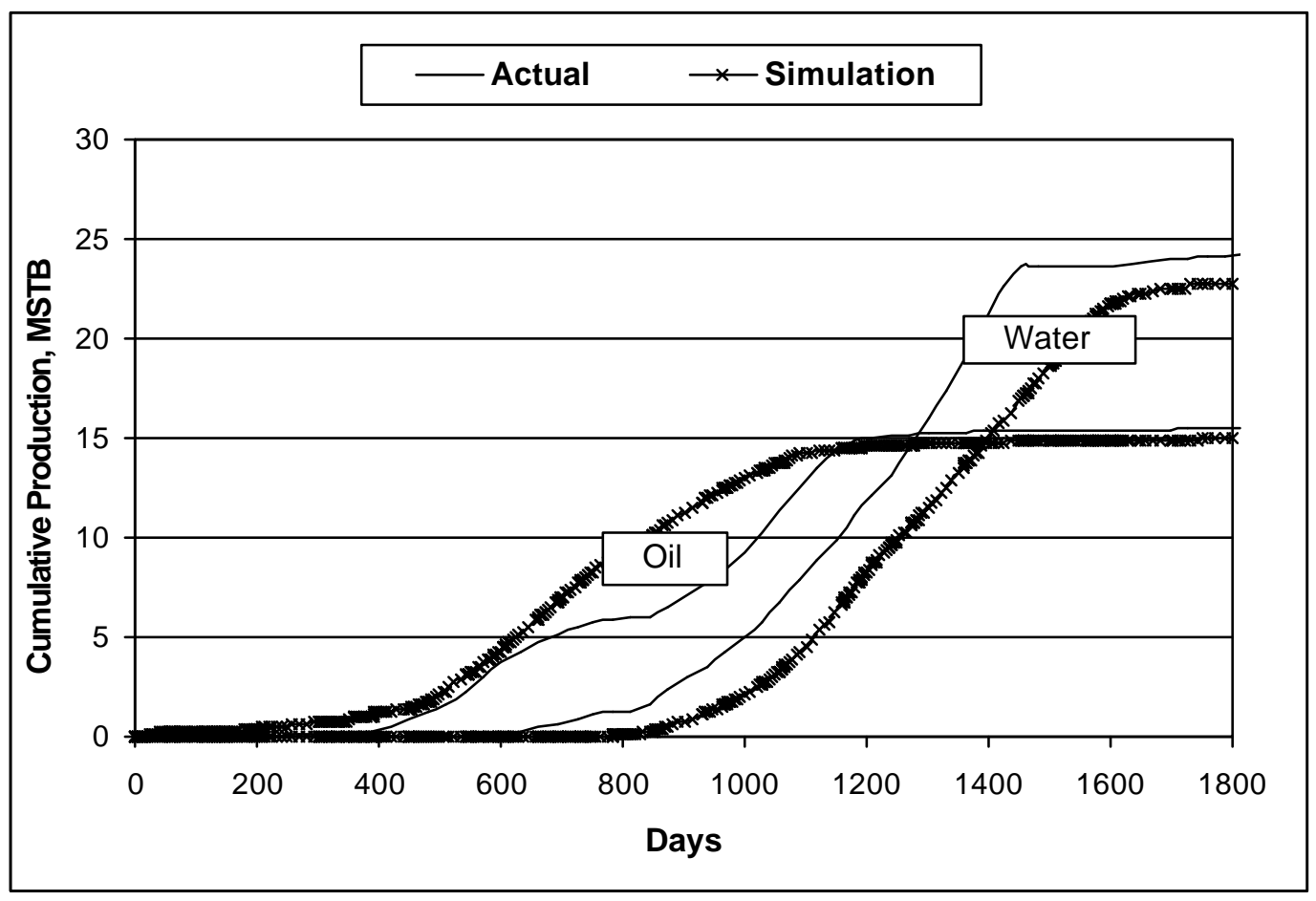

Figure 4.14 Comparison of Predicted and Actual Oil and Water Production for H-12 


\subsubsection{Application of Flow Unit Model to the Reservoir}

The Flow Unit concept, which was successfully applied in waterflood pilot area, was expanded to develop a general model of the reservoir. The study initiated by analyzing the core, miniperm, and log data available from the six wells with core analysis available as well as petrographic, lithological, and electrofacies analysis. To develop a general model for the reservoir, it was necessary to establish criteria for identification of the flow units based on Bulk Density and Gamma Ray log data. Table 4.3 summarizes the description of the flow units based on various $\log$ data. Figures 4.15 and 4.16 illustrate the porosity-permeability relationships for the two flow units. Comparing these Figures with Figure 4.1 clearly illustrates the presence of two separate units even though the correlation for Flow Unit I is not strong.

Flow Unit II is the major producing unit in the reservoir while Flow Unit I is a minor contributor to the total production. It should be noted that Flow Unit II crosses the stratigraphic units in the reservoir. In the western to central parts of the reservoir, it is mainly in psA (parasequence A). In central to eastern parts of the reservoir, Flow Unit II is in psB. It should be noted that in extreme east and northern parts of the reservoir, this flow unit could be in stratigraphic psC. However, this is only a hypothesis at this point since core data from stratigraphic psC are not available.

To develop a complete model of the reservoir, it was necessary to predict the permeability distribution for both flow units. To achieve this objective a new neural network was developed utilizing the flow unit information as input. The previously established procedure for verification of network predictions was employed. The results are summarized in Table 4.4. Comparing the $\mathrm{R}^{2}$-values in Table 4.4 with those in Table 4.1 shows significant improvement in several of the wells and minor reduction in the others. Overall, the results are improved over those without flow unit information. This conclusion tends to support the presence of two separate units and their definitions.

Table 4.3 Descriptions of the Flow Units

\begin{tabular}{|l|c|c|}
\hline WELL LOG PARAMETER & FLOW UNT I & FLOW UNIT II \\
\hline Bulk Density (g/cc) & $2.35-2.45$ & $2.31-2.41$ \\
\hline Porosity (\%) & $13-16$ & $15-20$ \\
\hline Gamma Ray (API Units) & $31-41$ & $40-60$ \\
\hline
\end{tabular}


Table 4.4. $\mathbf{R}^{2}$ Values for Permeability Prediction

\begin{tabular}{|c|c|c|}
\hline Verification Well & $\mathbf{R}^{\mathbf{2}}$ for training + test & $\mathbf{R}^{\mathbf{2}}$ for verification \\
\hline B-18 & 0.97 & 0.96 \\
\hline B-19 & 0.99 & 0.70 \\
\hline H-9 & 0.90 & 0.88 \\
\hline H-11 & 0.95 & 0.70 \\
\hline T-8 & 0.90 & 0.91 \\
\hline L-13 & 0.95 & 0.88 \\
\hline
\end{tabular}

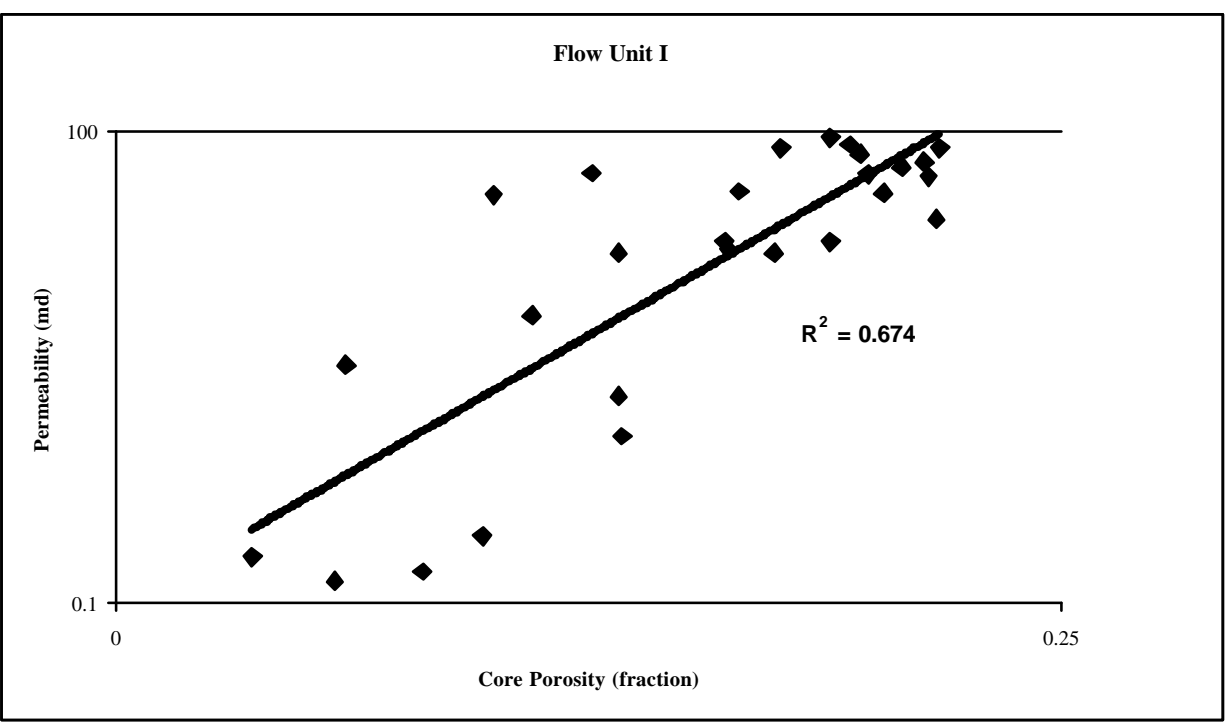

Figures 4.15 Porosity-Permeability Relationship for flow unit I

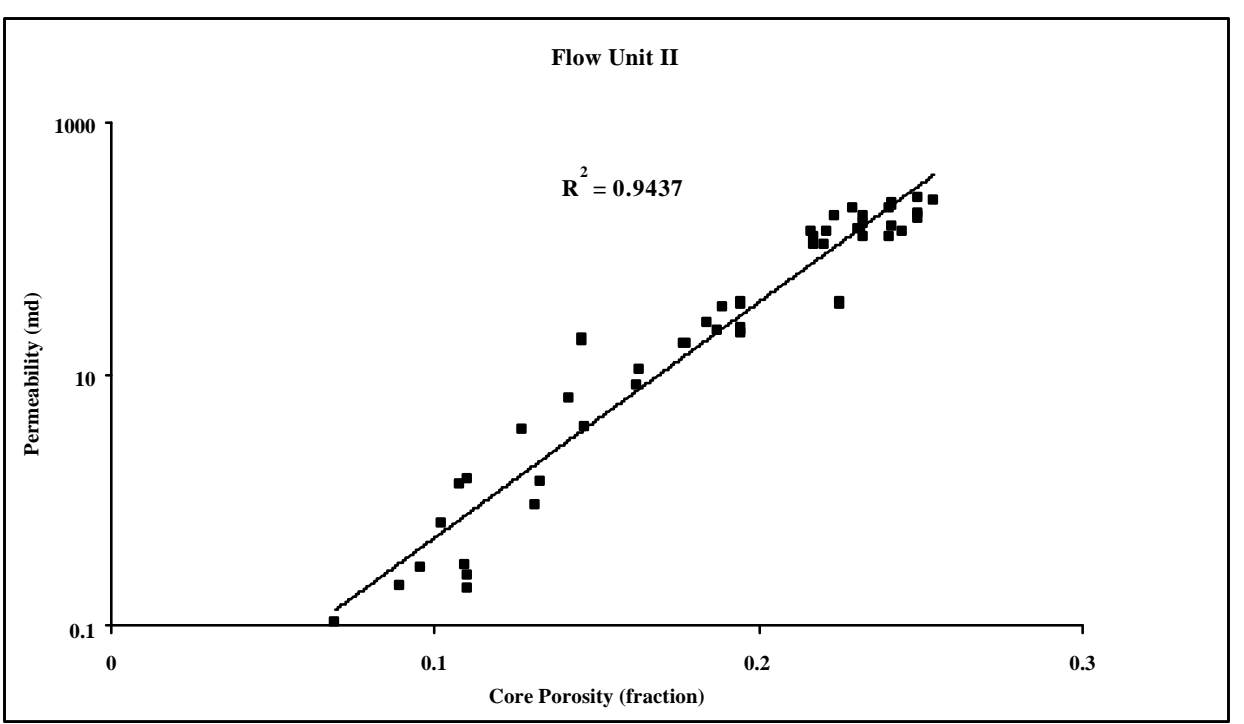

Figures 4.16 Porosity-Permeability Relationship for flow unit II 
To further investigate the flow unit definitions, the reservoir simulator was utilized to predict the performance of two flood patterns located to the north of the pilot area. The producers in these patterns are B-18 and B-21. This area was selected for several reasons. First, wells B-18 (producer in the first pattern) and B-19 (injector in the second pattern) have core analysis available. Second, these patterns are among the most prolific waterflood producers. Most importantly, this area is located in the part of the reservoir where Flow Unit II shifts from psA to psB. The Flow Unit II in B-18 is entirely in psA while in B-19 is entirely in psB.

The well log data from all the producers and injectors in the two patterns as well as core data from wells B-18 and B-19 were analyzed to establish the flow units in the two patterns. Figures 4.17 and 4.18 illustrate the flow units in wells B-18 and B-19. The neural network for permeability prediction was utilized to predict the permeability for all other wells in the patterns. A simple reservoir model based on well log data and permeability predictions was developed and used as input for the simulator in conjunction with injection pressure-rate data to predict the waterflood production history. The results are illustrated in Figures 4.19 and 4.20.

Considering the simple model utilized for simulation, the results are in very good agreement with the field history. It is evident that the model under-predicts the recovery for B-21 and overpredicts the recovery for B-18. Dividing the water injection rates equally between the two patterns is the main cause of these discrepancies. In fact the overall recovery for the two patterns combined, as illustrated in Figure 4.21, is extremely close to the field recovery. The results, verify the concept of the flow units in the reservoir. Further, it confirms the continuity of the Flow Unit II across psA and psB.

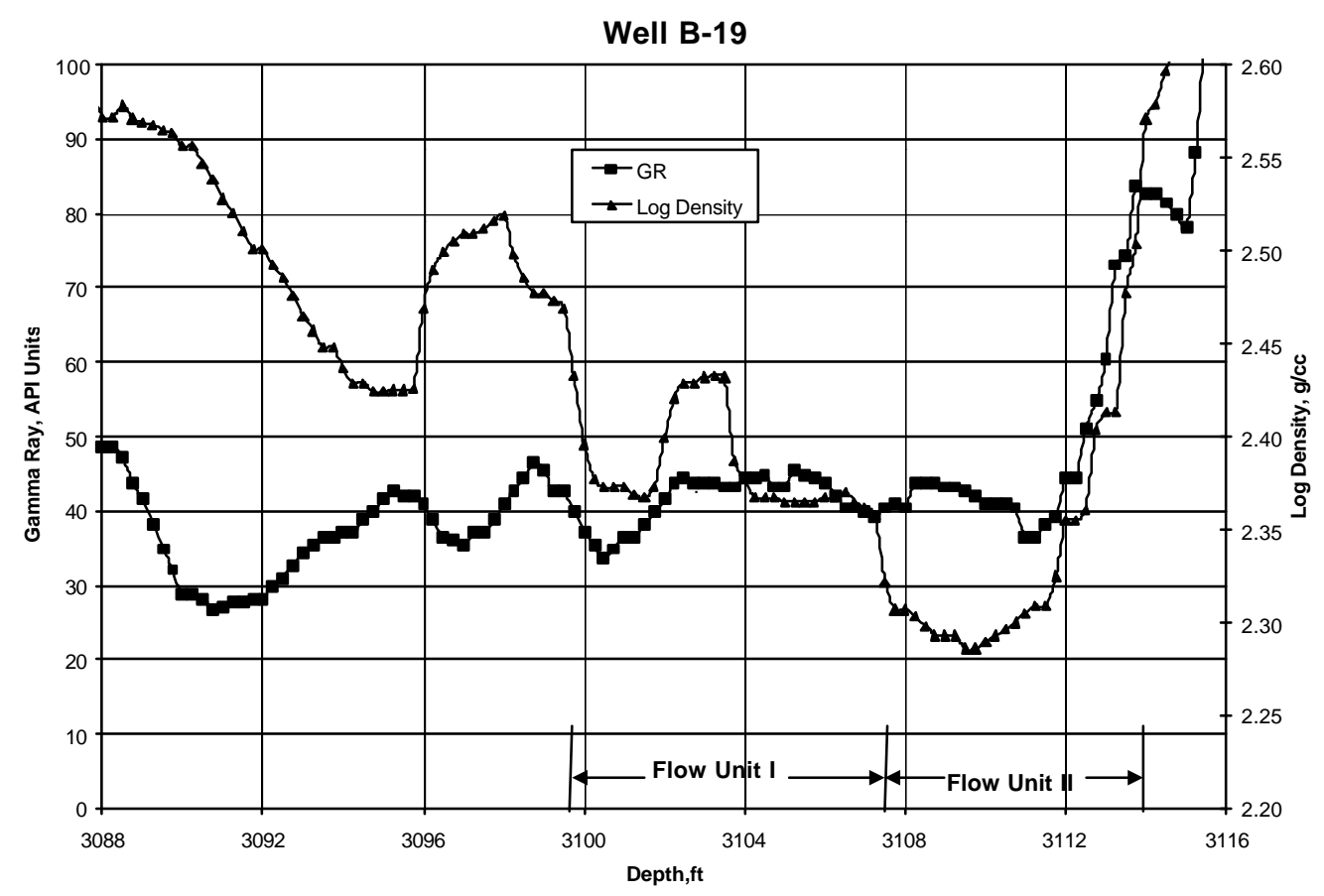

Figure 4.17 Flow Units In Well B-19 
Well B-18

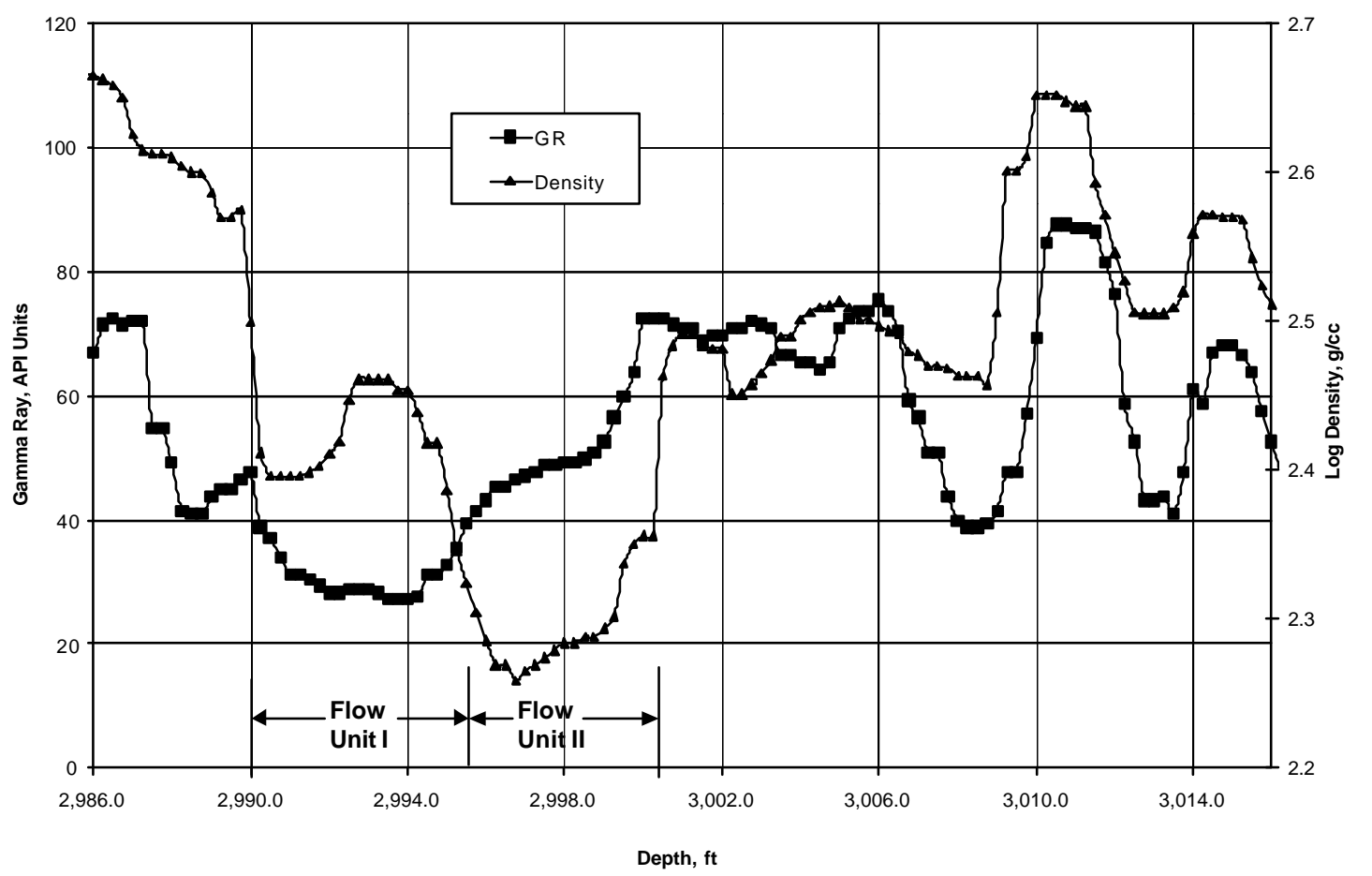

Figure 4.18 Flow Units In Well B-18

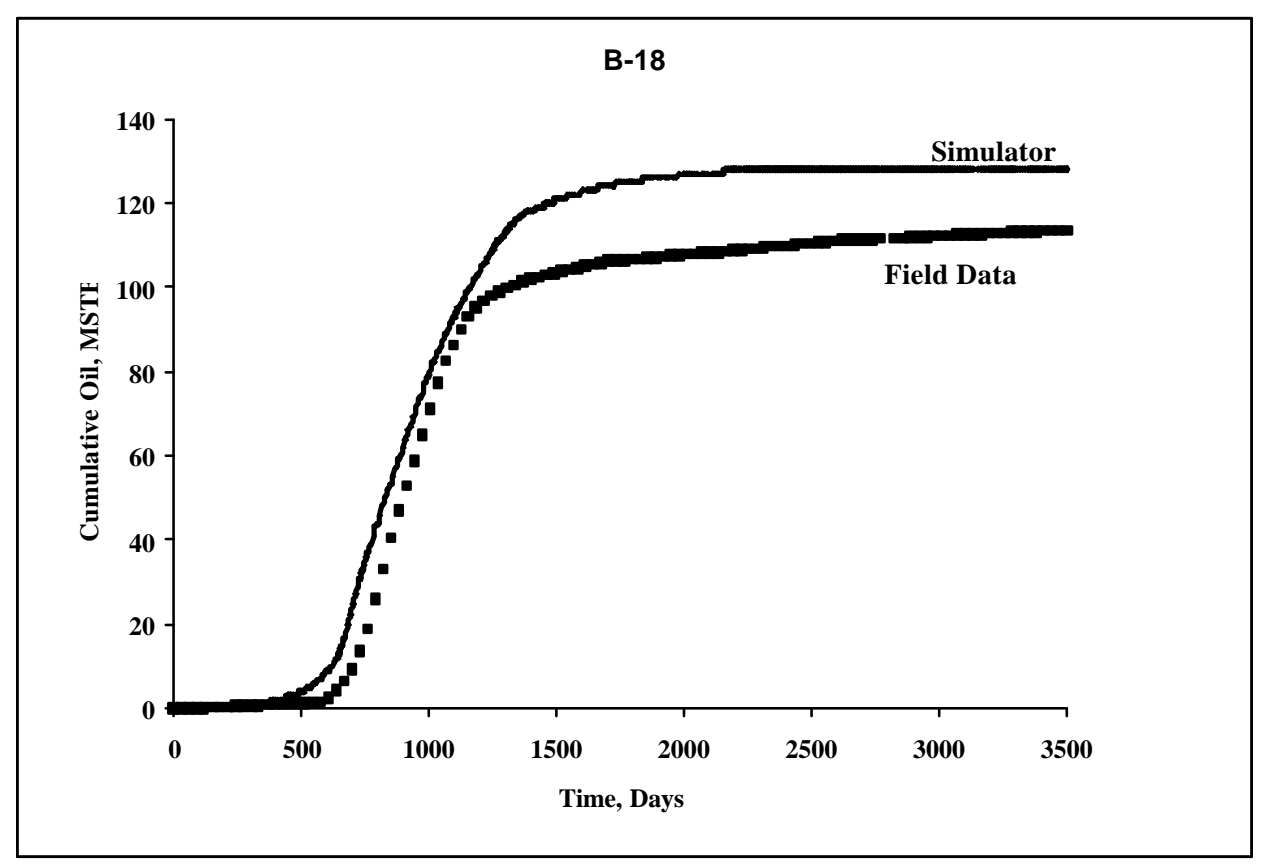

Figure 4.19 Comparison of the Field Production Performance and Simulator Predictions for B-18 Pattern 


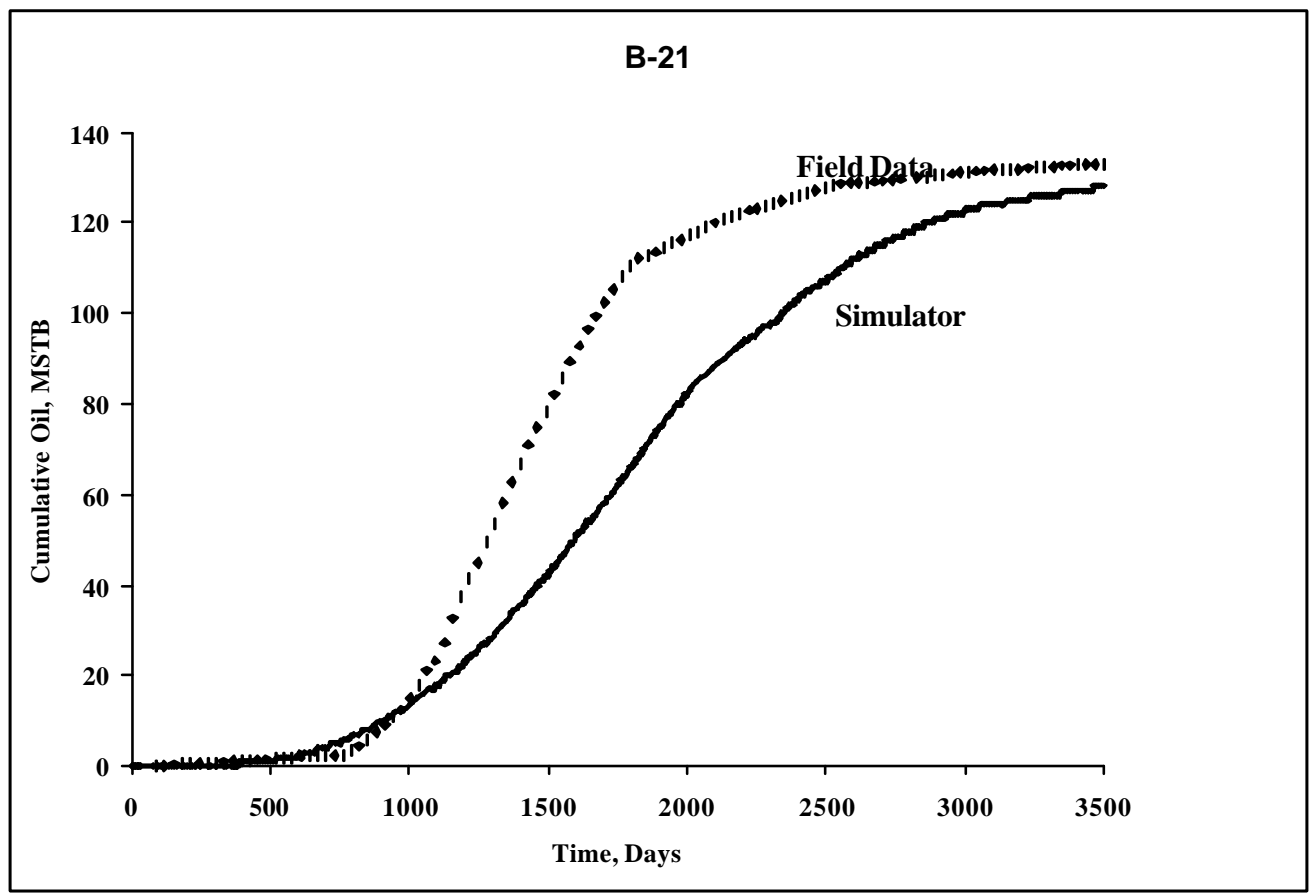

Figure 4.20 Comparison of the Field Production Performance and Simulator Predictions for B-21 Pattern

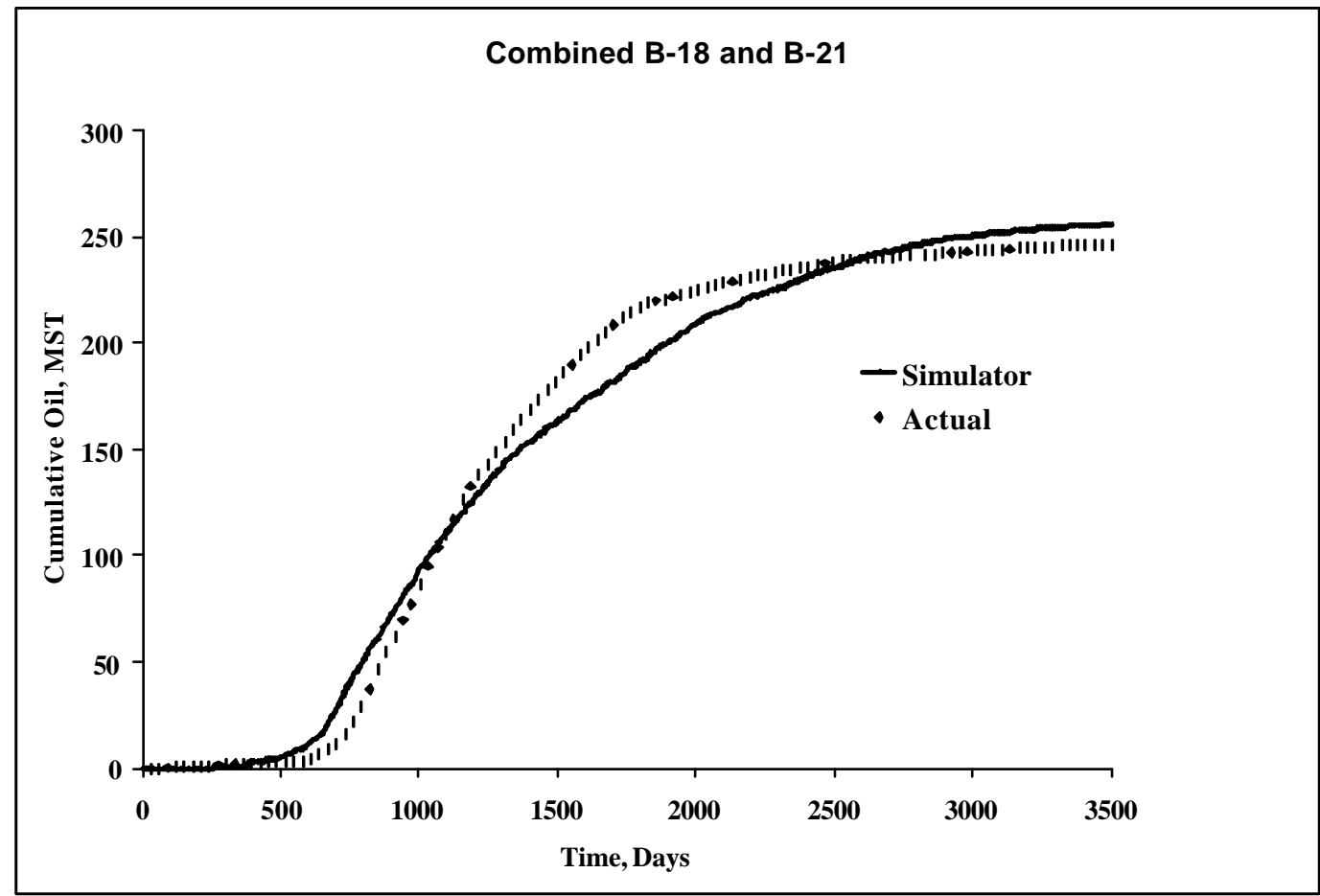

Figure 4.21 Comparison of the Field Production Performance and Simulator Predictions for Combined B-18 andB-21 Patterns 


\section{Summary and Conclusions}

The historical pattern of drilling and development in the Jacksonburg-Stringtown field suggests that the Gordon reservoir within the field should be more heterogeneous than the Mississippian Big Injun sandstone reservoir studied previously (Hohn and others 1993a, 1993b; McDowell and others, 1996).

The Gordon sandstone is composed of three parasequences (psA, psB, psC), formed along the Late Devonian shoreline of the Appalachian Basin. The parasequences comprise five lithofacies (Fss, Lss, Css, $\mathrm{Hb}$ and $\mathrm{Sh}$ ). The reservoir portion of the Gordon is restricted to sandstones of the Fss lithofacies within each parasequence. Within each parasequence, the reservoir is compartmentalized. Permeable sandstone is enclosed and interbedded with low permeability strata of the Lss, Css, and Sh lithofacies. Communication between reservoir compartments is generally unpredictable. Possible communication may exist in the eastern part of the field where compartments in psA and psB are in stratigraphic and geographic proximity.

Primary porosity observed in Gordon thin sections is intergranular; secondary porosity appears to occur in association with dissolved or partially dissolved potassium feldspars. Cements in Gordon samples consist of clay (primarily kaolinite associated with feldspars), calcite, silica, and siderite. In general, calcite and clay cements occur in an early, post-burial setting within the Gordon. The formation of clay cement continues with deeper burial and diagenesis as associated clays and feldspars are altered. Later in diagenesis, secondary quartz in the form of euhedral overgrowths and pore-filling chert is precipitated. Finally, and overprinting or replacing earlier cements, siderite (frequently euhedral) cement fills remaining porosity in many Gordon samples. The presence of abundant siderite cement may have serious implications for secondary development in the Gordon because chemical reactions between the composition of injected water and iron of cement must be taken into account.

Minipermeameter readings show considerably more variability that permeabilities measured from either core plugs or whole core due to the greater frequency of sampling with the minipermeameter and the smaller volume measured. Minipermeameter values generally exceed whole core values and are less than core plug values. Because whole core analysis samples a significantly larger volume of rock and may include sedimentary barriers to flow such as interbedded shales or stylolitic horizons, it is not unexpected that whole core permeabilities may be lower than "spot" permeabilities taken with the minipermeameter.

Detailed observation of Gordon core material led to the following conclusions: 1) core materials classified as pay sandstone based on $\log$ signature were found to have permeabilities ranging from 10 to $200 \mathrm{mD}$; 2) other, non-pay sandstones identified by log signature were found to have permeabilities ranging from 0 (below level of instrumental detection) to $5 \mathrm{mD} ; 3$ ) the distribution of permeability within pay sandstones was fairly uniform; 4) the distribution of small amounts of permeability within non-pay sandstones was usually either zoned parallel to bedding or "patchy"; 5) the conglomeratic material was always problematic in that it could take on the permeability characteristics of enclosing materials; 6) conglomeratic material was also found with permeabilities exactly the opposite of enclosing materials, e. g., extremely low permeability 
conglomerate in pay sandstone and high permeability conglomerate in non-pay or low permeability pay sandstone. The last two observations imply that conglomeratic materials, often difficult to pick on geophysical logs because of their thinness, can provide either an unexpected barrier to vertical flow or an unexpected path for horizontal flow ("thief zone").

Lack of significant structural complexity within the Jacksonburg-Stringtown field reduced the need for significant adjustment of log elevations to achieve good correlation between wells. Furthermore, the presence of a recognizable stratigraphic horizon on all geophysical logs (top of the Gordon interval) obviated the need to rely on computerized autocorrelation in the preparation of three-dimensional datasets based on correlated geophysical logs.

Four electrofacies based on a linear combination of density and scaled gamma ray best matched correlations made independently based on visual comparison of geophysical logs. Electrofacies 4 with relatively high permeability (mean value $>45 \mathrm{mD}$ ) was determined to be equivalent to the pay sandstone within the Gordon reservoir. Electrofacies cross-sections parallel to the synclinal axis within the field demonstrated the effects of a small fault that transects the south end of the field. The five meters of displacement across this fault is probably enough to isolate the reservoir in the southern end of the field from the remainder of the field. Electrofacies crosssections taken perpendicular to the syncline axis demonstrated a distinct asymmetry in distribution of electrofacies. Electrofacies 3, in particular, thickens dramatically from the center of the Gordon syncline towards the eastern margin of the field.

Because of generally low permeability $(5 \mathrm{mD}$ ) encountered at all localities selected as outcrop analogs to the Gordon reservoir, it was determined that no lithology present in outcrop was comparable to pay sandstones of the Gordon and thus no modeling could be performed. Once this determination had been made, further outcrop investigation was abandoned.

Core data from six wells in the reservoir were utilized in an artificial neural network to predict permeability from Gamma ray and bulk density logs, the first and the second derivatives of the log data with respect to depth, well location, and log baselines. A three-layer, back-propagation network with three slabs in the middle layer (each slab having a different activation function) could predict permeability values that correlated with observed values at an acceptable level. Similar results were obtained in the prediction of porosity from log and well parameters.

Well records, well logs, and core analysis data were utilized to construct a simple model of the pilot area. Injection pressure-rate information was then utilized in a reservoir simulator to predict oil production for both center producers in the pilot. Waterflood performance could not be accurately predicted using this approach, suggesting that a more detailed description of the reservoir characteristics and heterogeneities were necessary, leading to the use of flow units to model the reservoir.

Two flow units were defined. The first includes the lower part of the conglomerate-sandstone sequence and the upper part of the sandstone section, and the second is the lower part of the sandstone. The second flow unit has the higher porosity and permeability. A three-dimensional reservoir description including the flow units and injection pressure-rate information were then 
used as inputs for the reservoir simulator to predict oil production performance for the center producers in the pilot area. This description of the reservoir provided significantly better simulation results.

To develop a reservoir model encompassing the entire field, it was necessary to establish criteria for identifying flow units based on Bulk Density and Gamma Ray log data. Flow Unit II is the major producing unit in the reservoir while Flow Unit I is a minor contributor to the total production. Flow Unit II crosses stratigraphic units in the reservoir. In the western to central parts of the reservoir, it is mainly in psA (parasequence A) whereas in central to eastern parts of the reservoir, Flow Unit II is in psB. A neural network was used to predict permeability values for the flow units. The reservoir simulator was utilized to predict the performance of two flood patterns located to the north of the pilot area. Considering the simple model utilized for simulation, the results are in very good agreement with the field history. 


\section{References Cited}

Boone, D.A., King, P.E., Jr., Ferrebee, Mack. 1986, Stringtown field report and 1986 proposed waterflood development, Tyler and Wetzel counties, West Virginia: internal Pennzoil Company report, dated April 14, 1986, 25 p.

Davis, J., 1973, Statistics and Data Analysis in Geology, $1^{\text {st }}$ edition: John Wiley and Sons, New York, $550 \mathrm{p}$.

Hohn, M., Matchen, D., Vargo, A., McDowell, R., Heald, M., and Britton, J., 1993a, Petroleum Geology and Reservoir Characterization of the Big Injun Sandstone (Price Formation) in the Rock Creek (Walton) Field, Roane County, West Virginia: West Virginia Geological and Economic Survey Publication B-43, Morgantown, 76 p.

Hohn, M., McDowell, R., Vargo, A., Matchen, A., Heald., M., and Britton, J., 1993b, Petroleum Geology and Reservoir Characterization of the Big Injun Sandstone (Price Formation) in the Granny Creek Field, Clay and Roane Counties, West Virginia: West Virginia Geological and Economic Survey Publication B-44, Morgantown, 91 p.

Hohn, M., Patchen, D., Heald, M., Aminian, K., Donaldson, A., Shumaker, R., and Wilson, T., 1994, Measuring and Predicting Reservoir Heterogeneity in Complex Reservoirs: the Fluvial-Deltaic Big Injun Sandstone in West Virginia - Final Project Report: U. S. Department of Energy Final, DOE/BC/14657-15, 57 p.

King, Paul, 1980, Pilot waterflood justification, Stringtown Gordon reservoir Wetzel County, West Virginia: internal Pennzoil Company AFE supporting document, unpaginated.

McDowell, R., Avary, K., Hohn, M., and Matchen, D., 1996, Verification of the use of completion-location analysis for initial assessment of reservoir heterogeneity: A. A. P. G. 1996 Annual Convention Program, v. 5, p. 95, abstract.

Morrison, Greg, 1991, Stringtown geologic study: Pennzoil Products Company interoffice correspondence, $4 \mathrm{p}$. plus unpaginated attachment.

Poelchau, H., 1987, Coherence mapping - an automated approach to display goodnessof-correlation between wells in a field: Mathematical Geology, v. 19, p. 833-850.

Putscher, Noel W., and King, Paul E. Jr., 1983, Hearing Data Concerning Request for Pressure Increase at the Stringtown Unit, Oil and Gas Conservation Commission Stringtown Unit No. 1, Tyler and Wetzel counties, West Virginia, Pennzoil Exploration \& Production Company, $37 \mathrm{p}$.

Whieldon, Charles E., Jr., and Eckard, William E., 1963, West Virginia Oil Fields Discovered Before 1940: U.S. Bureau of Mines Bulletin 607, 187 p. 
abbreviations:

BOPA-barrels of oil per acre BOPD-barrels of oil per day MMBP-million barrels of oil 